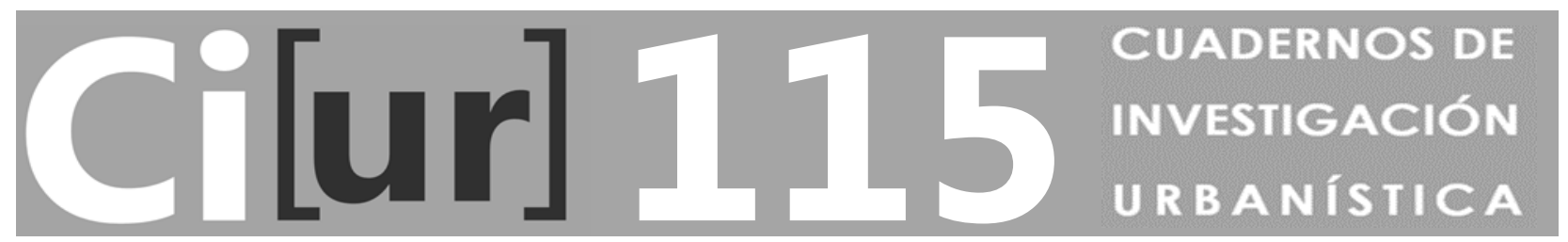

\title{
URBANISMO COLABORATIVO
}

CARMEN MORENO BALBOA

Arquitecta

Noviembre / Diciembre 2017 


\begin{tabular}{|c|c|}
\hline Director: & José Fariña Tojo \\
\hline \multicolumn{2}{|c|}{ Consejo de Redacción: } \\
\hline Director & Ester Higueras García \\
\hline Subdirector & María Cristina García González \\
\hline Jefe de redacción & María Emilia Román López \\
\hline Vocales & $\begin{array}{l}\text { Isabel Aguirre de Urcola (Escola Galega da Paisaxe Juana de Vega, A Coruña), Pilar Chías } \\
\text { Navarro (Univ. Alcalá de Henares, Madrid), José Antonio Corraliza Rodríguez (Univ. Autónoma } \\
\text { de Madrid), Alberto Cuchí Burgos (Univ. Politécnica de Cataluña), José Fariña Tojo (Univ. } \\
\text { Politécnica de Madrid), Agustín Hernández Aja (Univ. Politécnica de Madrid), Francisco } \\
\text { Lamíquiz Daudén (Univ. Politécnica de Madrid), María Asunción Leboreiro Amaro (Univ. } \\
\text { Politécnica de Madrid), Rafael Mata Olmo (Univ. Autónoma de Madrid), Luis Andrés Orive } \\
\text { (Centro de Estudios Ambientales, Vitoria-Gasteiz), Javier Ruiz Sánchez (Univ. Politécnica de } \\
\text { Madrid), Carlos Manuel Valdés (Univ. Carlos III de Madrid) }\end{array}$ \\
\hline Consejo Asesor: & $\begin{array}{l}\text { José Manuel Atienza Riera (Vicerrector de Estrategia Académica e Internacionalización, Univ. } \\
\text { Politécnica de Madrid), Manuel Blanco Lage (Director de la Escuela Superior de Arquitectura, } \\
\text { Univ. Politécnica de Madrid), José Miguel Fernández Güell (Director del Departamento de } \\
\text { Urbanística y Ordenación del Territorio, Univ. Politécnica de Madrid), Antonio Elizalde Hevia, } \\
\text { Julio García Lanza, Josefina Gómez de Mendoza, José Manuel Naredo, Fernando Roch Peña, } \\
\text { Julián Salas Serrano, Fernando de Terán Troyano }\end{array}$ \\
\hline Comité Científico: & $\begin{array}{l}\text { Antonio Acierno (Univ. Federico II di Napoli, Nápoles, ITALIA), Miguel Ángel Barreto (Univ. } \\
\text { Nacional del Nordeste, Resistencia, ARGENTINA), José Luis Carrillo (Univ. Veracruzana, Xalapa, } \\
\text { MÉXICO), Luz Alicia Cárdenas Jirón (Univ. de Chile, Santiago de Chile, CHILE), Marta Casares } \\
\text { (Univ. Nacional de Tucumán, Tucumán, ARGENTINA), María Castrillo (Univ. de Valladolid, } \\
\text { ESPAÑA), Dania Chavarría (Univ. de Costa Rica, COSTA RICA), Mercedes Ferrer (Univ. del } \\
\text { Zulia, Maracaibo, VENEZUELA), Fernando Gaja (Univ. Politécnica de Valencia, ESPAÑA), } \\
\text { Alberto Gurovich (Univ. de Chile, Santiago de Chile, CHILE), Josué Llanque (Univ. Nacional de } \\
\text { S. Agustín, Arequipa, PERÚ), Angelo Mazza (Univ. degli Studi di Napoli, Nápoles, ITALIA), Luis } \\
\text { Moya (Univ. Politécnica de Madrid, ESPAÑA), Joan Olmos (Univ. Politécnica de Valencia, } \\
\text { ESPAÑA), Ignazia Pinzello (Univ. degli Studi di Palermo, Palermo, ITALIA), Julio Pozueta (Univ. } \\
\text { Politécnica de Madrid, ESPAÑA), Alfonso Rivas (Univ. A. Metropolitana Azcapotzalco, Ciudad de } \\
\text { México, MÉXICO), Silvia Rossi (Univ. Nacional de Tucumán, ARGENTINA), Adalberto da Silva } \\
\text { (Univ. Estadual Paulista, Sao Paulo, BRASIL), Carlos Soberanis (Univ. Francisco Marroquín, } \\
\text { Guatemala, GUATEMALA), Carlos A. Torres (Univ. Nacional de Colombia, Bogotá, COLOMBIA), } \\
\text { Graziella Trovato (Univ. Politécnica de Madrid, ESPAÑA), Carlos F. Valverde (Univ. } \\
\text { Iberoamericana de Puebla, MÉXICO), Fernando N. Winfield (Univ. Veracruzana, Xalapa, } \\
\text { MÉXICO), Ana Zazo (Univ. del Bio-Bio, Concepción, CHILE) }\end{array}$ \\
\hline
\end{tabular}

\section{Realización y maquetación:}

Maquetación: Raquel Clemente Pereiro. ciur.urbanismo.arquitectura@upm.es

Distribución: Mairea Libros: distribucion@mairea-libros.com

\section{(c) COPYRIGHT 2017}

\section{CARMEN MORENO BALBOA}

I.S.S.N. (edición impresa): 1886-6654

I.S.S.N. (edición digital): 2174-5099

DOI: $10.20868 /$ ciur.2017.115

Depósito Legal: M-41356-2011

Año X, Núm. 115, noviembre - diciembre 2017, 100 págs.

Edita: Instituto Juan de Herrera

Imprime: FASTER, San Francisco de Sales 1, Madrid 


\section{Urbanismo Colaborativo Collaborative Urbanism}

DOI: $10.20868 /$ ciur.2017.115.3680

\section{DESCRIPTORES:}

Participación ciudadana / planificación urbana colaborativa / urbanismo colaborativo / urbanismo participativo / urbanismo emergente / planeamiento flexible / planificación radical

\section{KEY WORDS:}

Citizen Participation / Collaborative Urban Planning / Collaborative Urbanism / Participatory Urbanism / Emerging Urbanism / Flexible Planning / Radical Planning

\section{RESUMEN:}

¿Ha cambiado el concepto de ciudad en tan sólo 2400 años? Si la ciudad la componen los ciudadanos ¿son éstos distintos de los ciudadanos de las antiguas polis? Si el ciudadano es quien participa en las funciones de gobierno de su ciudad, ¿quién es ahora realmente, ciudadano? ¿Quién quiere serlo? y quién quisiera participar de dichas funciones, ¿cómo podría conseguirlo?

En la sociedad actual se producen dos situaciones antagónicas que afectan al desarrollo de la ciudad, por un lado las administraciones, actuando orientadas al interés general, reconocen pero congelan las posibilidades de participar de la población en el urbanismo y la creación de ciudad; y por otro lado la sociedad se mueve y actúa al margen de las administraciones en la mejora de su entorno y sus condiciones de vida, desde las denominadas iniciativas urbanas. Cuáles son los motivos de esta situación y cómo hacer que ambos movimientos coincidan en la generación del denominado "Urbanismo Colaborativo", es el objeto de este trabajo.

\section{ABSTRACT:}

Has the concept of city changed in only the past 2400 years? If the city is the one consisting the citizens, are these any different of the citizens ancient polis? If the citizen is one participating in his city's government functions, who is the real citizen now a days? Who wants to be one? Who wants to participate in those functions? How could someone acomplish that?

In today's society, there are two antagonistic situations that are affecting the development of the city, on the one hand the administrations, acting orientated to the general interest, they recognize but freeze the possibilities that the citizens have of participating in urbanism and the creation of the city. And on the other hand, the society moves and acts outside of the administrations for the improvement of their environment and their living conditions, doing this from the named urban initiatives. What causes this situation and how to put together both movements and for them to agree in the generation of the named "Collaborative Urbanism" is the subject and what this study wants to acomplish.

*Carmen Moreno Balboa es Arquitecta, especialidad Urbanismo, por la Escuela Técnica Superior de Arquitectura de Madrid, UPM, Máster en Urbanismo y Estudios Territoriales por el INAP-UIMP y Técnico Urbanista del INAP balboamorenocarmen@gmail.com

\section{CONSULTA DE NÚMEROS ANTERIORES/ACCESS TO PREVIOUS WORKS:}

La presente publicación se puede consultar en color en formato pdf en la dirección:

This document is available in pdfformat and full colour in the following web page:

http://www2.aq.upm.es/Departamentos/Urbanismo/institucional/publicaciones/ciur/ 


\section{ÍNDICE}

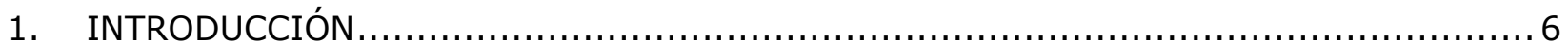

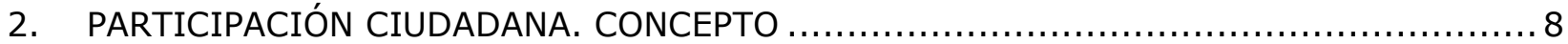

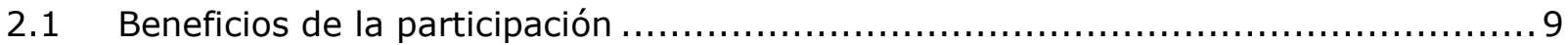

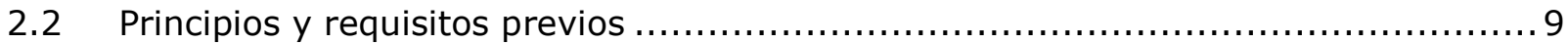

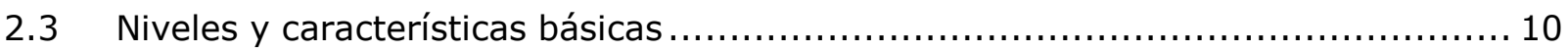

2.3.1 Información como base de la participación ............................................................11

2.3.2 Consulta como inicio de la colaboración..........................................................11

2.4 Participación ciudadana como corresponsabilidad ................................ 12

3. LA PARTICIPACIÓN EN LA LEGISLACIÓN URBANÍSTICA Y LOCAL ........................ 14

3.1 Análisis de normativa de Administración Local ...................................... 15

3.2 Análisis de la normativa sobre el procedimiento administrativo ..................... 16

3.3 La participación en la legislación urbanística estatal actual ......................... 18

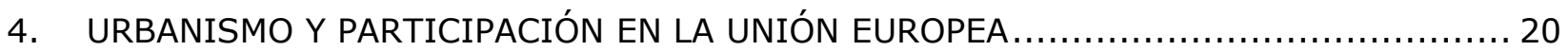

4.1 Resumen sobre la incidencia en el urbanismo desde la Unión Europea ............... 20

4.2 La importancia de la participación en las propuestas de la Unión Europea............ 22

4.3 La Carta Europea de la Democracia Participativa en procesos Urbanísticos........... 24

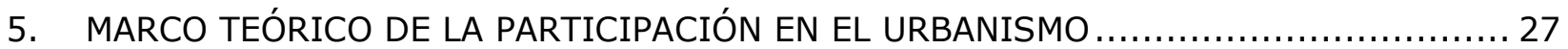

6. RESISTENCIAS A LA PARTICIPACIÓN PÚBLICA. NUEVOS RETOS ......................... 37

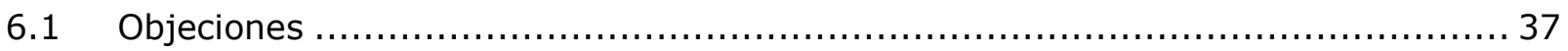

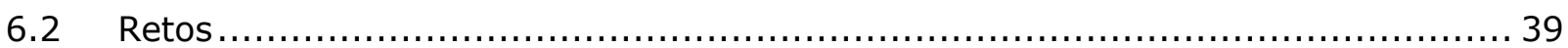

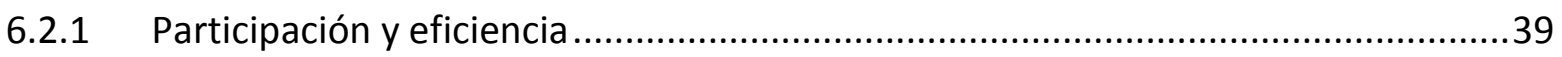

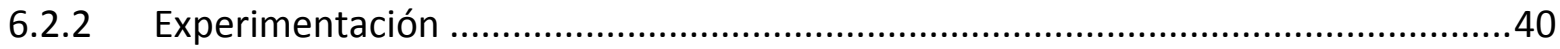

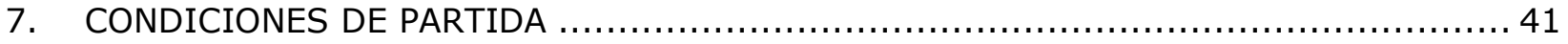

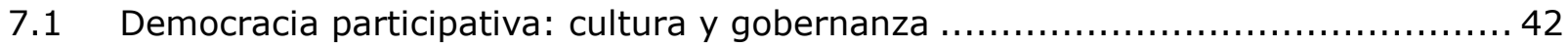

7.1.1 Condiciones para el cambio cultural ............................................................42

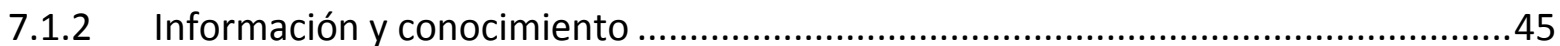

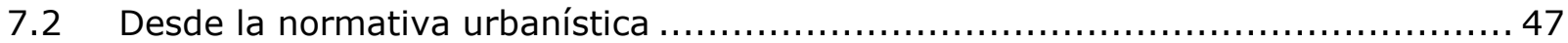

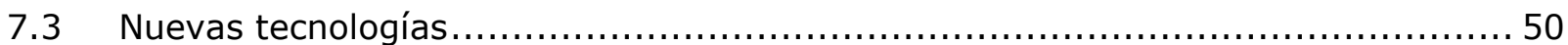

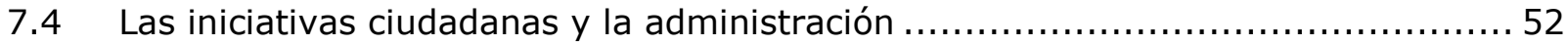

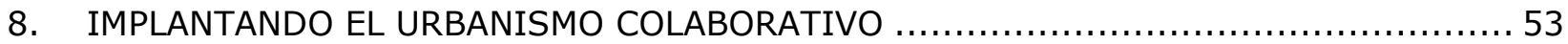

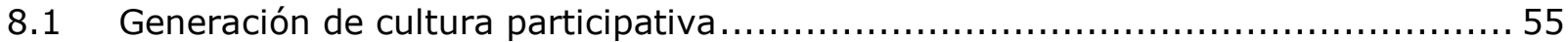


8.1.1 Oficina del Plan: Observatorios Territoriales ................................................56

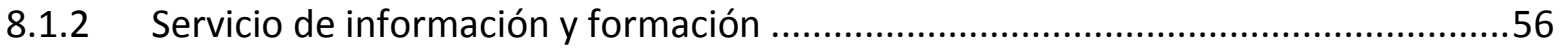

8.1.3 Accesibilidad y facilidad para la participación directa y espontánea .....................57

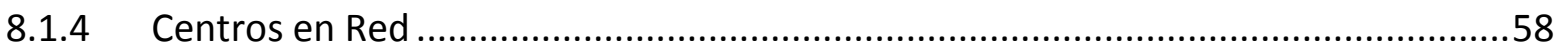

8.2 Flexibilidad normativa a nivel local y territorial. .................................. 60

8.2.1 El derecho de propiedad y el planeamiento ..................................................61

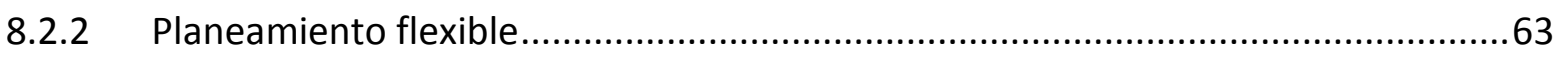

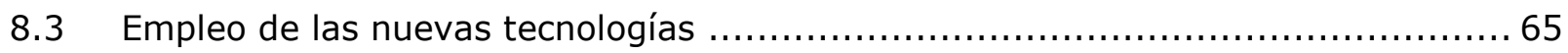

8.3.1 Medios de comunicación, páginas Web, redes sociales .....................................67

8.3.2 Medios de formación y colaboración..................................................................70

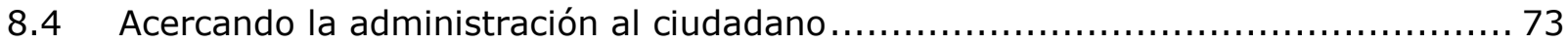

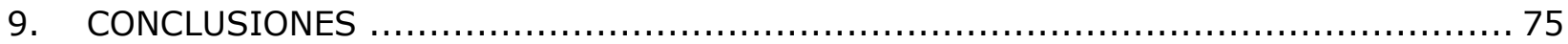

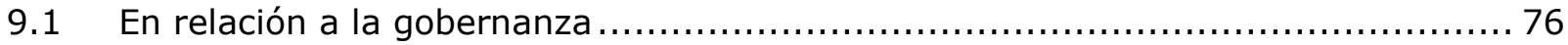

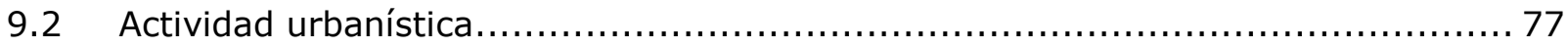

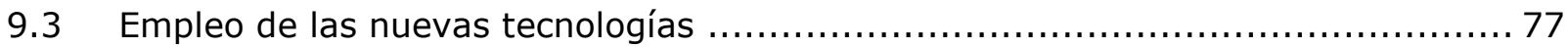

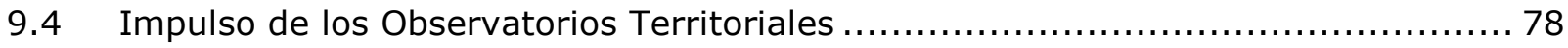

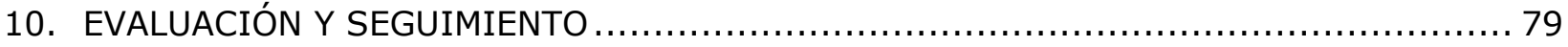

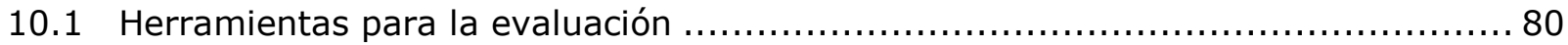

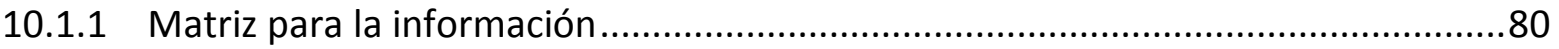

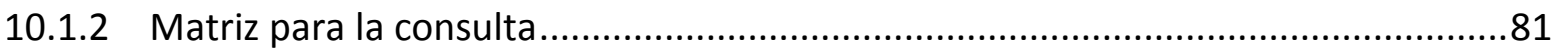

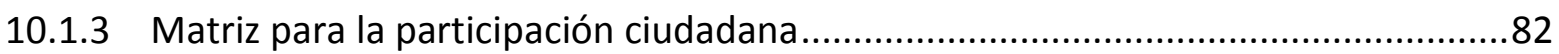

10.2 Herramienta para el seguimiento de la participación .................................. 85

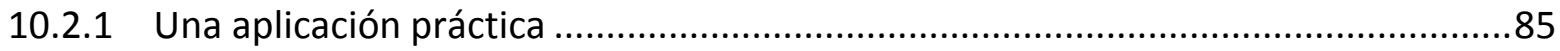

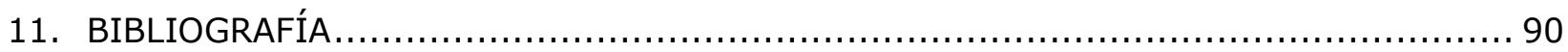




\section{INTRODUCCIÓN}

"Queremos finalmente destacar el valor de la ciudadanía entendida como el conjunto de derechos y responsabilidades de los habitantes de la ciudad y la conciencia que tienen éstos de su derecho a participar en la gestión de la ciudad y en la obtención de un conjunto de bienes y servicios. Asimismo, la ciudadanía supone la existencia de un sentimiento de pertenencia a la ciudad que está en la base de la asunción voluntaria por parte del ciudadano de sus responsabilidades" ${ }^{1}$

Abordar el tema de la participación ciudadana desde la perspectiva de la administración y en el contexto académico de estudios superiores de urbanismo y territorio, intentando no caer en lo popular y ni en lo estrictamente normativo, es una tarea de riesgo.

Y es así por varios motivos: en principio porque la participación apenas tiene cabida en la normativa urbanística -más allá de los procedimientos de información pública o alegaciones-, por otro lado porque hasta hace poco tiempo, las iniciativas ciudadanas se situaban al margen de la legalidad y surgían, en muchos casos, como acciones "radicales" de oposición o protesta contra las decisiones tomadas por las administraciones y las políticas públicas; también por la propia indefinición del concepto y su aplicación, y por tanto lo difuso que puede resultar su análisis y las conclusiones que a través del mismo se obtengan.

En el presente estudio se parte de acotar el concepto de participación y las condiciones de contexto para que pueda producirse con rigor; se analizan sus características básicas entendida como manifestación de la sociedad democrática que evoluciona hacia sistemas de decisión directa y corresponsabilidad; teniendo presente que "las Ilamadas a la participación ciudadana, para que sean efectivas, no pueden hacerse al margen del marco legal de referencia, puesto que estas serán de corto alcance, ya que más allá de la remisión al término "participar" primarán los derechos reconocidos en el sistema" ${ }^{2}$.

Para conocer el estado de la cuestión en el panorama normativo actual, como marco legal que determina su efectividad, se analiza cómo es considerada la participación ciudadana en la normativa urbanística a nivel estatal, europeo y en el ámbito internacional de Naciones Unidas. En este estudio se ponen de manifiesto grandes diferencias en el tratamiento de esta cuestión en cada caso, mientras que en España apenas tiene presencia y es restringida a procesos de información pública, en Europa y Naciones Unidas se trata como un asunto transversal fundamental, si bien es cierto que en ningún caso esta práctica ha superado la barrera de las indicaciones o directrices generales para formar parte de una directiva o ser objeto de normativa de desarrollo posterior.

\footnotetext{
${ }^{1}$ Declaración de Barcelona en la Conclusión de la Conferencia sobre Grandes Ciudades, 1985.

${ }^{2}$ FERNÁNDEZ, C. (2011).
} 
Dentro de este análisis global del concepto se hace un recorrido histórico partiendo de la segunda mitad del siglo XX, desde el punto de vista teórico y la filosofía política y social, se analizan las diversas corrientes y enfoques, a raíz de la aparición en 1961 del Libro de Jane Jacobs "Muerte y vida de las grandes ciudades" y los movimientos radicales que surgieron en los años 1960-1970 hasta los planteamientos más actuales amparados en el concepto el urbanismo o planificación colaborativa acotado por Patsy Healey .

Esta base teórica, desde el punto de vista técnico, social y político, sirve de punto de apoyo para la identificación de las barreras y resistencias a la participación, y determinar las líneas de trabajo para superarlas; centradas en la conveniencia de una cultura participativa y urbanística basada en la información y la formación accesible y comprensible. Fundamentada en la confianza mutua y la actuación por consenso como resultado de procesos de información, confrontación y diálogo, orientados al interés general en la toma de decisiones que afectan a la ciudad y, por tanto, a la vida de los ciudadanos.

Se plantean posibles líneas de intervención para el desarrollo de una cultura de la participación y la práctica del urbanismo colaborativo. Desde el análisis del marco jurídico-administrativo, el planeamiento territorial y urbano, y la definición de instrumentos y nuevos medios como los "Observatorios territoriales" o "Centros de Ciudad", con el objetivo de facilitar la cultura de la participación y la incorporación a la ciudad de las iniciativas cívicas entendidas como el pulso y la vitalidad de la sociedad que viene a enriquecer y ampliar los márgenes normativos, apoyadas en el uso de las nuevas tecnologías como instrumentos para la comunicación, la creación de redes y formación de un sentimiento de pertenencia, y la generación de un impacto social producido por la nueva realidad, posiblemente el germen de una sociedad más resiliente ${ }^{3}$.

"El reto que debe proponerse el urbanismo es el de articular formas, medidas, pautas y metodologías para la recuperación de la ciudad como construcción verdaderamente colectiva" ${ }^{4}$.

\footnotetext{
3 SUBIRATS, J. (2015). "Siguiendo a Holling, Magrinyà y Balanzó apuntan a que la resiliencia puede relacionarse con la capacidad de un sistema complejo de adaptarse a situaciones de desequilibrio, alcanzando otras estabilidades que permitan nuevas transformaciones."

${ }^{4}$ VERDAGUER, C. (2003).
} 


\title{
2. PARTICIPACIÓN CIUDADANA. CONCEPTO
}

\begin{abstract}
"Todavía estamos en una fase en la cual, en este tema como en otros, predomina el "ruido" y la confusión. Pero, al mismo tiempo, crece la convicción de que sólo experimentando y probando, acertando y equivocándonos, haremos avanzar nuestra joven realidad democrática y sus capacidades de resolución de los problemas que toda convivencia social plantea. No podemos trazar conclusión alguna por el momento. Sólo invitar a mirar con nuevos ojos esa inestimable realidad llamada democracia". ${ }^{5}$
\end{abstract}

No resulta fácil encontrar una definición oficial o consensuada de Participación Ciudadana, tal vez porque se trate de un concepto indeterminado o porque se presta a múltiples interpretaciones. Acudiendo a la RAE, "Participar" en su primera acepción significa (dicho de una persona) tomar parte en algo; ciudadano/na es la persona considerada como miembro activo de un Estado, titular de derechos políticos y sometido a sus leyes. En su etimología, si relacionamos ciudad y polis, el término nos lleva al concepto de política como todo lo relativo a la vida de la polis ${ }^{6}$. Así un ciudadano lo es en cuanto participa activamente en la actividad política; podría decirse que forma parte de su propia naturaleza.

Esta actividad ha ido variando en el tiempo en intensidad y ámbito de desarrollo, en función de la complejidad de los sistemas y la organización política de la sociedad. En una sociedad compleja como la actual, una aproximación genérica al concepto de participación ciudadana, sería la acción en política, colectiva o individual, de la que todos formamos parte. Esta acción podrá integrarse en la actividad política/administrativa o no, dependiendo del grado de madurez democrática y buen gobierno de las instituciones o del Estado. Esta actividad de los ciudadanos en las cuestiones públicas que lleva a una mayor influencia en la toma de decisiones, no implica la inobservancia de las normas o la falta de responsabilidad de los gobernantes ante sus actos.

Sobre los beneficios, requisitos y principios de la participación se profundiza más adelante, en el capítulo 5 dedicado al análisis de las teorías filosóficas y sociológicas sobre la participación en el urbanismo y el capítulo 8 en el que se analizan las vías para su desarrollo.

\footnotetext{
5 SUBIRATS, J. (2001).

${ }^{6}$ Politiké de la expresión politiké techne: el arte de vivir en sociedad o lo relativo a las cosas del estado o la ciudad.
} 


\subsection{Beneficios de la participación}

Si entendemos la participación como una relación entre las instituciones públicas, los ciudadanos y la sociedad en su conjunto, fortalecer esta relación produce beneficios para ambas partes ${ }^{7}$ :

- Innovación en los procesos y resultados: el intercambio de conocimiento y la información induce a la innovación; cuanto más profundo sea el proceso de participación, mejores serán las propuestas que se obtengan. Mayor complementación entre lo distinto.

- Políticas, planes, proyectos públicos de mejor calidad y resultado: la colaboración proporciona mejor base para la elaboración de planes públicos más eficientes y adecuados. Al ser un proceso abierto, la organización se encuentra en constante aprendizaje y mejora. Generar los planes de este modo facilita su implementación entre los ciudadanos que ya han participado en su elaboración.

- Incremento de la confianza mutua: entablar este tipo de relación es síntoma de administración abierta y transparente. Permite que los ciudadanos se familiaricen con los proyectos, o asuntos de la administración, y conozcan mejor las motivaciones de las actuaciones públicas resultantes lo que redunda en el fortalecimiento de la relación y aumento de la legitimidad de la administración. El conocimiento mutuo facilita el entendimiento y el diálogo, facilita llegar a consensos en beneficio de la comunidad.

- Democracia más fuerte: mediante el fortalecimiento de la relación administración/ciudadanía, de la que resulta un mayor compromiso de los ciudadanos a la hora de participar y asumir responsabilidades.

\subsection{Principios y requisitos previos}

Las relaciones constructivas de diálogo y consenso entre administración y ciudadanía deberían desarrollarse siguiendo los principios de: implicación, confianza, transparencia e independencia. Involucrar a los ciudadanos en los procesos de toma de decisiones requiere unas condiciones de partida:

- Administración pública:

- Debe reconocer la capacidad autónoma de los ciudadanos para discutir y plantear alternativas.

- Debe compartir la elaboración de la agenda y comprometerse a considerar las propuestas elaboradas en común.

- Contar con una legislación favorable, procedimientos claros y precisos.

- Apoyo a largo plazo y recursos que garanticen una sociedad civil sostenible, con lugares de diálogo y cooperación ${ }^{8}$.

7 CONSEJO DE EUROPA (2009)

${ }^{8}$ CONSEJO DE EUROPA (2009). Del Código de Buenas Prácticas: también incluye como requisitos previos: Estado de Derecho, adhesión a principios democráticos fundamentales y la voluntad política, que no se han enumerado puesto que son condiciones de partida que ya se dan en el estado Español. 
- Ciudadanía:

- Debe asumir una mayor responsabilidad para lograr mejorar su participación en la elaboración de las políticas públicas.

- Es necesario partir de un mínimo de cultura participativa que implica una mayor actividad pública.

- Procesos de participación:

- Abiertos, accesibles.

- Parámetros de participación acordados y conocidos.

\subsection{Niveles y características básicas}

Las clasificaciones ${ }^{9}$ de los niveles de participación son variadas aunque coinciden en el criterio de base, esto es en el nivel de implicación del ciudadano. La Asociación Internacional para la Participación Pública (IAP2) ${ }^{10}$ : información, consulta, implicación, colaboración y empoderamiento en el que los ciudadanos toman la decisión final identificado con la corresponsabilidad; el Consejo de Europa (2009) habla de cuatro niveles: información, consulta, diálogo y alianzas identificadas con la corresponsabilidad y colaboración estrecha en la toma de decisiones y ejecución de las acciones. Para la OCDE ${ }^{11}$ los niveles se reducen a tres: información, consulta y participación activa fundamentada en el principio de la co-participación.

\section{NIVELES DE PARTICIPACIÓN}

\begin{tabular}{|c|c|c|c|c|}
\hline OCDE & CONSEJO EU & IAP2 ${ }^{10}$ & ORIGEN & INFLUENCIA \\
\hline \multirow{2}{*}{ P. Activa } & \multirow[t]{2}{*}{ Alianzas } & Empoderamiento & Públ/priv & $\begin{array}{l}\text { Corresponsabili- } \\
\text { dad }\end{array}$ \\
\hline & & Colaboración & Públ/priv & Colaboración \\
\hline \multirow{2}{*}{ Consulta } & Diálogo & Implicación & Públ/priv & Cooperación \\
\hline & Consulta & Consulta & Públ/Priv & Bidireccional \\
\hline Información & Información & Información & Público & Unidireccional \\
\hline
\end{tabular}

La OCDE establece para cada uno de estos niveles de relación sus propias características consideradas como parámetros de calidad para que la relación sea óptima en cada caso.

\footnotetext{
${ }^{9}$ ORDUÑA, Ma A. (2016).

${ }^{10}$ IAP2: International Association for Public Participation.

${ }^{11}$ OCDE (2006).
} 


\subsubsection{Información como base de la participación}

Como se recoge en el Libro Blanco de la Sostenibilidad en el Planeamiento Urbanístico Español ${ }^{12}$ "La participación necesita un soporte imprescindible que es el de la información. ... aunque existe información adecuada y fiable, no es suficiente, ya que resulta imprescindible que se transmita a la gente de manera comprensible." No es posible una participación activa útil sin contar previamente con una información adecuada, fiable y comprensible, para la OCDE "La información es la clave del fortalecimiento de las relaciones entre administración pública y ciudadanía".

El procedimiento administrativo contempla la información pública, como mecanismo para facilitar la información de los ciudadanos afectados por determinado plan o programa, y ofrece la oportunidad de dar a conocer su opinión, normalmente en forma de alegaciones o sugerencias. Este aspecto se tratará más adelante.

\section{CARACTERÍSTICAS DE LA INFORMACIÓN}

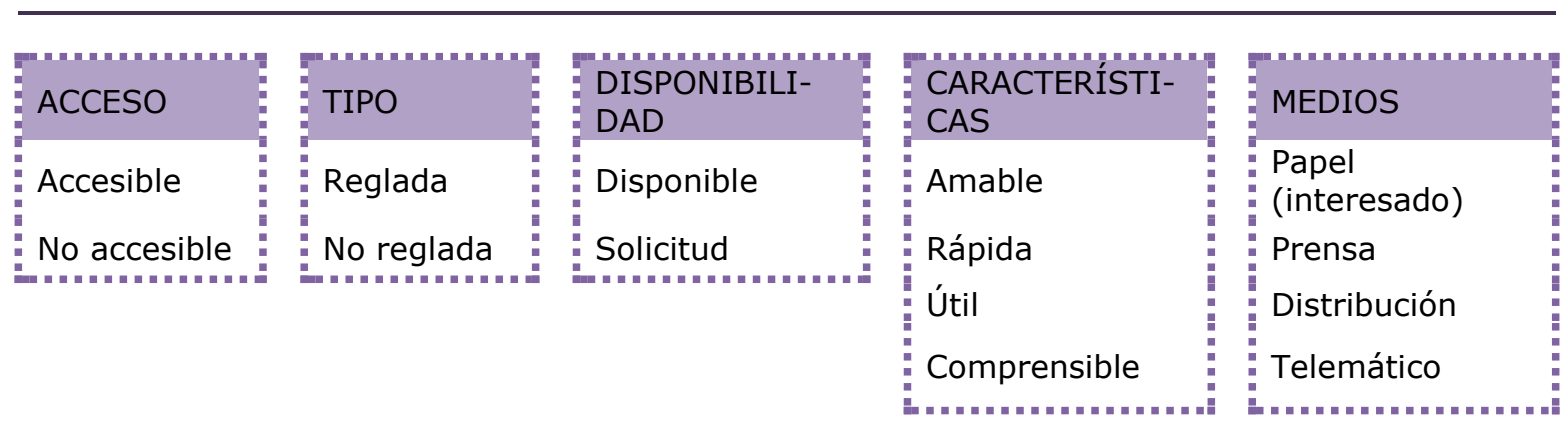

Tabla 2. Características de la información.

Fuente: Elaboración propia.

\subsubsection{Consulta como inicio de la colaboración}

En cuanto a la consulta el concepto es algo menos claro que el de información, en ocasiones se entiende que puede ser bidireccional, y en otros ámbitos se ciñe a la solicitud de datos que la administración dirige a los ciudadanos o grupos de interés respecto a algún asunto concreto. Sin embargo, acudiendo al significado y etimología de la palabra, se relaciona con considerar y deliberar, y se define como examinar, tratar un asunto con una o varias personas; así pues debería ser bidireccional y deliberativo.

En general, la consulta se plantea como una acción que parte de la administración hacia el ciudadano sin embargo en la práctica esta acción se realiza con frecuencia en ambos sentidos, legalmente reconocido por el derecho de petición. En ocasiones esta comunicación facilita el conocimiento de los problemas o necesidades de los ciudadanos sobre temas concretos y puede dar lugar a su

12 FARIÑA, J. y NAREDO. JM. (2010). 
consideración y solución o adaptación de las condiciones de partida, según el asunto.

\section{CARACTERÍSTICAS DE LA CONSULTA}

$\begin{array}{lll}\text { ACCESO } & \text { DISPONIBILI- } \\ \text { General } & \text { DAD } \\ \text { Reducido }- & \text { Reglada } \\ \text { Condiciona- } & \text { No reglada } \\ \text { do } & \text { Informal }\end{array}$

CARACTERÍSTICAS
Puntual - petición
Encuesta opinión
Plebiscito
referendum
Información pública

MEDIOS
Quejas y sugerencias
Comisiones
consultivas
Comis.
Parlamentarias
Instituc. de vigilancia

Tabla 3. Características de la consulta.

Fuente: Elaboración propia.

\subsection{Participación ciudadana como corresponsabilidad}

Como se ha dicho, la OCDE ${ }^{13}$ denomina esta acción como participación activa. La define como un proceso de co-participación, basado "en el supuesto de que los ciudadanos pueden contribuir de manera eficaz y original a la elaboración de políticas, (planes, proyectos) a partir del conjunto de recursos de la sociedad, para enfrentar los numerosos problemas de gobernabilidad que se plantean hoy en día."

Esto implica considerar al gobierno y a la administración como un promotor, creador de estructuras-macro, orientado a que los agentes y ciudadanos puedan organizar sus actividades y relaciones. Su ámbito de desarrollo más inmediato es el ámbito local, mediante la promoción de organizaciones ciudadanas y la formalización de estructuras participativas, su regulación y evaluación, tanto del proceso como del resultado de la acción.

Atendiendo a sus características se puede establecer una primera clasificación de la participación ciudadana en el urbanismo, como ámbito sustancial, que servirá de base al sistema de evaluación planteado en el capítulo 10.

${ }^{13}$ OCDE (2006). 


\begin{tabular}{|c|c|c|c|c|c|}
\hline \multicolumn{2}{|c|}{ PÚBLICOS } & \multicolumn{4}{|l|}{ ORGANIZACIÓN } \\
\hline PÚBLICO & GRUPO-OBJETIVO & FORMAL & & INFORMAL & \\
\hline & Partes involucradas & Público & Privado & Público & Privado \\
\hline & $\begin{array}{l}\text { Por criterios de } \\
\text { diferenciación }\end{array}$ & Área & Asociaciones & Ocasional & $\begin{array}{l}\text { Quejas y } \\
\text { sugerencias }\end{array}$ \\
\hline & $\begin{array}{l}\text { Según la fase del } \\
\text { proceso }\end{array}$ & Reglamentaria & Reglamento & Sondeo & $\begin{array}{l}\text { Acceso a } \\
\text { representantes }\end{array}$ \\
\hline & $\begin{array}{l}\text { Por sector de } \\
\text { intervención }\end{array}$ & Cauce & Asambleas & Encuesta & Redes sociales \\
\hline & Organizaciones & Consejo de Barrio & Cauces & & $\begin{array}{l}\text { Grupos de } \\
\text { presión }\end{array}$ \\
\hline
\end{tabular}

Tabla 4. Características de la participación activa Parámetros 1/3.

Fuente: Elaboración propia.

\section{CARACTERÍSTICAS DE LA PARTICIPACIÓN CIUDADANA - Proceso}

$\begin{array}{ll}\text { ASPECTO TEMPORAL } \\ \text { PUNTUAL } & \text { CONTINUADO } \\ \text { Aislado } & \text { Sistematizados } \\ \text { Sucesivo } & \text { Mediante TICs } \\ & \text { Redes Sociales } \\ & \text { Procesos organizados }\end{array}$

\section{HERRAMIENTAS}

TRADICIONALES

DIGITALES

Registro Administrativo Correo Electrónico

Buzones ocasionales

Buzón de sugerencias

Quejas y sugerencias

Redes Sociales

Sesiones

Aplicaciones específicas

Talleres

Aplicaciones genéricas

Tabla 5. Tabla 5. Características de la participación activa Procesos 2/3.

Fuente: Elaboración propia. 


\section{CARACTERÍSTICAS DE LA PARTICIPACIÓN CIUDADANA - Objetivos}

\begin{tabular}{lll}
\hline ETAPAS & \\
\hline CONOCIMIENTO & ANÁLISIS & TOMA DE DECISIÓN \\
Opinión & Debilidades & Leyes, normas \\
Percepción & Amenazas & Política pública \\
Expectativas & Oportunidades & Planes Generales: estratégico, urbanístico,,.. \\
& Fortalezas & Planes sectoriales: movilidad, deportes,,.. \\
& & Programas \\
& & Proyectos obras, sectoriales
\end{tabular}

Tabla 6. Características de la participación activa Objetivos 3/3.

Fuente: Elaboración propia.

\section{LA PARTICIPACIÓN EN LA LEGISLACIÓN URBANÍSTICA Y LOCAL}

"Tanto en España como en Europa el progreso y el equilibrio social han estado asociados desde la antigüedad al esplendor de la vida urbana y al consiguiente florecimiento municipal" ${ }^{14}$.

En la legislación española encontramos el concepto de la participación ciudadana vinculada a otros aspectos de la actividad administrativa y de gobierno como la información pública y la transparencia, con los que sin duda guarda relación aunque se tiende a identificar a aquella con dichos conceptos, lo que lleva a confusión y a limitar su alcance. Se comprueba que no se regulan expresamente los procesos o fórmulas de participación y en general, la regulación es rígida y poco adaptable a las necesidades actuales de los ciudadanos, tanto para incorporar sus propuestas como para ejercer una verdadera colaboración.

Para obtener una visión general de la regulación de las acciones de información, consulta y participación se analizan las normas estatales que puedan ser más relevantes: las relativas a la actividad de administración local, el procedimiento administrativo común y específicamente la regulación urbanística.

La Constitución Española introduce el concepto de la participación en su título preliminar, artículo 9.2, por el que se determina que los poderes públicos deben facilitar la participación de todos los ciudadanos en la vida política, económica, cultural y social. En relación al Gobierno y la Administración, en el artículo 105 recoge los ámbitos en los que se incluye a los ciudadanos en las cuestiones administrativas: audiencia en la elaboración de disposiciones que les afecten, acceso a archivos y registros y la garantía de la audiencia al interesado cuando

${ }^{14}$ Ley 7/1985, de 2 de abril, Reguladora de las Bases del Régimen Local. Exposición de motivos. 
proceda. La relación con el ciudadano abarca el derecho a la información bajo la modalidad de la solicitud y la audiencia en los temas que les competan a criterio de la administración.

\begin{tabular}{ccc} 
Norma & Artículo INFORMACIÓN CONSULTA PARTICIPACIÓN TRANSPARENCIA \\
\hline $\begin{array}{c}\text { Constitución } \\
\text { Española }\end{array}$ & 9.2 & 105
\end{tabular}

Tabla 7. Análisis de normativa $1 / 2$.

Fuente: Elaboración propia.

\subsection{Análisis de normativa de Administración Local}

La administración local es la más próxima al ciudadano, su actividad incide directamente sobre la vida de las personas, es el marco vital de la participación ciudadana, como recoge la Ley 7/1985 "Los Municipios son Entidades básicas de la organización territorial del Estado y cauces inmediatos de participación ciudadana en los asuntos públicos...". En la regulación municipal la participación ciudadana siempre ha estado presente de modo más o menos explícito. Se analizan las normas más significativas de su régimen jurídico.

- Reglamento de Servicios de las Corporaciones locales de $1955^{15}$ - aún vigenteel artículo 31 recoge: "1. Con el fin de atender a las necesidades de sus administrados, las Corporaciones Locales prestarán los servicios adecuados para satisfacerlas", para ello es condición indispensable que el administrado haya comunicado de algún modo dicha carencia a la corporación. Esta relación ya puede entenderse como una forma de participación. En ese momento, el ciudadano era considerado como "administrado" es una relación desigual; sin embargo, las necesidades de los ciudadanos son el objeto de la actividad municipal, bien prestando determinado servicio para ello bien facilitando la actuación del propio ciudadano para la satisfacción de determinada carencia.

- Ley de Bases del Régimen Local, otorga un gran protagonismo a la participación; desde su preámbulo se exalta el valor y la importancia de la participación auténtica "La experiencia histórica demuestra de modo irrefutable que el florecimiento de la vida local presupone el disfrute de amplia autonomía nutrida por la participación auténtica de los vecinos". El artículo 1 señala que los Municipios son los cauces inmediatos de participación ciudadana en los asuntos públicos, que institucionalizan y gestionan con autonomía los intereses propios de las correspondientes colectividades. La relación ya es más equilibrada y la administración es gestora de sus competencias y potestades para el interés público. Ello implica comunicación y relación con los ciudadanos.

Reconoce el derecho a participar de los vecinos (art 18.1.b) y regula su acceso a la información y participación en el Capítulo IV del Título $\mathrm{V}$ artículos del 69 al 72, estableciendo la obligación de las Corporaciones Locales de facilitar la

\footnotetext{
${ }^{15}$ Decreto de 17 de junio de 1955, por el que se aprueba el Reglamento de Servicios de las Corporaciones Locales, en desarrollo de la Ley de Régimen Local de 12/12/1950.
} 
información sobre su actividad y la participación de todos los ciudadanos en la vida local, sin menoscabar la toma de decisión de los órganos representativos legalmente establecidos. De hecho introduce el deber de impulsar la utilización de tecnologías de la información para facilitar la participación y comunicación, incluyendo las consultas ciudadanas. Contempla de modo específico la información y consulta en materia urbanística, la posibilidad de realizar consultas populares. Por último, recoge que deben favorecer el desarrollo de las asociaciones para la defensa de los intereses generales facilitando información, medios y ayudas económicas, impulsando su participación en la gestión municipal (art. 72).

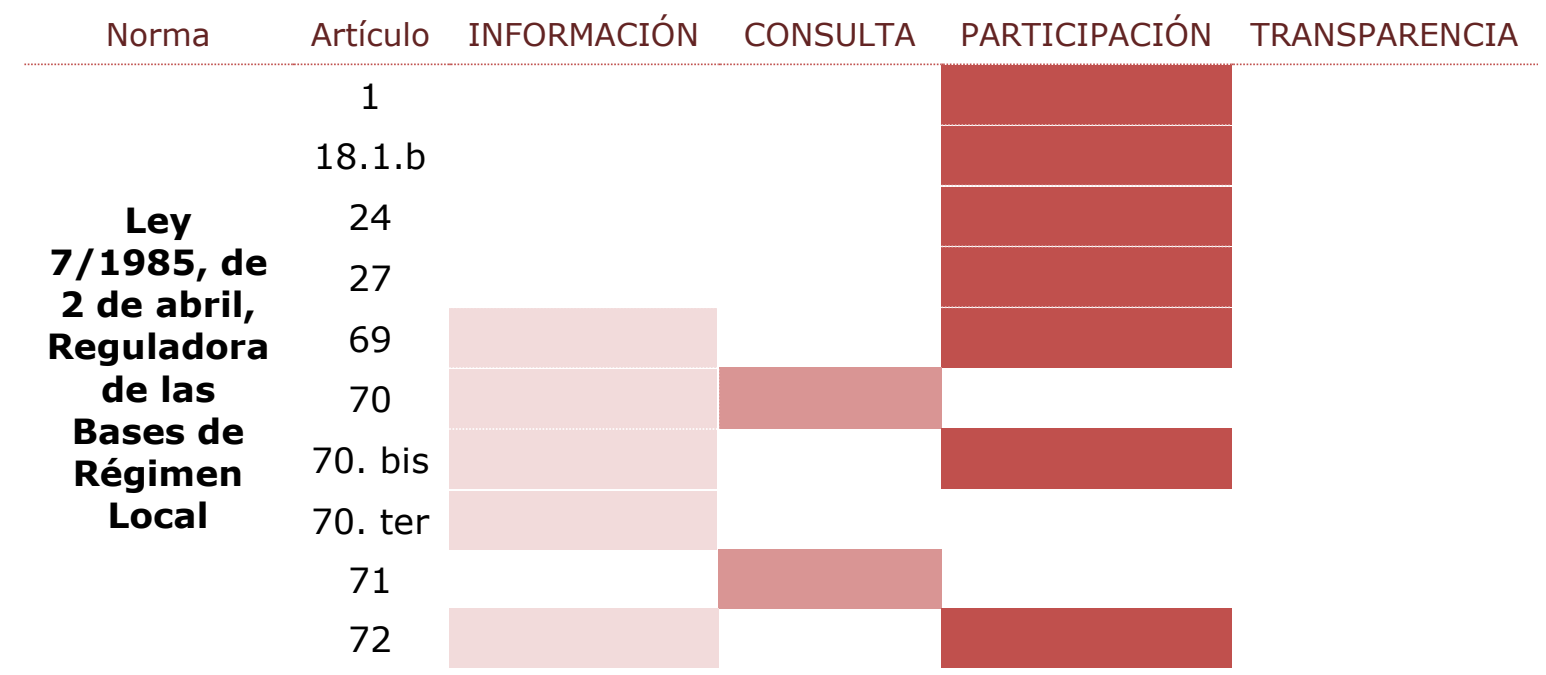

Tabla 8. Análisis de normativa 2/2.

Fuente: Elaboración propia.

\subsection{Análisis de la normativa sobre el procedimiento administrativo}

La reciente legislación sobre el procedimiento administrativo incorpora algunas novedades en estos aspectos respecto a la Ley anterior ${ }^{16}$. Sin embargo, no regula expresamente una participación activa, y en general la norma es rígida y con prevalencia de la administración en la relación entre las instituciones y los ciudadanos. Establecer una regulación facilitaría su puesta en marcha, y la superación de la actual relación entre ciudadano y administración basada en un procedimiento que, si bien pretende salvaguardar los derechos del interesado, es complejo, extenso y, en ocasiones, incomprensible.

Entre ambas leyes se ha incorporado al ordenamiento ex novo, la Ley 19/2003 de Transparencia, Acceso a la Información y Buen Gobierno, que supone un punto

\footnotetext{
16 Ley 30/1992, de 26 de noviembre, de Régimen Jurídico de las Administraciones Públicas y del Procedimiento Administrativo Común. Derogada por la Ley 39/2015, de 1 de octubre, del Procedimiento Administrativo Común de las Administraciones Públicas, vigente desde el 2 de octubre de 2016.
} 
de inflexión en la regulación de la actividad de gobierno y la relación con los ciudadanos.

- Ley 30/1992, derogada: en relación al procedimiento, la Ley 30/92 contemplaba la facultad de los interesados en iniciarlo, y su participación en el trámite de audiencia e información pública, aspectos fuertemente reglados y que daban poco margen a la iniciativa privada y la posibilidad de colaborar. Otra vía de actuación era el recurso, como vía de oposición contra las resoluciones y actos administrativos. En ninguno de los casos se trata la participación en el sentido analizado en este trabajo.

- Ley 39/2015, vigente desde el 1/10/2016: incorpora novedades para incrementar la participación ciudadana, dirigido al nivel de consulta, concretamente en el procedimiento de elaboración de normas, recabando previamente la opinión de los ciudadanos y empresas a cerca de los problemas que se pretenden solucionar, la necesidad y oportunidad de su aprobación, objetivos y posibles soluciones alternativas regulatorias y no regulatorias. En cuanto al procedimiento común se mantienen las regulaciones del trámite de audiencia y de información pública. Regula el acceso a la información, potenciando la administración electrónica y protegiendo en mayor medida los derechos de los ciudadanos a la información determinando que debe ser: puntual, ágil y actualizada.

Si hacemos un análisis "cuantitativo" de la legislación, aunque sea a modo de referencia, puede servir para hacernos una idea del protagonismo de las acciones que estamos analizando. Vemos que el término PARTICIPAR -PARTICIPACIÓN en relación al fomento de la participación ciudadana, en la Ley 30/92 aparece una vez en la exposición de motivos y dos veces en el texto de la Ley; en la Ley 39/2015 se encuentra diez veces, de las cuales cuatro están recogidas en la exposición de motivos y otras tres en el texto, de ellas, dos se refieren a la participación en la elaboración de normas. Una posible conclusión de este análisis alternativo, puede ser que el asunto de la participación empieza a tener más peso en la gestión pública, por ello su aparición en el preámbulo sin embargo aún no tiene cabida en el procedimiento, por lo que aún no es una realidad en la actividad administrativa.

EI término CONSULTA - CONSULTAR en el sentido de acceso a la información y de pedir opinión ciudadana, en la Ley 39/2015 se utiliza en treinta ocasiones de las cuales veinte se emplean en el sentido analizado. En la Ley anterior de once veces utilizada, cinco se refieren al acceso de los particulares. El concepto de la consulta se ha reforzado al incorporar este proceso en la elaboración de normativa. 


\begin{tabular}{lcccc} 
Norma & INFORMACIÓN & CONSULTA & PARTICIPAR & TRANSPARENCIA \\
\hline Ley $30 / 1992$ & 22 & 5 & 3 & 1 \\
Ley $39 / 2015$ & 31 & 20 & 10 & 6 \\
\hline Incremento & $\mathbf{4 1 \%}$ & $\mathbf{2 3 3 \%}$ & $\mathbf{3 0 0} \%$ & $\mathbf{5 0 0} \%$ \\
\hline
\end{tabular}

Tabla 9. Términos de participación en la legislación sobre el procedimiento administrativo. Fuente: Elaboración propia.

Se podría concluir que, al menos en intención, la legislación estatal avanza hacia la incorporación de los procesos de participación en la actividad administrativa. Se considera bastante afianzado el derecho a la información, se ha introducido recientemente el de consulta y seguramente la participación activa sea el siguiente paso; mientras, el concepto de transparencia y buen gobierno, irrumpe con fuerza en nuestra legislación.

\subsection{La participación en la legislación urbanística estatal actual}

El Real Decreto Legislativo 7/2015, de 30 de octubre, por el que se prueba el texto refundido de la Ley de Suelo y Rehabilitación Urbana, regula las condiciones básicas para garantizar la igualdad en el régimen del suelo y el desarrollo sostenible, competitivo y eficiente del medio urbano. Haciendo un análisis cuantitativo similar al anterior:

\begin{tabular}{lcccc} 
Norma & INFORMACIÓN & CONSULTA & PARTICIPAR & TRANSPARENCIA \\
\hline RD $7 / 2015$ & 28 & 0 & 42 & 2 \\
& 6 & $1 / 4$ & 2 & \\
& INF. PÚBLICA & $\begin{array}{c}\text { ALEGACIÓN } \\
\text { /RECURSO }\end{array}$ & $\begin{array}{c}\text { PARTICIPACIÓN } \\
\text { CIUDADANA }\end{array}$ & \\
\hline
\end{tabular}

Tabla 10. Términos de participación en la legislación urbanística estatal.

Fuente: Elaboración propia.

Podemos deducir que la participación ciudadana no está regulada, se incorpora como un derecho de los ciudadanos en el ámbito de la ordenación del territorio y ordenación y ejecución urbanística y de su evaluación ambiental, mediante la formulación de alegaciones, observaciones, propuestas, reclamaciones y quejas. Por otro lado, la consulta no se ha incorporado específicamente, y la información está arraigada en la regulación, especialmente en relación con la información pública.

A pesar de que el asunto de la participación prácticamente no se regula en la legislación, es importante identificar y analizar la relación entre el ciudadano y la administración en las diversas etapas de la actividad urbanística, desde el punto de vista de la participación, consulta o incluso transparencia: 
- Planeamiento: redacción y aprobación de los planes de ordenación territorial y urbanística, con naturaleza de disposición de carácter general, en los que se recoge las normas que definen el destino del territorio, el modelo de ciudad y la calidad de vida de sus habitantes.

- Ejecución: mediante la redacción y aprobación de proyectos técnicos y jurídicos para la transformación del suelo y la tramitación de autorizaciones para la edificación y usos del suelo y las construcciones; en los que se define la realidad material de lo previsto en el planeamiento, su relación con el paisaje y con la actividad cotidiana de los ciudadanos

- Uso y Mantenimiento: el desarrollo en el tiempo de lo ya ejecutado, y el uso sucesivo de lo construido y del territorio; sujeto a las normas del planeamiento, con carácter indefinido. Se delimita la capacidad de actuación de los ciudadanos y se rigidiza en cuanto a condiciones a cumplir y su carácter definitivo.

En todas ellas está en juego la realidad cotidiana de los ciudadanos y usuarios del entorno urbano y del territorio, por lo que la participación debería ser primordial. Si tomamos como punto de partida el planeamiento - por su carácter normativo y por ser el fundamento de las otras dos etapas-, la participación en el urbanismo se relaciona con dos aspectos de la gobernanza básicos:

- En relación con los principios de buena regulación: los planes urbanísticos tienen naturaleza de disposición de carácter general, en su tramitación se tendrán en cuenta los principios de buena regulación contenidos en el art. 129 de la Ley 39/2015: necesidad, eficacia, proporcionalidad, seguridad jurídica, transparencia y eficiencia.

Deberían estar justificados desde el interés general y basados en la identificación de los fines perseguidos, para ello la consulta pública y participación activa es fundamental. En relación a la transparencia, se fundamenta en el acceso sencillo, universal y actualizado a la normativa y documentos propios del proceso; la definición clara de los objetivos y su justificación, y posibilitar que los destinatarios tengan una participación activa en su elaboración.

- En relación a la transparencia en el urbanismo ${ }^{17}$ : la Ordenación Territorial y Urbanística son funciones públicas no susceptibles de transacción, que organizan y definen el uso del territorio y del suelo de acuerdo con el interés general, por lo que debe conciliar distintos, y a veces encontrados, intereses en juego. Sin embargo, el proceso de toma de decisión tiene un alto componente discrecional. Para evitar que dicha discrecionalidad devenga en un "decisionismo" irracional o interesado, es preciso evitar la arbitrariedad. Como instrumento de control y límite el artículo 4.1 del RD7/15, remite a la motivación y los intereses generales a los que sirve. Además, la participación ciudadana actúa como mecanismo para lograr un adecuado y acertado

${ }^{17}$ CHAMORRO, J.M. (2016). 
ejercicio de ordenación. Se entiende así, la participación ciudadana como legitimación del planeamiento, de modo que el resultado "no es más transparente sino más lógico y acertado".

Otro aspecto a favor de la transparencia es el derecho a la información y a obtener copia o certificación de las disposiciones o actos que complementa lo dispuesto en la L39/2015.

Igualmente se entiende relacionado con este tema el trámite de información pública, con relevancia formal y material, en el que la administración está obligada a tomar en consideración las alegaciones y, motivadamente, acordar su aceptación o rechazo.

Como se expone, la participación en el urbanismo aporta transparencia y, por tanto, legitimidad al proceso y a las decisiones que conforman el plan, su ejecución y su desarrollo futuro.

\section{URBANISMO Y PARTICIPACIÓN EN LA UNIÓN EUROPEA}

"Artículo 10. 3. Todo ciudadano tiene derecho a participar en la vida democrática de la Unión. Las decisiones serán tomadas de la forma más abierta y próxima posible a los ciudadanos.

Artículo 11. 1. Las instituciones darán a los ciudadanos y a las asociaciones representativas, por los cauces apropiados, la posibilidad de expresar e intercambiar públicamente sus opiniones en todos los ámbitos de actuación de la Unión.

2. Las instituciones mantendrán un diálogo abierto, transparente y regular con las asociaciones representativas y la sociedad civil" ${ }^{18}$.

\subsection{Resumen sobre la incidencia en el urbanismo desde la Unión Europea ${ }^{19}$}

La Unión Europea no tiene competencias en materia de urbanismo, si bien ha ido estableciendo objetivos y directrices desde diversos ámbitos y organismos, no siempre coordinados ni con una dirección clara. No obstante, la importancia del urbanismo, la necesidad de coherencia de las políticas urbanas, y de compartir una visión de futuro es patente.

Las primeras cuestiones que se abordaron partían de las políticas medioambientales, seguidas de las relacionadas con la cohesión económica a mediados de los ochenta y de las políticas sobre competitividad económica en los primeros años del siglo XXI. Los aspectos relacionados con la gobernanza y la participación se han ido definiendo de modo transversal a lo largo de estos años.

\footnotetext{
18 Tratado de la Unión Europea. Versión consolidada. Diario Oficial de Unión Europea C326/13. Fecha 26/10/2012

${ }^{19}$ FARIÑA, J. (2013) blog
} 
El primer documento de la Unión dedicado específicamente a la ciudad es El Libro Verde del Medio Ambiente Urbano, publicado en 1990; cuya aportación principal fue plantear un enfoque global de las cuestiones ambientales y urbanas y la creación de un grupo de expertos sobre Medio Ambiente urbano de la Unión Europea en 1991. En ese mismo año se publicó el documento Europa 2000: Perspectivas de Desarrollo del Territorio de la Comunidad, en el que se abordaba la planificación territorial.

Con la Carta de Aalborg, como resultado de la Primera Conferencia Europea sobre Ciudades Sostenibles de 1994, se inicia la Campaña de Ciudades Europeas Sostenibles. La Carta representa un hito entre los documentos redactados por la UE en relación a las ciudades; la política urbana europea se centraba en la sostenibilidad, y planteó los programas de iniciativas locales a favor de aquella. Reafirmaba la importancia de hacer un seguimiento, verificar si los efectos de las políticas de desarrollo sostenible eran los esperados y así, poder corregir las posibles desviaciones y adaptar las estrategias a las problemáticas que fueran surgiendo; se introdujeron nuevos sistemas de indicadores. A partir de este momento, decenas de miles de autoridades locales firmaron la Carta y han puesto en marcha Agendas 21: instrumentos flexibles y colaborativos, que se desarrollan según el criterio de los ciudadanos en cada caso. Este programa no vinculaba al planeamiento urbano.

En 1998, en la comunicación titulada Marco teórico de actuación para el desarrollo urbano sostenible en la Unión Europea aparecen las cuestiones relacionadas con la gobernanza y la participación. A partir de este momento se cambia el enfoque de la intervención de la Unión en el urbanismo pasando de un intento de legislar a establecer estrategias entorno al medio ambiente urbano y a temas económicos vinculados a la cohesión y la competitividad. La Estrategia Territorial Europea de 1999 ETE ${ }^{20}$ no constituye un modelo a seguir sino una fuente de referencia para las acciones que tengan impacto territorial; o los Principios Directores para el Desarrollo Territorial Sostenible del Continente Europeo de 2000.

En 2007, en la reunión informal de ministros responsables de desarrollo urbano, se firma la Carta de Leipzig sobre ciudades Europeas Sostenibles ${ }^{21}$-aún vigenteen la que se establecen dos grandes ejes de recomendaciones: hacer un mayor uso de las políticas integradas de desarrollo urbano y prestar especial atención a los barrios menos favorecidos impulsando actuaciones integradas económica, social y medioambientalmente.

En 2011 se aprobó la Agenda Territorial de la Unión Europea 2020 y más recientemente, en la reunión de Ministros de 2016, se ha firmado el Pacto de Amsterdam, último documento comunitario en relación al urbanismo dentro de la Agenda Urbana de la UE, centrado en tres elementos clave de las políticas

\footnotetext{
20 Los objetivos principales de la Estrategia Territorial Europea son tres: 1- Desarrollo de un sistema urbano policéntrico y equilibrado y de una nueva relación entre los ámbitos rural y urbano. 2- Garantizar la igualdad de acceso a las infraestructuras y al conocimiento. 3- Desarrollo sostenible, gestión responsable y protección de la naturaleza y del patrimonio cultural.

${ }^{21}$ MINISTERIO DE FOMENTO (2017)
} 
comunitarias: mejorar la regulación, mejorar la financiación y mejorar el conocimiento ${ }^{22}$.

Por otro lado, en paralelo, la Unión Europea ha ido desarrollando programas que han supuesto una intervención indirecta en las políticas urbanas, los más reconocidos son los URBAN ejecutados en dos fases: I 1994-99 y II 2000-06 y los URBACT nacidos en relación a los primeros, para la difusión de sus resultados y metodologías. Es en estos programas donde más énfasis se ha puesto en la práctica de la participación ciudadana. Es patente la importancia que la UE otorga a la participación, al conocimiento y a la información, y el objetivo de difundirlo mediante redes físicas y virtuales de relación, comunicación e intercambio.

\subsection{La importancia de la participación en las propuestas de la Unión Europea}

Desde el punto de vista de la importancia de la participación ${ }^{23}$, El Libro Verde sobre el Medio Ambiente Urbano introducía esta práctica en el ámbito urbano como elemento fundamental de la buena administración, considerando la ciudad el entorno en el que es posible participar de modo directo y donde el individuo puede desarrollar sus valores personales y cívicos. Considera la participación indispensable para el éxito de las políticas urbanas: "A la hora de aplicar una política urbana de medio ambiente, es conveniente para los intereses de la comunidad crear estructuras que faciliten el diálogo, la reflexión en común y la cooperación entre los diversos sectores de cada ciudad y entre las diferentes ciudades. Estas estructuras podrían servir también de puente con la Comunidad para el intercambio de información y opiniones" ${ }^{24}$. Estas ideas se recogen y reformulan en el capítulo 0 de este trabajo, como posibles líneas de estudio para generar una cultura participativa en el urbanismo.

Se introduce la necesidad de informar y formar a la población en asuntos relacionados con la planificación urbana y la ciudad como base fundamental para una participación activa y eficaz: "En este ámbito el Libro Verde introducía como sugerencia de actuación la creación de una red comunitaria de centros locales de iniciativa urbanística, que deberían organizarse en cooperación con los organismos públicos que ya realizaban tareas de información y planificación urbanas. Estos nacerían con los objetivos de informar a la población de la política comunitaria y de cómo esta incidía en la realidad urbana, fomentar y facilitar el diálogo, la planificación en común y la cooperación entre los grupos que intervienen en el medio ambiente urbano y, por último, facilitar el intercambio de información entre las ciudades respecto a las problemáticas que afrontaban y la experiencia sobre

\footnotetext{
22 COMISIÓN EUROPEA (2016): "The Urban Agenda for the EU is a new working method to ensure maximum utilisation of the growth potential of cities and to successfully tackle social challenges. It aims to promote cooperation between Member States, Cities, the European Commission and other stakeholders, in order to stimulate growth, liveability and innovation in the cities of Europe."

${ }^{23}$ GREGORIO, S. de. (2016).

${ }^{24}$ COMISIÓN EUROPEA (1990).
} 
cómo afrontarla." Esta propuesta de crear una red de centros de información no tuvo el desarrollo deseado ${ }^{25}$.

Es en el $V$ Programa de Acción Comunitaria de 1992, en el que se inicia el impulso de un cambio de comportamiento enfocado a la concienciación y actuando en el origen de los problemas. Mediante el Programa URBAN, iniciado en 1994, se afronta la degradación urbana actuando en el origen del problema: aspectos sociales y económicos, involucrando a la comunidad y los actores locales.

En la comunicación Hacia una Agenda Urbana en la Unión Europea de 1997, se pone de manifiesto el bajo nivel de participación de la población en los procesos democráticos locales, que se incrementaba en las áreas marginales, como consecuencia de la inexistencia de un sentimiento de identidad; y por otra parte la creciente demanda de la población para incidir en las decisiones que les afecta, señalaba la importancia de implicar a la población a través de procesos de participación, asegurando así que las necesidades fueran tenidas en cuenta, consideradas en la legislación y en los programas de actuación.

En relación al concepto de gobernanza, vinculado con la participación, información y transparencia, la Comisión Europea presentó en 2001 la Comunicación: La Gobernanza Europea. Un libro Blanco; que si bien pretendía mejorar la percepción de los ciudadanos sobre la Unión Europea, también reformaba el concepto e incidía en el ámbito urbano en las dimensiones multinivel, horizontal y participativa. Proponía cuatro líneas de actuación ${ }^{26}$, que posteriormente se han trasladado a las políticas de cada uno de los países de la Unión y concretamente a España, influyendo transversalmente en la actuación política y administrativa; como se ha mencionado en el apartado 2.4 y recoge el documento de la OCDE en relación a la participación activa.

La Carta de Atenas en 2003 del Consejo Europeo de Urbanistas, avanza en la importancia de la participación ciudadana en la planificación y el urbanismo, define La Ciudad Participativa: "Las ciudades son lugares de encuentro donde se nutre la interacción social. La planificación se debe esforzar en crear un concepto de vecindad para reforzar la identidad local, el sentimiento de pertenencia y una atmósfera humana. En particular, las unidades más pequeñas de la ciudad -la manzana, el barrio o el distrito- deben jugar un papel esencial en proporcionar un marco para el contacto humano y permitir la participación pública en la gestión del programa urbano. Al mismo tiempo, estas células urbanas han de relacionarse con la red de la ciudad, para proporcionar el contexto para la acción local. Para dar apoyo a las comunidades locales es necesario que haya flexibilidad en la toma de decisiones" 27.

\footnotetext{
${ }^{25}$ Otros autores lo han retomado, FARIÑA, J. (2011) en el Libro Blanco y aquí se recoge y se concreta, justificando su importancia.

26 Dichas líneas de actuación son: Un mayor grado de participación y apertura, diseño de mejores políticas, gobernanza mundial y centrar las instituciones.

${ }^{27}$ CONSEJO EUROPEO DE URBANISTAS (2003).
} 


\subsection{La Carta Europea de la Democracia Participativa en procesos Urbanísticos 28}

En consonancia el Consejo Europeo de Urbanistas ha aprobado recientemente La Carta Europea de la Democracia Participativa en procesos Urbanísticos, para invitar a todos los actores a los procesos de planificación, incluidos políticos y ciudadanos, considerando que "Todas las decisiones políticas tienen un impacto directo o indirecto sobre la ordenación del territorio.

- Cada acción es básicamente la planificación de una acción cultural.

- Todas las acciones de planificación tienen un impacto en la calidad de vida.

- La Ordenación del Territorio es relevante para asegurar el acceso a los servicios esenciales y el ejercicio de los derechos".

Considera la participación como una herramienta para asegurar que los procesos de planificación son justos y respetuosos con la diversidad de opiniones y necesidades específicas.

En su prefacio incorpora novedades significativas en el concepto de participación en relación con la cultura -superando la gobernanza como lugar propio de esta práctica- que ensancha sus límites y aumenta su valor: "La cultura debe ser considerada como el cuarto pilar de la sostenibilidad. Por lo tanto, tenemos que recordar que no hay acción urbanística que no conlleve implicaciones culturales. La información, la formación y la participación son factores culturales estrechamente relacionados".

La Carta introduce un marco para la participación basado en los siguientes conceptos:

- Ciudades y regiones como lugar natural para ejercer la democracia participativa, por la variedad de temas relacionados con el urbanismo con impacto directo en la calidad de vida de las poblaciones.

- En todas las etapas: diagnóstico, planificación, ejecución; proyectos, planes estratégicos o urbanos que deben llevarse a cabo con las personas.

- Los urbanistas y planificadores están comprometidos mediante la información completa y la participación en la formulación de soluciones.

- El proceso de globalización que ha generado un nuevo y difícil contexto político, económico y social.

- Las autoridades, a todos los niveles, deben asumir un liderazgo compartido con los ciudadanos.

28 Aprobada en la Asamblea General de la ECTP-CEU de Dublín el 17/10/2015. Versión en español: http://aetu.es/colaboraciones/ectp-ceu/ 
- La sociedad civil está desempeñando un mayor papel como actores claves y fuerza motriz del desarrollo y mantenimiento de una verdadera Democracia Participativa.

- Los sistemas de información en tiempo real y las grandes cantidades de datos, deben ser administrados desde los procesos participativos.

El documento establece una definición de la participación pública en el planeamiento territorial y urbano como: "una modalidad de participación pública que tiene por objeto facilitar la adopción de decisiones coproducidas por todos los interesados y fundados en el interés común que minimicen los conflictos derivados de las diferencias de opinión sobre las necesidades y soluciones".

Es un proceso co-producido en el que prevalece el interés general. Implica una plena y completa información y acceso a la misma, y garantizar el mismo nivel de comprensión de todos los participantes: formación y aprendizaje colectivo; fomentado y promovido por los urbanistas. Para ello, las autoridades públicas establecerán reglas en cada caso que deberán ser adecuadas para el funcionamiento del proceso y la adopción de decisiones.

Fomenta el uso de las nuevas tecnologías, como herramientas accesibles, fáciles de usar y satisfactorias para los participantes, junto con técnicas de deliberación y reflexión, que no sólo ayudan al entendimiento sino que además estrechan lazos y permiten crear una cultura de pertenencia.

Resalta el papel de los técnicos como dinamizadores, que aportan conocimientos y aseguran la equidad y cumplimiento de las normas y leyes; y de las autoridades en los diferentes niveles, comprometidos con el urbanismo participativo, incluye la vía del recurso para proteger los derechos de los participantes.

La relevancia de esta Carta se encuentra en la condensación de las cuestiones que giran en torno al urbanismo participativo y aunque trata aspectos generales, marca el objetivo y el contexto en que debe desenvolverse el proceso e involucra a la población, a los urbanistas y las autoridades para el buen desarrollo del proceso y garantía de buenos resultados. 


\section{CRONOLOGÍA DE DOCUMENTOS BÁSICOS Y PROGRAMAS DE LA UNIÓN EUROPEA}

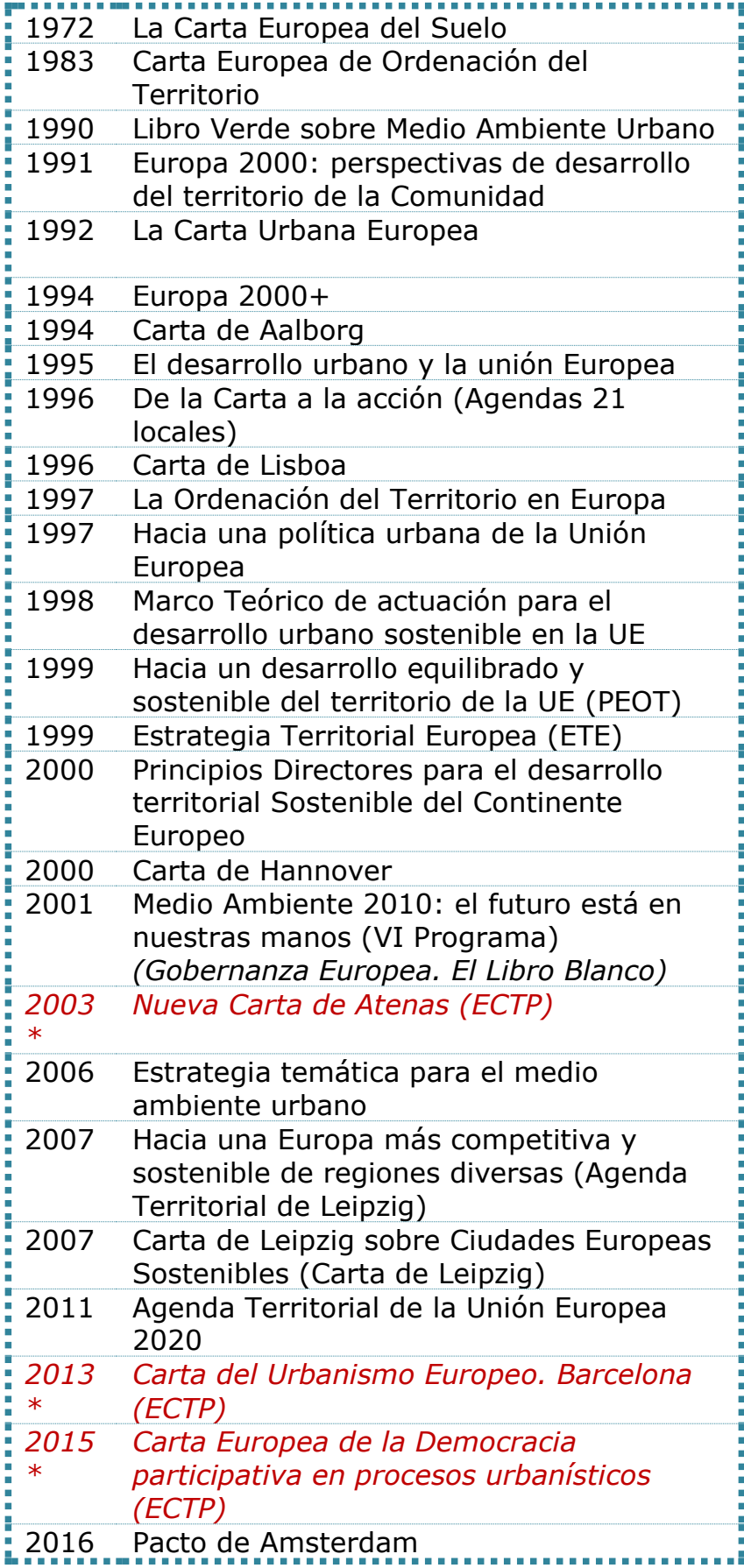

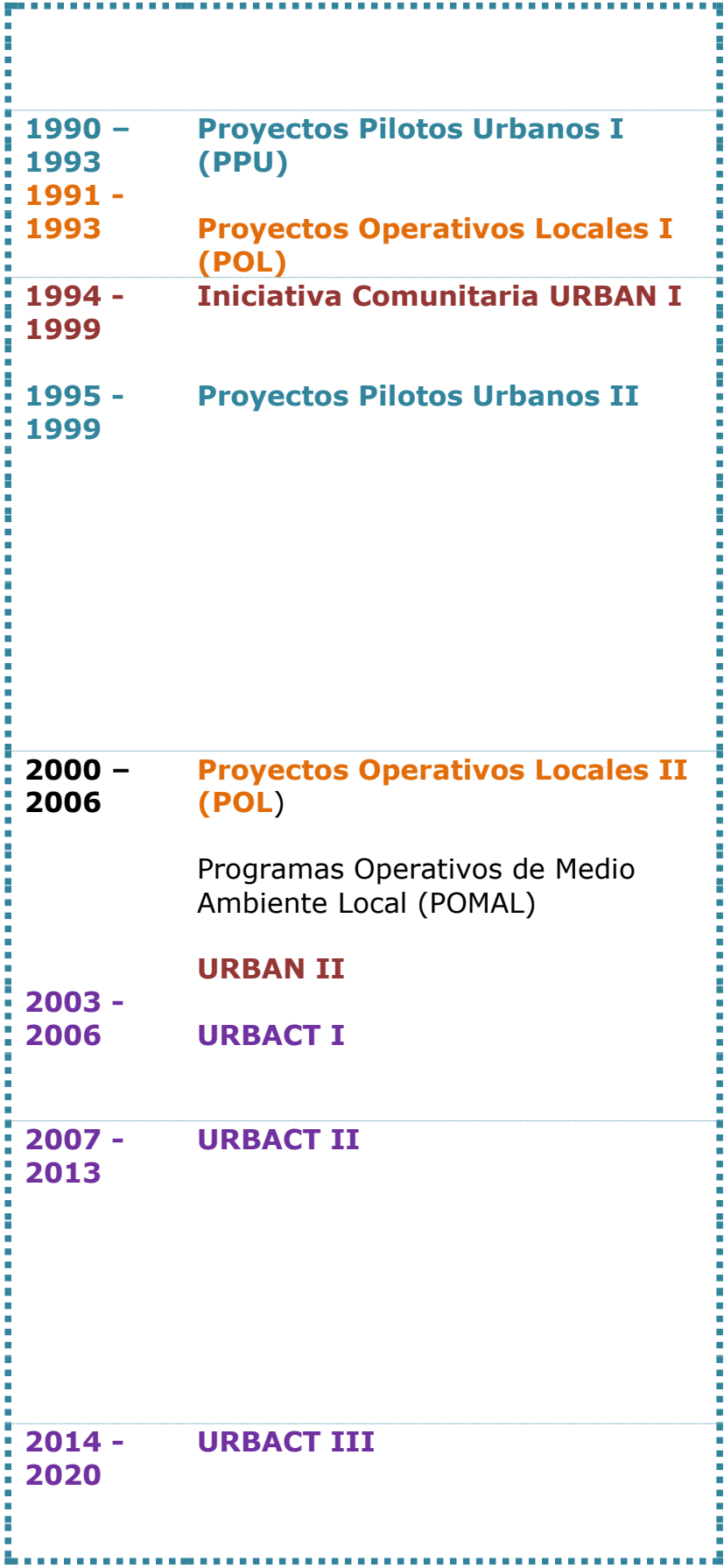

Tabla 11. Cronología de documentos y programas de la UE.

Fuente: Elaboración propia. ${ }^{29}$

${ }^{29}$ Los documentos de ECTP-CEU se han incluido entre los elaborados por la UE para su mejor ubicación temporal. 


\title{
5. MARCO TEÓRICO DE LA PARTICIPACIÓN EN EL URBANISMO
}

\begin{abstract}
"El grupo en su conjunto aprende en ocasiones como hacer posible algo que antes nunca lo fue, porque el trabajo de grupo puede hacer que la polarización se sustituya por cooperación, el recelo por confianza, los objetivos propios por objetivos compartidos. Este trabajo compartido puede ayudar a convertir la alienación en compromiso y la frustración en esperanza" 30
\end{abstract}

Las teorías sobre la participación en el urbanismo se desarrollan con mayor intensidad a partir de la década de los sesenta, estos planteamientos teóricos tuvieron incidencia en algunas de las políticas urbanas, especialmente en las enfocadas a la regeneración de la ciudad en Europa y Estados Unidos. Estos planteamientos y los resultados de las primeras experiencias fueron trasladados a las estrategias y programas impulsados por la Unión Europea, como hemos visto en el capítulo 4, han sido incorporadas paulatinamente a las políticas públicas de los países miembros de la Unión.

Como ejemplo de la consolidación de estas prácticas, en concreto en España, la Ley de Suelo Estatal y el Plan Estatal de Vivienda apuestan por la regeneración y renovación urbana, y los casos de éxito en su aplicación se han apoyado en la colaboración, la coproducción y participación de todos los agentes, particularmente los vecinos afectados por estas actuaciones.

Las propuestas teóricas en este campo, se han basado en aportaciones de otras disciplinas que convergen en el urbanismo como la sociología, geografía, filosofía del derecho,... como veremos más adelante en los casos de estudio ${ }^{31}$, que van desarrollando diferentes posturas alternativas a la planificación tradicional. Algunas de las principales teorías se enumeran a continuación:

\footnotetext{
${ }^{30}$ INNES, J. Y BOOHER, D. (2000).

${ }^{31}$ Ver Trinitat Nova capítulo 13.2
} 


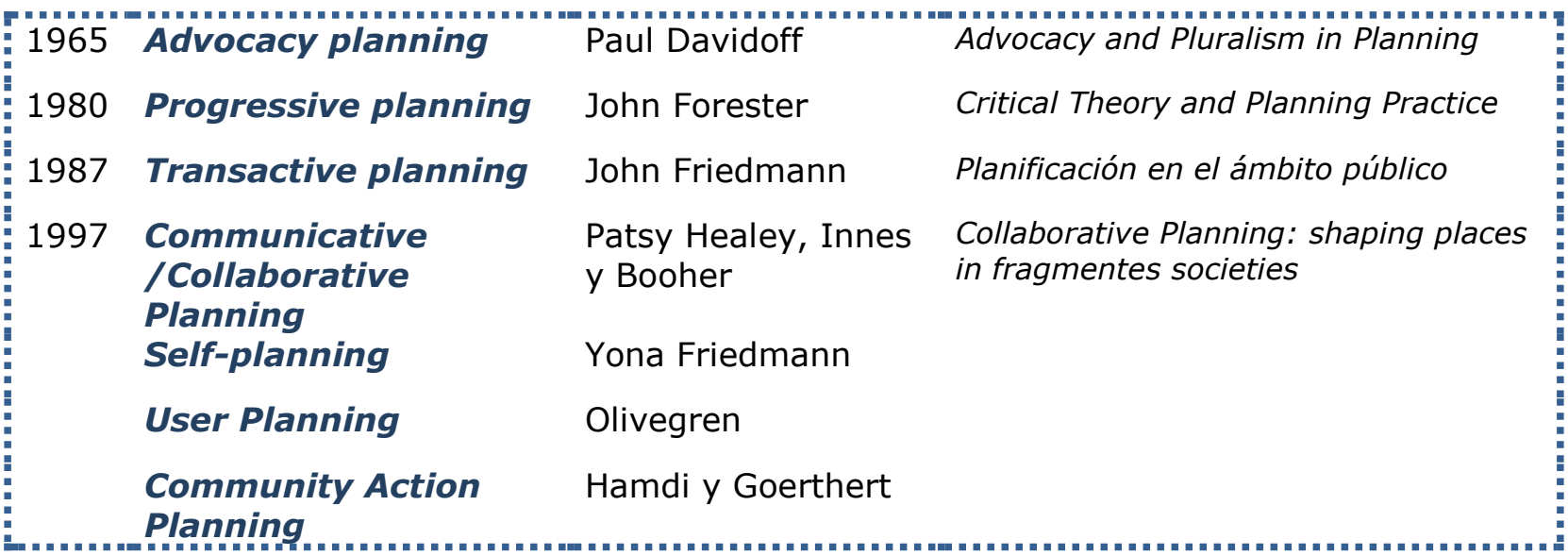

\begin{tabular}{|c|c|c|c|}
\hline 2001 & $\begin{array}{l}\text { Community Planning } \\
\text { and Design }\end{array}$ & Sanof Horelli & $\begin{array}{l}\text { A Methodology of participatory } \\
\text { Planning }\end{array}$ \\
\hline 2000 & $\begin{array}{l}\text { Argumentative } \\
\text { Planning }\end{array}$ & John Forester & $\begin{array}{l}\text { Deliberative Practitioner: Encouraging } \\
\text { participatory planning processes }\end{array}$ \\
\hline 2000 & Deliverative plannig & John Forester & $\begin{array}{l}\text { The Deliverative Practitioner: } \\
\text { Encouraging participatory planning } \\
\text { processes }\end{array}$ \\
\hline & Co-management & Paulson & \\
\hline & Partnerships & Mitchell, Murray & \\
\hline
\end{tabular}

Tabla 12. Teorías sobre la planificación participativa.

Fuente: Elaboración propia a partir del resumen de Sonia de Gregorio.

En relación al contexto en que se desarrollan estas teorías y experiencias, que en 1961 se publicó el libro de Jane Jacobs "Muerte y Vida de las Grandes ciudades", probablemente el libro más influyente de la planificación urbana, que pone el punto de mira del urbanismo en aspectos sociales, ecológicos, de seguridad, a raíz de las operaciones de renovación urbana que se estaban realizando en EEUU cuyos resultados eran cuestionables. Y que en palabras de su autora se plantea como un ataque: "Este libro es un ataque contra el actual urbanismo y la reconstrucción urbana. También es, principalmente, un intento de presentación de unos nuevos principios de planificación y reconstrucción urbana, diferentes e incluso opuestos a los que se enseñan hoy en todas partes desde las escuelas de arquitectura y urbanismo hasta los suplementos dominicales de los periódicos y las revistas femeninas. (...) Es más bien un ataque contra los principios y los fines que han 
modelado el moderno y ortodoxo urbanismo y reconstrucción urbana" ${ }^{32}$. Había empezado la guerra.

Si entendemos que, según Friedmann, son cuatro los métodos tradiciones de la planificación:

- Planificación como reforma social: constituye la tradición de la teoría de la planificación. Definida como la que es llevada a cabo por la administración, entendida como apoyo al sistema establecido basado en el capitalismo liberal. La planificación social y física como instrumento para mejorar y contrarrestar los peores efectos del desarrollo económico.

- Planificación como análisis de políticas.

- Planificación como aprendizaje social.

- Planificación como movilización social: Promueve cambios estructurales. Es la única que se dirige a los que el sistema ha apartado de las decisiones, como modo de organización para impulsar la transformación del sistema. Fundada en la crítica social, en la acción desde abajo. La práctica política de la ciudadanía es decisiva para cambiar el orden político de una sociedad. Denominada planificación radical.

La planificación como reforma social es la imperante en el urbanismo. Sin embargo la planificación como movilización social, la planificación radical, ha ido avanzando y haciéndose más visible y necesaria. Así, la planificación colaborativa surge como un entendimiento entre estos dos métodos antagónicos, que nacen de dos realidades tangibles, opuestas, pero que deben confluir para facilitar el avance de la sociedad. Si bien cada método tiene unos principios muy diferentes, de ahí la importancia de los conceptos de colaboración y consenso. Como veremos más adelante, en el apartado 7.4, hoy en día, esta planificación radical tiene su reflejo en las iniciativas ciudadanas y su intervención en la ciudad. Surge en el siglo XIX, como reacción a las consecuencias sociales de la revolución industrial.

Esta corriente tiene origen en experiencias como la DGEI: Expedición Geográfica de Detroit, concebida como misión cartográfica y educativa de carácter radical, impulsado en 1971 por el geógrafo William Bunge. Pretendía la emancipación de la clase obrera negra, como revolución ecológica o biológica: una transformación de la relación del hombre y su entorno. La DGEI proponía un enfoque distinto de la participación, como práctica de la acción, como una revolución: "Bunge quería investigar acerca de la sociedad negra pero, a la vez, pensaba que ésta tenía que aprender a hacerlo por su cuenta" ${ }^{33}$. Estas experiencias destacan dos enseñanzas fundamentales:

\footnotetext{
32 JACOBS, J. (1961).

${ }^{33}$ FARIÑA, J. (2012).
} 
1. La necesidad de los planificadores de tener contacto con la realidad.

2. Los residentes son los que mejor conocen el sitio en el que viven, si se suministra a los vecinos los instrumentos adecuados para analizar y sistematizar la realidad que habitan, serán los más adecuados para proponer soluciones eficientes.

Como resultado surge el denominado Planificador de $A p o y O^{34}$, que si bien actuaban dando voz a los "pobres urbanos" defendiendo sus intereses y aportando su conocimiento técnico para convertir sus aspiraciones en propuestas asequibles; no tenían una posición independiente en relación a las administraciones que contrataban estos servicios, por lo que su actuación estaba limitada por las condiciones de partida. No obstante, estas experiencias mostraron las múltiples opciones y puntos de vista sobre la ciudad más allá de la planificación tradicional que consideraba una única opción, en general, en privilegio de los intereses de unos pocos frente a una mayoría plural.

Desde estas contribuciones, Davidoff ${ }^{35}$ en 1965 plantea la figura del advocateplanner, como planificador para la integración de todos los intereses presentes. Partía de la consideración de cuestiones de interés público, las políticas urbanas y su implementación, por lo que debían decidirse de acuerdo a las prácticas democráticas de toma de decisión, y no de forma unilateral, mediante los organismos públicos.

De hecho, en un sistema democrático la oposición y la crítica a las políticas y actuaciones de las instituciones públicas debería ser tan habitual -e incluso deseable- como el apoyo a la misma. Abogaba por un Planeamiento Plural, en el que la propuesta de la administración pública no fuera la única, si no que se barajaran múltiples alternativas independientes que contuvieran los intereses presentes en la comunidad. El plan resultante sería mejor plan, pues el debate mejoraría el nivel de racionalidad del proceso. De este modo el planificador actúa como defensor de los grupos menos influyentes; superando la postura de estos grupos que no eran capaces de participar de forma positiva y propositiva sino como reacción y oposición al plan presentado por la administración.

El planificador tiene una posición similar a los abogados en el mundo del Derecho, en cuanto a la defensa de los intereses de su cliente, además de llevar a cabo una labor educativa, informando de los avances, del proceso, los cambios, condicionantes, legislación, resultados, ...; otro aspecto importante es la labor de persuasión para conseguir sus objetivos. Todo ello supone una aproximación a las condiciones de colaboración y consenso de la planificación participativa. Hasta ahora las posturas eran diversas y encontradas y se buscaba la defensa del interés propio frente a los otros, no la aceptación de la pluralidad.

"El cuestionamiento de la capacidad del Estado para planificar basándose sólo en el conocimiento experto que toma forma en este periodo, es uno de los ejes de

\footnotetext{
${ }^{34}$ FRIEDMANN, J. (2001).

${ }^{35}$ DAVIDOFF, P. (1965).
} 
transformación hacia prácticas de planificación más inclusivas y de consideración de la diversidad. También están presentes en la aportación de Davidoff la importancia de que la información llegue por igual a todos los afectados o interesados y el proceso educativo en el que entra el grupo social en cuestión a través de su relación con el advocate planner" ${ }^{36}$.

Simultáneamente otros autores presentan opiniones encontradas respecto a la participación en el urbanismo, Sherry Arnstein ${ }^{37}$ en 1969, constata mediante experiencias concretas que no todos los procesos de participación son positivos y ofrecen una pluralidad de visiones y la implicación de los ciudadanos, sino que servía de instrumento para validar los planes de la administración, interviniendo en la opinión pública como mecanismo de manipulación de la comunidad. Concluía que la participación debía conllevar una redistribución de poder en la comunidad. Establecía una escala de participación:

- Participación nula, cuyo objeto es la manipulación,

- Participación intermedia, tokenism ${ }^{38}$, como proceso de diálogo,

- Alto grado de participación en los que se produce diversos grados de cesión (o devolución) de poder a los ciudadanos. Tanto en la toma de decisiones como en la implementación del plan. En el escalón más alto la comunidad local toma las decisiones en las pone en práctica con el apoyo y recursos del sector público.

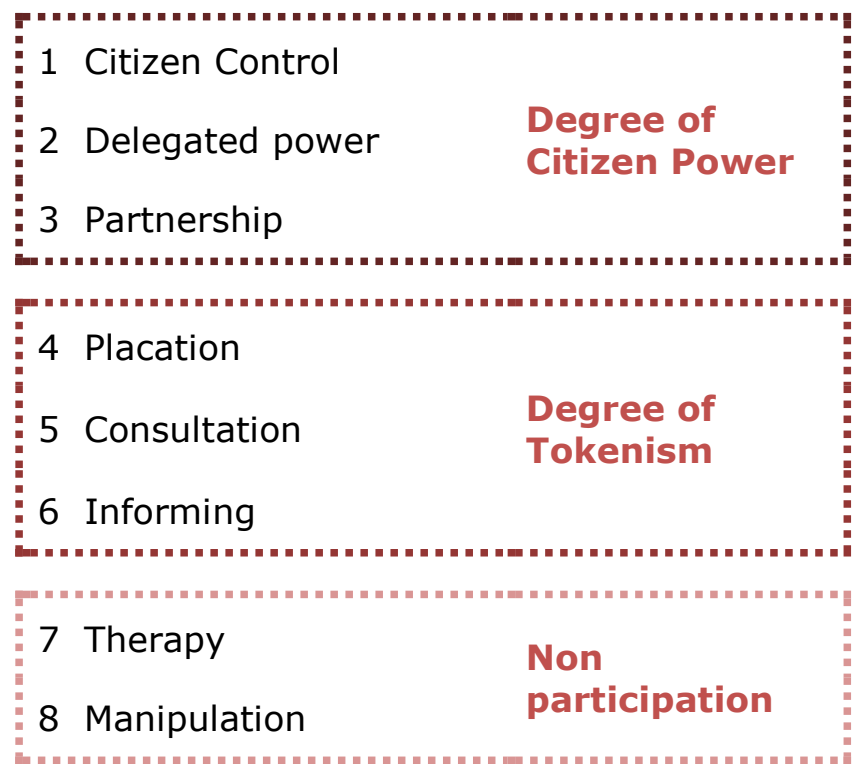

Tabla 13. Escala de Participación definida por Sherry Arnstein. 1969.

Fuente: Elaboración propia.

${ }^{36}$ GREGORIO, S. de (2012).

${ }^{37}$ ARNSTEIN, S. R. (1969).

${ }^{38}$ Falsa participación permitiendo la intervención de un reducido grupo de participantes. 
En este momento de emergencia del neoliberalismo en Estados Unidos, las principales críticas al modelo participativo, se fundamentan en considerarlo un intento de desmantelamiento del sistema y de debilitar al Estado.

Con el cambio económico, político y social de los años ochenta se revitaliza la reivindicación social de la participación ciudadana en la vida política y en concreto en la planificación, plasmándose en nuevas propuestas teóricas. Con la crisis económica, y la paulatina retirada de la administración pública como actor económico principal hacia una globalización integrada por el capital, la producción y la fuerza del trabajo, con la consiguiente entrada de nuevos actores en la política urbana, la competitividad urbana se convierte en uno de los objetivos principales de las políticas urbanas, tanto a nivel global como a nivel local. Autores como Saskia Sassen ${ }^{39}$ plantean el papel de las áreas urbanas y metropolitanas en las economías regionales, nacionales e internacionales que se potencian en entornos favorables como la Unión Europea.

En este contexto, ante el resurgimiento de la ciudad como centro de poder, las situaciones de degradación urbana lastraban su desarrollo por lo que fue necesario actuar para la mejora de la cohesión social por tanto, de las condiciones económicas y competitivas de las ciudades desde las actuaciones de regeneración urbana. En el nuevo escenario fragmentado la planificación necesitaba un consenso, el método tradicional era un obstáculo por su rigidez y la falta de diversidad; conviene un sistema más flexible, que mediante la participación pueda adaptarse a nuevos procesos proactivos y experimentales.

Estos cambios estructurales dan lugar a procesos de reorganización de competencias y poder, en sentido ascendente y descendente, de descentralización y subsidiariedad, adquiriendo nuevas competencias los organismos internacionales y a su vez recuperando otras las entidades locales. Surgen nuevos modelos de gobierno en los que los ciudadanos y los nuevos actores adquieren un mayor protagonismo en la vida política, definido en el concepto de gobernanza. En la planificación los grupos del conocimiento no experto se complementan con el conocimiento experto de técnicos y políticos. Marca el inicio del diálogo inclusivo y la planificación colaborativa ${ }^{40}$.

Las teorías sobre planificación avanzan en diversos sentidos en relación a la información y a la actuación de los técnicos en los procesos de participación, Forester ${ }^{41}$ considera al planificador como organizador o desorganizador de la atención pública, ya que los ciudadanos depositan en ellos su confianza y estos son los que dan forma a sus aspiraciones y demandas, alimentan la participación y manejan la información. Mediante el uso de la información o la desinformación pueden manipular los procesos de toma de decisiones. La desinformación es un obstáculo para la práctica de su propuesta de planeamiento progresivo, por lo que

\footnotetext{
39 SASSEN, S. (1991).

40 Nuevos enfoques bottom up que tienen su reflejo institucional en propuestas como la Cumbre de Río de Naciones Unidas de 1992, Informe Meadows 1972 "Los límites del crecimiento" (The limits to Growth), el informe Brundtland 1987 "Nuestro futuro común" (Our Common future) elaborado por diversas naciones para la ONU.

${ }^{41}$ FORESTER, J. (1989).
} 
el planificador debe identificar las formas de desinformación y contrarrestarlas, dando así poder a los ciudadanos en las cuestiones que les afectan.

Posteriormente Forester ${ }^{42}$ apunta al Deliverative planning, en el que el proceso real y genuino de participación sólo se produce cuando entre los actores tiene lugar:

- el aprendizaje: a raíz de las discusiones y crítica del conocimiento experto.

- Y la construcción de redes de relaciones entre los actores: construcción de memoria, de pertenencia al proceso.

En otra línea teórica se desarrolla la propuesta de Friedmann ${ }^{43}$, ante la crisis de la planificación en los años ochenta propone recuperar la comunidad política como guía de un proyecto de reconstrucción social, a través de la práctica de la planificación radical. Caracterizada por cuatro elementos de la movilización social perseguida por la planificación radical:

- Sirve a los intereses de emancipación de los que no tienen voz.

- Entiende la historia como un proceso contradictorio, no armónico, en el que el acceso al poder social es posible. Modelo de conflicto.

- Conlleva la práctica de la política radical para crear formas concretas de cambio estructural.

- Obtiene la información del aprendizaje social, unidad dialéctica de la teoría y de la práctica.

Necesita de una teoría que sostenga la acción, no es un proceso de participación reactiva contra los planes, sino "una forma regeneradora de planificación ligada a las prácticas de la transformación social". El planificador radical es un mediador entre teoría y práctica, contribuye a que la sociedad evolucione a un modelo más dependiente de sí misma y políticamente activa, denomina al proceso de aprendizaje social Planificación Transactiva, aquella en que el diálogo permite un aprendizaje mutuo entre el actor y el planificador.

Como evolución de estas teorías, y en el contexto económico, social y medioambiental referenciado -economía global y papel de las ciudades como centro actividad, las transformaciones sociales y la inmigración, la nueva estructura política y de poder, protección del medio ambiente, el cambio climático- surgen teorías en campos de la filosofía política, las ciencias sociales, que asumen los entornos participativos para la inclusión social. Algunas a favor de la transformación del Estado desde dentro a través de la participación ciudadana.

Para Healey ${ }^{44}$, desde la filosofía política, se producen tres contribuciones para la afianzar la participación en el sistema institucional:

\footnotetext{
42 FORESTER, J. (2000)

${ }^{43}$ FRIEDMANN, J. (2001).

${ }^{44}$ HEALEY, P. (2006-1997).
} 
- En los ochenta, la transformación del marco institucional en Reino Unido, desarrollado por David Held, en la definición de derechos y deberes y el significado de la igualdad en el contexto de la gobernanza.

- En los noventa, el desarrollo del modelo de democracia discursiva para la participación, de John Dryzek, en la que se promueve la formación de asociaciones ciudadanas dotándolas de recursos y formas de proceder basadas en el diálogo.

- Y las teorías de John Friedmann.

En relación con los postulados de Forester en cuanto a la creación de redes, Healey se orienta a las relaciones sociales, no solo las organizaciones formales que tienen responsabilidad política, sino a las redes relacionales que conectan a estas y otras con redes más amplias y sus procesos de gestión colectiva. Considera dos niveles de gobernanza, las organizaciones formales y las relaciones informales, que definirá como:

- Hard infraestructure: comprende los sistemas legislativos y de procedimiento que fijan las reglas en las que se basa la práctica. Es importante evitar nuevos juegos de poder que desvirtúen el proceso.

- Soft infraestructure: se refiere al diseño y la puesta en marcha de la práctica del planeamiento. La administración debe incentivar la práctica democrática inclusiva, de ahí surgirá el cambio, ya que los individuos tienen la capacidad de transformar las estructuras sociales.

No hay modelos para la práctica de procesos colaborativos, según Healey, porque cada lugar y proceso tienen condiciones de partida diferentes; sin embargo en cada comunidad política sí debe existir un conocimiento del estado de su gobernanza ${ }^{45}$, en función de cuatro parámetros: Derechos y deberes, control y distribución de los recursos, la especificación de los criterios para alcanzar los desafíos y la distribución de competencias. Según las respuestas las comunidades podrán establecer estrategias para mejorar su gestión de los asuntos de interés general, orientado a una gobernanza democrática pluralista y una Planificación Colaborativa, dentro del enfoque comunicativo de la teoría de la planificación ${ }^{46}$.

De hecho, los procesos participativos de planeamiento bloqueados se deben a que existe una multiplicidad de actores y grupos sociales con sistemas culturales diversos y por tanto con una visión distinta de lo que es el interés general. Desde el planeamiento podrán trabajar en la definición común del problema, favoreciendo la capacidad institucional del lugar, esto es la calidad de las relaciones y su capital social, intelectual y político. El fracaso no siempre es negativo, los pequeños logros pueden dar lugar a nuevas oportunidades para otros modos de proceder. Las características de los procesos colaborativos, según Healey, Innes y Booher, son:

\footnotetext{
45 Healey define gobernanza como los procesos a través de los cuales las sociedades y los grupos gestionan sus asuntos de interés general.

${ }^{46}$ INNES, J. (1995).
} 
- Implicación de múltiples actores en nuevas áreas de diálogo a las que acuden libremente y crean sus normas de comportamiento.

- Tarea que les motive y sea significativa, con la perspectiva de producir resultados.

- Reconocen las dependencias mutuas.

- Todos tienen el mismo poder y están predispuestos a escuchar y respetar al resto de los participantes.

- Cuentan con la misma información accesible y compartida.

- Los actores deben ser representativos.

- Los valores de justicia inclusiva y sostenibilidad tienen que ser vigentes en todo el proceso.

- Se comprometen a llegar al consenso ${ }^{47}$.

- Se integra experiencia y conocimiento del lugar, el conocimiento científico y técnico.

Y sus resultados / beneficios -en el marco de este trabajo sirven de base para analizar y evaluar los procesos participativos, como se recoge en las conclusiones del capítulo 0, los describen como:

- Se genera conocimiento y poder a través del aprendizaje colectivo y la capacidad de innovar.

- Se opera un cambio en los participantes: nuevas ideas, otras visiones.

- Su mantenimiento crea marcos de referencia y se pueden acordar intervenciones.

- El proceso puede dar lugar a combinar innovación y eficacia.

- Generación de red: relaciones personales e institucionales, fundamentadas en el entendimiento y la confianza mutua: relational resources, que derivan en capital intelectual y social. Nueva forma de poder: búsqueda de soluciones compartidas y flujo de información: distributed self-organizing action.

- Construcción de un alto grado de confianza.

- Mayor capacidad de resolver los problemas que otras formas de política.

- Mayor capacidad institucional: genera capital social, intelectual y político. Los participantes son más competentes, están mejor informados y confían más en su capacidad para cambiar las cosas.

\footnotetext{
47 HEALEY, P. (2006-1997). Consensus Building: por consenso entiendo algún tipo de apreciación compartida en relación a diferentes aspectos de un problema, a los valores y maneras de entenderlo, a la distribución de las consecuencias y cómo afrontarlas, y al reconocimiento de que se ha llegado a las decisiones de manera legítima, al menos desde el punto de vista de aquellos implicados en el proceso colaborativo.
} 
- Enriquece el resultado: capacidad de aprendizaje, interacción, retroalimentación y combinación de ensayo y error.

- Resultado con mayor nivel de complejidad, productividad, competencia, estabilidad, eficacia y organización.

Para Innes y Booher, el éxito de los procesos de participación colaborativa se debe al poder transformador del diálogo, cuando el grupo asume que todos tienen el mismo poder, cuentan con la misma información, son escuchados y siguen sus pautas, los participantes experimentan un cambio con respecto a sus ideas porque adquieren otras nuevas mediante las cuales consideran las visiones de los otros actores como legítimas. Así para la toma de decisiones en un entorno de multiplicidad de actores, la participación se debe estructurar mediante la construcción del consenso en oposición al método decisional de arriba-abajo, por mayoría o el enfrentamiento.

El proceso y el resultado están unidos, de hecho el proceso enriquece el resultado a través de la interacción, la retroalimentación, la capacidad de aprendizaje y la combinación del ensayo/error. Los participantes llegan a una nueva visión compartida que permite entender mejor la realidad llegando a mejores resultados y al fortalecimiento de capacidad local. Señalan la conveniencia de un facilitador o mediador experto, en grupos complejos o de tamaño significativo, en relación con el advocacy planner, progressive planner y el transactive planner; que facilite la construcción del consenso.

Las teorías de la planificación colaborativa son vigentes hoy día y siguen desarrollándose, si bien también los detractores consideran que sus hipótesis y métodos son discutibles, el debate sigue abierto y por tanto sigue la búsqueda de un modelo de participación en la planificación desde el ámbito público. En España recientemente han surgido grupos de profesionales que siguen la línea de acción marcada por estos autores, llevando a la práctica procesos participativos, en muchos casos impulsados desde las administraciones locales, con diversas trayectorias. "Es nuestra obligación dar un giro rotundo a la práctica profesional. Para lo cual no hay que inventar la rueda, sino recuperar herramientas $y$ metodologías postergadas y actualizarlas para que respondan a las nuevas lógicas de red y al cambio de época" 48.

48 PAISAJE TRANSVERSAL (2014). 


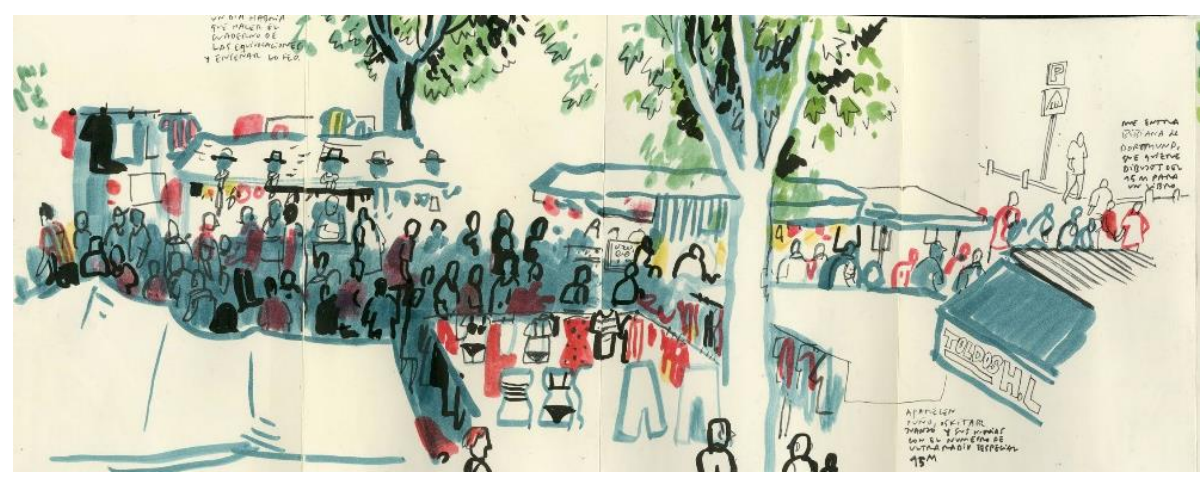

Figura 1. Enrique Flores. DibujaMadrid 2011. As human agency, despite the continual constrains on us, we thus have some power, the power to choose, to invent, to think differently 49.

Fuente: Enrique Flores.

\section{RESISTENCIAS A LA PARTICIPACIÓN PÚBLICA. NUEVOS RETOS}

"Hay un vacío entre las reglas que ya no sirven y las que aún tenemos que imaginar... el verdadero debate es cómo llenar ese vacío" 50

En el análisis del marco teórico se apuntan posiciones en contra de la participación que se centran en que se pretende el desmantelamiento del estado o a la pérdida de su hegemonía y poder de decisión, seguramente posturas alarmistas exageradas, si bien es cierto que los nuevos modelos de gobernanza comportan cambios en lo establecido y esto provoca cierto vértigo y miedo a lo desconocido, pues lo nuevo aún está por llegar. "La tradición señala que consultar a la gente, implicarla en procesos decisionales colectivos, sólo acarrea quebraderos de cabeza, obstáculos y retrasos. Autoridad y jerarquía sin consentimiento, y respeto absoluto a las decisiones de la autoridad y la jerarquía surgidas a través de los mecanismos de representación democrática, son las constantes que han influido en esta visión escéptica sobre la participación" 51

\subsection{Objeciones}

Algunos argumentos esgrimidos en contra de la participación se centran en aspectos como:

- Incrementa los plazos en la toma de decisiones: el proceso es más largo y complicado.

- Aumenta la necesidad de recursos y encarece el proceso: implica costes de tiempo, económicos, modificaciones en proyectos...

\footnotetext{
${ }^{49}$ HEALEY, P.

${ }^{50}$ BAUMAN, Z. (2016). 7/11/2016.

http://www.elmundo.es/papel/lideres/2016/11/07/58205c8ae5fdeaed768b45d0.html

${ }^{51}$ SUBIRATS, J. (2001).
} 
- No aporta valor añadido al resultado: pues los que participan no tienen el conocimiento preciso sobre los temas públicos.

- Genera exceso de particularismos: cada participante actúa en defensa de sus intereses, perdiendo la defensa de los intereses generales.

- Sólo considera el corto plazo: en relación a los intereses que cada participante defiende, sin que se contemplen objetivos a medio o largo plazo que, sin embargo, son más beneficiosos para la generalidad de la población.

- Erosiona instituciones y partidos: su legitimidad y autoridad, pues se entiende como una falta de capacidad de representación y de defensa de los intereses generales.

Otro gran problema es la constatación de la falta de participación argumentada desde diversos puntos de vista:

- Los ciudadanos no quieren participar: aunque muestren descontento por no ser escuchados, a la hora de la verdad no se implican. Por la falta de motivación por los asuntos tratados o por el desencanto del propio proceso.

- Cuando participan lo hacen de forma inconstante: falta de compromiso y de continuidad.

- Siempre participan los mismos: bien por el conocimiento e información desigual entre la población, bien por la implicación o experiencia, finalmente es una minoría los que están presentes en los procesos cuya representatividad está poco justificada.

- Sólo hay participación cuando hay conflicto o falta de acuerdo con una decisión.

- Quienes se movilizan sólo representan sus propios intereses: o los de su entorno, su sector, edad... y por tanto no representan el conjunto de la ciudadanía.

Sin embargo, como ya se ha ido argumentando, la participación no sólo es conveniente sino que aparece como práctica necesaria en nuestra sociedad democrática, impulsada por los nuevos modos de hacer política -que de forma más o menos tangible se van produciendo-, porque la sociedad así lo reclama evolucionando en su propio sentido de corresponsabilidad, superando las "quejas de bar" y adoptando una actitud más responsable. Hoy en la complejidad de la vida cotidiana, las nuevas tecnologías facilitan el acceso a esta participación, si bien no sustituyen el encuentro personal, sí facilitan mantener la actividad. Otra cuestión es la controvertida la brecha digital ${ }^{52}$.

\footnotetext{
52 EXPANSIÓN (2016). "UGT ha advertido de que la brecha digital en España no sólo no se está cerrando, sino que se ha convertido en "estructural", por lo que ha pedido al Gobierno que coloque la inclusión digital de la ciudadanía y de los trabajadores entre sus prioridades y no persista en su "desidia".

Las principales razones que explican esta elevadísima cantidad de personas fuera de la era digital son la falta de interés $(67,4 \%)$ o de los conocimientos necesarios (41\%) y los costes relacionados con la conexión (25\%)."
} 
En palabras de J. Subirats en cuanto a los planteamientos escépticos: "Nuestra visión es distinta. Pensamos que es cada vez más difícil mantener ese tipo de posiciones. Sea por la enorme difusión de información y el notabilísimo acceso a la educación producido en muchos países en las últimas décadas, sea por la propia sofisticación en el progreso científico que cada vez nos deja con menos respuestas unívocas desde el punto de vista técnico sobre cómo resolver problemas. En muchas de esas críticas hacia formas más directas de participación ciudadana, laten, de hecho, escepticismos y suspicacias sobre las mismas bases de la democracia" ${ }^{53}$.

\subsection{Retos}

En su opinión son dos los retos que debe afrontar la participación como vía de consolidación de la democracia y de resolución de los problemas que genera la vida colectiva, cómo afrontar dichos retos desde el urbanismo colaborativo es el resultado de este trabajo que se resume en el capítulo 0.

- Demostrar que participación y eficiencia no son contradictorias, sino complementarias.

- Reducir los riesgos y minimizar los problemas que esta plantea, buscando y experimentando nuevas vías.

\subsubsection{Participación y eficiencia}

El sistema estructural derivado de la globalización y la complejidad de la sociedad actual plantea problemas cada vez más difíciles de definir, de segmentar y por tanto de ser abordados desde esferas concretas, ya establecidas. Las estructuras tradicionales del sector público van quedando obsoletas, y chocan con los nuevos requerimientos de la sociedad.

Desde el punto de vista de la actividad política en el establecimiento de líneas de actuación, toma de decisiones y la actividad administrativa -en cuanto a acciones y procesos- es necesario un cambio de actitud y de funcionamiento. Los ciudadanos cuentan con medios que facilitan el acceso a la información, que les permiten emitir sus opiniones y contrastarlas con otros individuos y grupos; esto que sucede en todos los ámbitos de la vida cotidiana, no puede dejar de producirse en la esfera pública en aquellas cuestiones que le afectan directamente, sin embargo, las administraciones aún no han reaccionado a este cambio.

La aproximación de la administración al ciudadano se ha dado en aspectos superficiales, instrumentales, pero no a nivel profundo que implicaría un verdadero acceso a la información: transparencia, y un verdadero diálogo con los interesados: flexibilidad.

En cuanto a los problemas que se plantean, es claro que no hay una solución técnica universal, objetivamente correcta y mejor en términos absolutos. Cuando además nos referimos a un ámbito social concreto, las soluciones técnicas

${ }^{53}$ SUBIRATS, J. (2001). 
"asépticas" chocan con la realidad. Nos encontramos ante situaciones en las que es necesario el consenso.

\section{GRADOS DE CONSENSO}

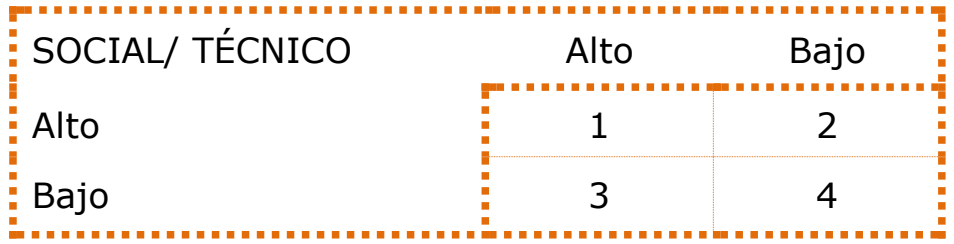

Tabla 14. Matriz: Grados de Consenso.

Fuente: Elaboración propia.

En este terreno son necesarias las vías democráticas de resolución de problemas que deben desarrollarse en toda su potencia, para que el diálogo entre actores, grupos, expertos y políticos, desde sus diferentes visiones del asunto, permita llegar al consenso. "El tema no reside en la capacidad de "vender" soluciones, si no en la capacidad de compartir definiciones de problemas para de esta manera aumentar la legitimidad del camino que lleva desde esta definición compartida a una situación considerada por todos mejor que la anterior."

En asuntos que afectan a intereses sociales puede haber consenso en el ámbito técnico, pero difícilmente tendrán éxito si no se abre el debate con los ciudadanos; ciertas dificultades infranqueables pueden esconder elecciones no técnicas, sin embargo las surgidas del consenso tendrán más probabilidades de ser aceptadas, incluso por aquellos afectados negativamente en sus intereses, si la vía de decisión ha sido legítima. Y es la forma de que finalmente salgan adelante.

Desde el punto de vista de la eficiencia, serán más eficientes aquellas decisiones surgidas del consenso, con el apoyo de los afectados; independientemente de los costes o plazos, que serían aún más ineficientes o inútiles, sin el acuerdo necesario para su implementación. "Participar no es, en principio, ni bueno ni malo, aunque todos estamos de acuerdo en que la simple ampliación de los espacios de participación ya tiene un valor en sí mismo. No se trata de que la gente participe más. (...) lo que hace falta es entender que cuando hablamos de participación no hablamos sólo de los intereses afectados, o de aquellos grupos o colectivos más organizados y acostumbrados a movilizarse, sino del conjunto de la población afectada directamente $o$ indirectamente por la decisión. $Y$ esto quiere decir encontrar mecanismos para conseguir esta implicación social amplia."

\subsubsection{Experimentación}

Son muchas las organizaciones y estructuras que van surgiendo entorno a la participación: consejos ciudadanos, comités de participación, núcleos de intervención participativa, jurados ciudadanos, fórums...el objetivo común es compartir la complejidad de las decisiones entre el máximo de ciudadanos posible, 
sin embargo no hay solución universal; dependerá de los condicionantes y limitaciones de cada caso para encontrar la mejor fórmula participativa.

Aquí el uso de las nuevas tecnologías de la información y comunicación adquiere un papel determinante. No para continuar con los mecanismos tradicionales, sino pensando en una nueva concepción de la democracia. Se profundiza en estos conceptos en el apartado 8.3 en cuanto a las nuevas capacidades que ofrecen las nuevas tecnologías para facilitar la participación en experiencias concretas, para generar conocimiento y transmisión de información, y lo que es más importante, para generar y mantener una cultura de la colaboración y el consenso.

Otro enfoque de la necesidad de experimentar es el que se pone de manifiesto con las iniciativas ciudadanas. Como ya se ha indicado, cada vez son más numerosas y abarcan todo tipo de actividades, estas representan la vitalidad de la ciudad, su capacidad de actuar y corresponsabilizarse en la gestión de los asuntos que les competen y dan respuesta a necesidades de la sociedad para las que la administración aún no ha creado los mecanismos para resolverlas. Como se recoge en el apartado 8.4. Según la teoría de J. Subirats y M. Fernández ${ }^{54}$, es preciso dejar espacios para la innovación y experimentación, dar cabida a la actividad social que surja, para sacar las conclusiones que lleven a aprovechar el talento de nuestras sociedades, que en cada caso tendrá sus características propias, pero con valor universal en la medida en que sean adaptables.

\section{CONDICIONES DE PARTIDA}

"Es claro quién es un ciudadano: quien tiene la posibilidad de participar en la función deliberativa (legislativa) o judicial. Y llamamos ciudad al conjunto de tales ciudadanos".

Vemos cómo la participación aplicada a cualquier campo, y expresamente al urbanismo, conlleva importantes ventajas que superan ampliamente los inconvenientes que pueda suponer su empleo. Los beneficios se enmarcan en dos aspectos fundamentales: en la consolidación de la democracia, o como expresaban los teóricos de la planificación colaborativa en el "estado de la gobernanza"; y en la resolución de los problemas que genera la vida colectiva, aportando mayor eficiencia y desde la flexibilidad; conceptos que van más allá de un proceso concreto o una inquietud puntual, como explica J. Subirats. Se apoyan en las capacidades de la ciudadanía y en el empleo de las nuevas tecnologías que facilitan la comunicación y la expresión de opiniones individuales, y el acceso a la información y la difusión de conocimientos imprescindible para la participación efectiva.

${ }^{54}$ FERNÁNDEZ, M. (2016) 


\subsection{Democracia participativa: cultura y gobernanza}

Lo visto hasta ahora tiene su traducción directa en el urbanismo con algunas particularidades que merece la pena comentar. Dentro del marco de las políticas y gestión pública la práctica del urbanismo incide en las cuestiones que más directamente afectan a los ciudadanos, aquellas que tienen que ver con su calidad de vida, las condiciones de su vivienda, sus posibilidades de actividad económica y de trabajo, el acceso a dotaciones y equipamientos, la calidad de los espacios libres o de su territorio... por ello es el ámbito en el que la participación se presenta en su estado original, más vital y completo.

\subsubsection{Condiciones para el cambio cultural}

Como se ha visto, la Carta del ECTP-CEU (2015) habla de producir cambios culturales y sociales que únicamente se pueden alcanzar con políticas públicas que se mantengan en el tiempo. No se trata únicamente de procesos puntuales y evaluaciones cuantitativas: el número de participantes, de propuestas viables o cambios en un plan; sino de la transformación de las prácticas y procedimientos administrativos y de gestión pública, incorporando la participación pública, y evaluando en el medio y largo plazo los cambios e impactos culturales y sociales que se producen.

Estos cambios están ampliamente estudiados en las teorías del cambio ${ }^{55}$, y el modelo lógico para producir y evaluar la eficiencia de programas y políticas del sector público y organizaciones sin ánimo de lucro, en las que el objetivo final no es un beneficio económico sino cambios sociales, culturales, educativos... En este trabajo, estos impactos se han utilizado como parámetros de evaluación en la herramienta que se propone en el capítulo 10.

55 MOORE, M. (1998) 


\begin{tabular}{|c|c|c|c|c|}
\hline INPUT & & OUTPUT & OUTCOME & IMPACTO \\
\hline $\begin{array}{c}\text { Recursos, } \\
\text { medios, } \\
\text { personas }\end{array}$ & $\begin{array}{c}\text { Acciones, } \\
\text { estrategias }\end{array}$ & $\begin{array}{c}\text { Resultados } \\
\text { cuantifica- } \\
\text { bles }\end{array}$ & $\begin{array}{c}\text { Cambios no } \\
\text { cuantifica- } \\
\text { bles }\end{array}$ & $\begin{array}{c}\text { Cambios } \\
\text { culturales y } \\
\text { sociales }\end{array}$ \\
\hline $\begin{array}{l}\text { Conocimiento } \\
\text { existente y } \\
\text { conocimiento } \\
\text { experto. } \\
\text { Recursos } \\
\text { financieros y } \\
\text { materiales } \\
\text { dedicados al } \\
\text { desarrollo del } \\
\text { proceso }\end{array}$ & $\begin{array}{l}\text { Tareas o } \\
\text { trabajos } \\
\text { desarrollados } \\
\text { mediante los } \\
\text { inputs o } \\
\text { recursos } \\
\text { movilizados } \\
\text { para producir } \\
\text { determinados } \\
\text { resultados u } \\
\text { outputs }\end{array}$ & $\begin{array}{l}\text { Resultados, } \\
\text { productos o } \\
\text { servicios } \\
\text { directos o } \\
\text { inmediatos, } \\
\text { producto del } \\
\text { desarrollo del } \\
\text { proceso o } \\
\text { actividad }\end{array}$ & $\begin{array}{l}\text { Efectos } \\
\text { probables o } \\
\text { alcanzados a } \\
\text { corto y medio } \\
\text { plazo de los } \\
\text { resultados de } \\
\text { una } \\
\text { intervención o } \\
\text { proceso. }\end{array}$ & $\begin{array}{l}\text { Cambios } \\
\text { generalizados a } \\
\text { largo plazo } \\
\text { (tanto positivos } \\
\text { y como } \\
\text { negativos) o } \\
\text { efectos } \\
\text { producidos por } \\
\text { el desarrollo de } \\
\text { una } \\
\text { intervención o } \\
\text { proceso, directa } \\
\text { o } \\
\text { indirectamente, } \\
\text { intencionado o } \\
\text { no. }\end{array}$ \\
\hline
\end{tabular}

Tabla 15. Modelo lógico de la Teoría del Cambio.

Fuente: Elaboración propia.

Si evaluamos la relación de los beneficios del planeamiento colaborativo expuestos por Healey, vemos que la importancia de este proceso no se encuentra en la resolución de problemas concretos - de lo que ya se ha visto que no existen las soluciones inequívocas- sino en el avance hacia una gobernanza o mejora de la calidad de la democracia participativa que enlaza con las teorías actuales sobre la sociedad resiliente como sistema deseable para la mejor adaptación a los cambios a los que estamos sometidos, apoyado en relaciones más fuertes entre las personas y su entorno. 


\begin{tabular}{|c|c|}
\hline $\begin{array}{l}\text { CAMBIOS } \\
\text { (OUTCOMES) }\end{array}$ & $\begin{array}{l}\text { - } \quad \text { Su mantenimiento crea marcos de referencia y se pueden acordar } \\
\text { intervenciones. } \\
\text { - Generación de red: relaciones personales e institucionales, } \\
\text { fundamentadas en el entendimiento y la confianza mutua: relational } \\
\text { resources, que derivan en capital intelectual y social. } \\
\text { - Enriquece el resultado: capacidad de aprendizaje, interacción, } \\
\text { retroalimentación y combinación de ensayo y error. } \\
\text { - Resultado con mayor nivel de complejidad, productividad, } \\
\text { competencia, estabilidad, eficacia y organización }\end{array}$ \\
\hline $\begin{array}{l}\text { ACTOS } \\
\text { ACT) }\end{array}$ & $\begin{array}{l}\text { - Se opera un cambio en los participantes: nuevas ideas, otras } \\
\text { visiones } \\
\text { - Se genera conocimiento y poder a través del aprendizaje colectivo y } \\
\text { la capacidad de innovar. } \\
\text { - Construcción de un alto grado de confianza } \\
\text { - Mayor capacidad de resolver los problemas que otras formas de } \\
\text { política } \\
\text { Mayor capacidad institucional: capital social, intelectual y político. } \\
\text { Los participantes son más competentes, están mejor informados y } \\
\text { confían más en su capacidad para cambiar las cosas. } \\
\text { Nueva forma de poder: búsqueda de soluciones compartidas y flujo } \\
\text { de información: distributed self-organizing action }\end{array}$ \\
\hline
\end{tabular}

Tabla 16. Resultados de la planificación colaborativa.

Fuente: Elaboración propia.

Por supuesto la participación tiene su razón de ser en la intervención en la ciudad, en la identificación de problemas, el acuerdo de soluciones y la ejecución de las acciones en un proceso colaborativo, basado en el diálogo y llevado a buen fin mediante el consenso, este objetivo es el más inmediato y en general el más buscado. Por él se movilizan recursos y se destina el tiempo y esfuerzos de vecinos, técnicos y representantes de la administración. En estos casos, el proceso se abre y se cierra entorno a un objetivo concreto. Sin duda estas experiencias aportan beneficios que podemos encuadrar en la categoría de los outcomes, pero no llega a generar impacto.

Este tipo de participación puntual en el tiempo y con un objetivo a corto plazo, no puede producir cambios en la sociedad, si el objetivo no está fijado previamente no se evalúa y el proceso no dura lo suficiente como que dicho impacto se produzca. Esta situación genera insatisfacción y desilusión entre los participantes, que van perdiendo el interés al constatar una falta de implicación más generalizada.

Poner el objetivo en el largo plazo, desarrollando acciones continuadas y facilitando el acceso a la información y la interacción, es un camino aún por recorrer y evaluar a favor de la cultura de la participación. 


\subsubsection{Información y conocimiento}

A lo largo del análisis realizado ha quedado patente el valor de la información para la participación como requisito previo, como parte de los procedimientos urbanísticos, como garantía de calidad del proceso, como elemento fundamental de la educación en la participación para el desarrollo de la democracia y el urbanismo colaborativo.

Pero obtener la información por parte de los ciudadanos, hoy por hoy requiere un esfuerzo, que no siempre están dispuestos a realizar, incluso con el empleo de la tecnología, como se recoge más adelante.

Las dificultades para el acceso a la información son dos principalmente: que esté disponible, y que sea comprensible, sin caer en la infantilización de los asuntos. En concreto, en cuestiones de urbanismo es muy habitual que confluyan los dos problemas:

- No es sencillo conseguir información actualizada y fiable: si bien los ayuntamientos y administraciones disponen de páginas web y hacen uso de las TICs para la difusión de la información generada, entre ella la urbanística, lo cierto es que no suele estar disponible en su totalidad ni actualizada.

- Además, la información suele ser de carácter técnico, jurídico o administrativo, que tanto en su forma como en su fondo resulta compleja y en muchos casos ininteligible.

Sin embargo, éste es un aspecto clave para avanzar en la incorporación de la sociedad en la toma de decisiones, y no puede suponer un esfuerzo más para el ciudadano, sino al contrario sería deseable que la información "fuera en su busca", que de alguna manera forme parte de su día a día, tan accesible como saber qué tiempo hará mañana o el estado del tráfico en las carreteras.

Esta actividad no puede estar basada únicamente en el uso de las TICs, sino abarcar todos los medios y herramientas disponibles con los que la administración cuenta para llegar al ciudadano. De hecho la atención presencial sigue siendo la clave para la obtención y difusión de la información. Sin distinción entre administraciones grandes o pequeñas, aunque en ámbitos reducidos es más asequible interactuar directamente. El trato personal, la posibilidad de resolver dudas, solicitar datos, documentos y otras informaciones más sutiles, no se puede reemplazar por los medios tecnológicos. Favorece el conocimiento mutuo y la generación de espacios de relación y confianza entre administración y ciudadanos, fortaleciendo las condiciones para la colaboración.

La disponibilidad no debería ser un objetivo político, pues es de especial interés para las administraciones públicas en sí mismas, para el desarrollo de sus objetivos y proyectos en cualquier materia, para la colaboración de los ciudadanos y grupos de interés, para su ejecución y obtención de resultados satisfactorios. El acceso a la información tanto buscado como ofrecido, es el ingrediente básico para iniciar la elaboración de la gestión pública compartida. 
También hay que considerarlo en ambos sentidos, pues la administración necesita contar con la información que sus ciudadanos le pueden proporcionar y por tanto facilitarles, igualmente, los medios para obtenerla. En ocasiones, la información en este sentido del flujo, proviene de grupos o individuos cercanos al poder, o a los interlocutores válidos según el asunto, y están cargadas de intereses particulares, que si bien puede ser legítimo deben ser contrastados con otros y puestos en relación con los intereses generales, e incluso con el bien común. Por tanto es preciso que este flujo de información se produzca desde todas las fuentes posibles y con intereses legítimos, conocidos y ponderables: "Actividad pública $y$ transparencia van de la mano, en la medida en que nos encontramos ante un ámbito de la acción pública sectorial donde, si cabe, es más necesario que el ejercicio de las potestades públicas se ejerza satisfaciendo realmente el interés general $y$, evitando usos desviados de las mismas" ${ }^{56}$.

Desde el punto de vista de la comprensión de los asuntos, las barreras a remover no son solo técnicas y de especialidad jurídica, los primeros problemas los genera el propio lenguaje administrativo unido al trato despersonalizado; el lenguaje, las expresiones y planteamientos, en demasiadas ocasiones son incomprensibles para el interesado destinatario de las comunicaciones oficiales. Son numerosas las iniciativas, guías y propuestas "contra el lenguaje oscuro, recargado y espeso de la administración" ${ }^{57}$.

Por otro las cuestiones sectoriales, especialidades o técnicas deben ser resueltas sin caer en la falta de rigor o en la infantilización de los contenidos como denuncian Rosario del Caz y Manuel Saravia ${ }^{58}$ : "Se parte tantas veces del prejuicio de que los documentos técnicos que constituyen estos proyectos son en principio (por su propia naturaleza) incomprensibles para el público, para la propia población afectada. Y se define en consecuencia la necesidad de documentos preparados "para no especialistas", que con frecuencia deriven en unas tontas y edulcoradas segundas versiones de lo planificado. En algunos casos se simplifican hasta el ridículo para que puedan ser entendidos por unos vecinos a los que se considera incapaces de analizarlos tal como son (o de hacerse con asesores de confianza). (159) ¿Es admisible esta actitud?" Como ellos exponen, la adecuación para su mejor entendimiento, de la información que se traslada a la ciudadanía da pie a adaptaciones poco rigurosas e incluso innecesarias, pues de ser necesario siempre existe la posibilidad de contar con un técnico o especialista que traslade la información a los vecinos $y$, en su caso, que defienda sus intereses.

\footnotetext{
${ }^{56}$ CHAMORRO, J.M. (2016).

57 LENGUAJE ADMINISTRATIVO (2017).

${ }^{58}$ CAZ, R. del y SARAVIA, M. (2005).
} 


\subsection{Desde la normativa urbanística}

Como se vio en el capítulo 3, la legislación urbanística se queda muy corta a la hora de incorporar la verdadera participación en la actividad urbanística, y no supera el concepto que sobre la misma elabora la normativa reguladora del procedimiento administrativo. Cualquier aproximación a la participación por parte de las administraciones que supere lo legalmente establecido, es fruto de un interés extralimitado y de un convencimiento tal vez intuitivo, por parte de los políticos y, menos frecuentemente, de los técnicos.

Si como hemos visto la incorporación de la participación en la toma de decisiones obliga desarrollar la capacidad de diálogo, entendimiento de los intereses del otro y finalmente llegar a consensos en beneficio del interés general; para que los acuerdos lleguen a ser ejecutados y obtener un resultado positivo, se requiere capacidad de adaptación, de modificación de lo establecido o lo previsto, de reajustar los planes, en una palabra flexibilidad, en el caso del urbanismo se habla de un "urbanismo adaptativo".

Sin embargo, el urbanismo se desarrolla sometido a dos artificios "paralizantes" a la hora de responder a la colaboración y acción ciudadana con la suficiente flexibilidad: la planificación urbanística y el procedimiento administrativo en relación con el urbanismo especialmente los procedimientos de aprobación, revisión y modificación de planes y los de intervención en la ejecución del planeamiento.

En cuanto a la planificación, los cambios recientes ponen de manifiesto la rigidez del sistema, como señala Luciano Parejo Alfonso 59 "La lógica en muchos casos desordenada del desarrollo urbano, la tendencia a la sobrerregulación y a la rigidez en la planificación física, pero, sobre todo y con carácter más general, la crisis económica, que se ha instalado desde 2007/2008 y sus consecuencias en la dinámica inversora del sector público y el privado..., están determinando cambios en las estrategias de la gestión de las ciudades." Esta rigidez se debe fundamentalmente a dos factores:

1. Vigencia de los planes: los instrumentos de ordenación territorial y urbanística tienen una vigencia indefinida. La Ley del Suelo de 1956, establecía su revisión cada 15 años ${ }^{60}$, sin embargo el Real Decreto 1346/1976 de 9 de abril, por el que se aprueba el Texto Refundido de la Ley sobre régimen del Suelo y Ordenación Urbana, no determinaba plazo, indicando que los Planes Generales Municipales de Ordenación se revisarán en el plazo que en los mismos se señale. Lo cierto es que esta revisión es muy costosa en tiempo y recursos, y rara vez se ha llevado a cabo en plazo. Únicamente se han revisado los planes de municipios que han experimentado grandes y rápidos desarrollos, o eso se pretendía.

\footnotetext{
59 PAREJO, L. (2016).

${ }^{60}$ Ley de 12 de mayo de 1956 sobre régimen del suelo y ordenación urbana. Artículo treinta y siete: "Los planes generales de ordenación serán revisados cada quince años".
} 
Las necesidades de la sociedad van cambiando, más aún cuando se han producido cambios sustanciales en las aspiraciones globales en los últimos años, como se recoge en los documentos emitidos por los organismos internacionales en relación al medio ambiente, cambio climático, cohesión social, desarrollo sostenible... además del impacto de la tecnología y los nuevos modos de relación personal, laboral, uso del espacio y del tiempo.

2. Contenido y naturaleza: los planes ostentan la naturaleza de disposiciones de carácter general. En su contenido, entre otros muchos, para el suelo urbano se encuentra la reglamentación detallada del uso pormenorizado, volumen y condiciones higiénico- sanitarias de los edificios o construcciones, así como de las características estéticas de la ordenación de la edificación y de su entorno; y la asignación de usos pormenorizados correspondientes a las diferentes zonas, definiendo de forma detallada la específica utilización de los terrenos incluidos en cada una de ellas ${ }^{61}$.

Este contenido, más que ningún otro, afecta directamente a la vida y la actividad de los vecinos y propietarios, puesto que determina el régimen jurídico de los bienes, limita los derechos, las condiciones relativas a las construcciones, y a los usos de éstas y en general del suelo. Por tanto incide en las posibilidades que lo construido y el suelo ofrecen, desde la iniciativa privada, para el desarrollo de actividades, para atender las necesidades de la población o la mejora de condiciones y calidad de vida.

Estas condiciones son objeto de un gran número de propuestas ciudadanas orientadas a plantear nuevos usos, nuevas actividades, idear posibilidades y nuevas condiciones técnicas para su utilización, que chocan con las determinaciones del Plan, que no solo no las contempla, sino que o bien impone condiciones inasumibles o bien no contempla la posibilidad de una adaptación adecuada en cuanto a tiempos y conceptos.

La aprobación de reglamentos y ordenanzas forman parte de la potestad reglamentaria de las administraciones públicas, y son documentos con una redacción concisa y de tramitación relativamente ágil. Que pueden ser modificados y adaptados a lo largo de su vigencia de manera que se adecuan a las carencias, expectativas o intereses ciudadanos que en cada momento primen. Esto no es posible en el caso del planeamiento urbanístico pues cualquier cambio implica una modificación del Plan cuya tramitación supone unos plazos y recursos poco operativos. En palabras de Manuel Fernández 62 "Ya sea en forma de adaptaciones ad-hoc, de ocupaciones, de usos informales, de actividades fugaces o de reclamaciones prácticas del espacio público, la ciudad es una sucesión de actos y proyectos que adaptan la materialidad de la ciudad a las necesidades", o debería serlo.

\footnotetext{
${ }^{61}$ Artículo 29 del Real Decreto 2159/1978, de 23 de junio, por el que se aprueba el Reglamento de Planeamiento Urbanístico.

${ }^{62}$ FERNÁNDEZ, M. y GIFREU, J. (2016).
} 
Como vemos estas características del planeamiento urbanístico dificultan las posibilidades de flexibilizar la actividad urbanística y por tanto afectan a la participación y acción ciudadana de forma negativa, en el momento en que las propuestas y aspiraciones vecinales no tienen cabida en las determinaciones establecidas por los planes.

A su vez el procedimiento administrativo y el régimen de las administraciones locales inciden en las probabilidades de éxito de un urbanismo basado en la participación: "Justamente por este carácter de política pública, el principal reto del Pla BUITS ha sido la apertura de un camino administrativo que pueda ser recorrido periódicamente con seguridad jurídica y adaptado también a la realidad asociativa. (...) El equipo impulsor del Pla BUITS nos hemos sentido a menudo como exploradores equipados con machetes que se abren camino en una selva administrativa llena de arbustos en forma de tasas, de licencias, de seguros de responsabilidad civil o de permisos de obra" ${ }^{63}$.

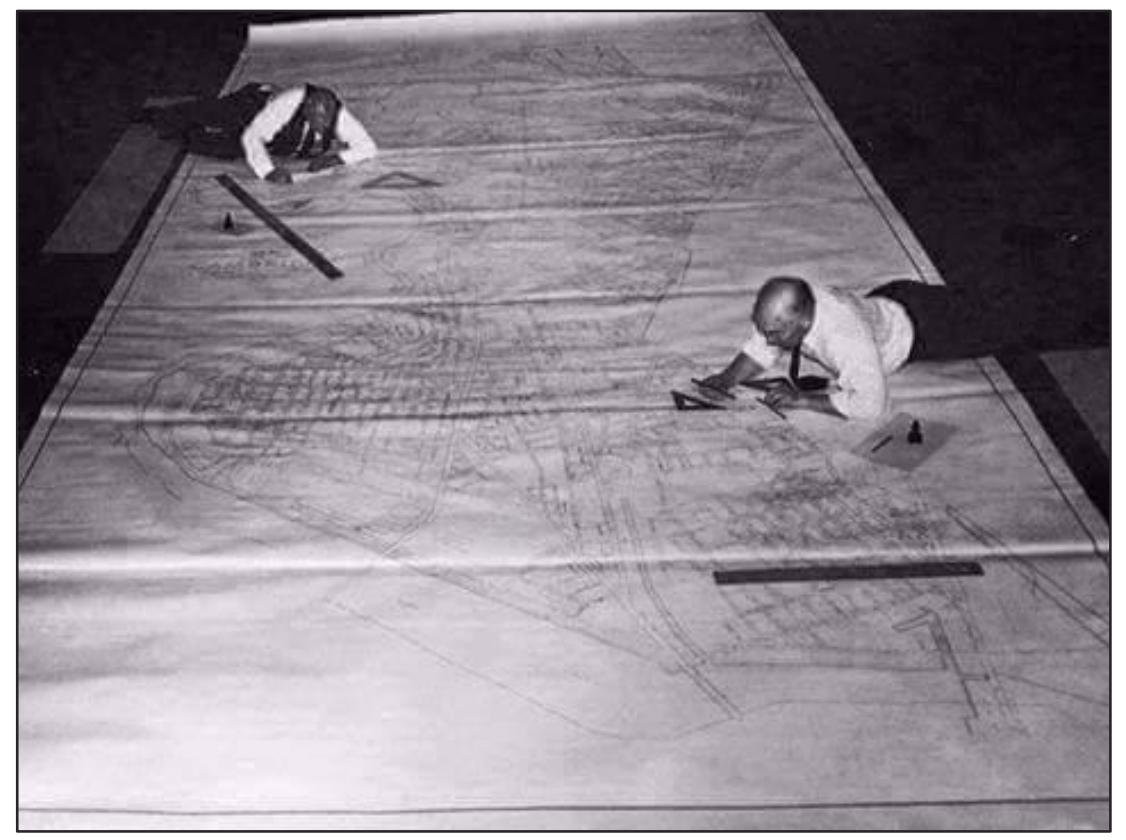

Figura 2. "Planificando".

Fuente: Desconocida.

63 TORRAS, L. (2016). 


\subsection{Nuevas tecnologías}

En relación con el cambio social al que nos venimos refiriendo, las nuevas tecnologías han supuesto un cambio radical en todos los ámbitos de nuestra sociedad "Hasta el punto de que podemos considerar Internet como una palanca de cambio con una vocación transformadora y una magnitud de influencia a la altura de la imprenta de Gutenberg y la máquina de vapor de Watt. Desde luego, esta revolución en ciernes no opera exclusivamente en una dimensión tecnológica, también lo hace en el ámbito económico, político y social" ${ }^{64}$.

Las nuevas tecnologías de la información y comunicación han ayudado y facilitado el camino hacia la participación y la búsqueda y obtención de opinión pública; han ido evolucionando hacia la interacción con el usuario, desde las web 2.0 hasta las redes sociales, el P2P o el código abierto, el usuario ha ido adquiriendo protagonismo.

Podríamos establecer dos vías de actuación a partir del uso de la tecnología: por un lado una interacción directa e inmediata, y por otro, la generación y el intercambio de conocimiento mediante procesos de código abierto.

Así vemos, que se busca obtener la opinión de los usuarios, avanzando hacia la simplificación de los mecanismos para emitirla; desde un "like" a las diversas emociones que recoge Facebook, o las interacciones que se producen mediante Instagram o los temas y la actividad alrededor de estos en Twitter o las etiquetas o "hastags" que marcan la orientación de la intervención. En todas estas acciones el usuario manifiesta una valoración u opinión, que inmediatamente es publicada, conocida e incluso genera una reacción.

Es cierto que esta actividad se produce en asuntos más cotidianos o conocidos por la población. En temas tan específicos y complejos como pueda ser el urbanismo, en sus aspectos más técnicos o jurídicos para que las opiniones puedan realmente aportar algo al debate, es necesario contar con información y un mínimo conocimiento; sin embargo son los vecinos y ciudadanos los que mejor conocen sus barrios y entornos en los que se desenvuelve su vida cotidiana, por lo que es una opinión experta y a considerar.

Son muchas las herramientas informáticas y aplicaciones orientadas a transmitir este conocimiento a los gestores urbanos que han ido evolucionando hacia otros modelos más colaborativos como Hackity App ${ }^{65}$. Cuyo éxito radica en la facilidad de uso y las posibilidades de interactuar que ofrecen. Distinto a lo que sucede con la tecnología orientada a la creación de las denominadas Smart Cities ${ }^{66}$ que deberán seguir evolucionando: "La tecnología no rige la ciudad; sino más bien, al revés, es la ciudad la que manda sobre la tecnología. Las metrópolis digitales se basan en los deseos de los ciudadanos, que están expresados a través de sus gobiernos, y deben

\footnotetext{
${ }^{64}$ PAISAJE TRANSVERSAL (2014)

65 http://www.letshackity.com/en/hackity-app/

66 El Economista.es. 24/03/2017. "La presidenta de Siemens cree que hay "decepción" con las smart cities porque "no han tocado el corazón de las ciudades".
} 
ser diferentes, acordes a las preferencias de sus habitantes. Van más allá de la tecnología y no es hardware, ni el software ni el conocimiento, sino todo junto".

En este aspecto, convendría que las administraciones adaptaran su funcionamiento a este tipo de interacción, a la facilidad y accesibilidad con la que los ciudadanos se expresan en otros ámbitos cotidianos, de un modo tan inmediato y transparente como puede ser su actividad en una red social. Incorporando estas nuevas herramientas a su actividad diaria, que si bien están aún poco testadas como para llegar a ser sustitutas de un procedimiento administrativo, bien se pueden ir experimentando en procesos concretos de los que obtener conclusiones más globales ${ }^{67}$.

Otro aspecto de la aplicación de la tecnología en el campo del urbanismo y de la ciudad se relaciona con la generación de conocimiento e información, el vínculo que ha surgido entre la ciudad y la cultura digital, "EI P2P (peer to peer), el código abierto, el software libre o las licencias copyleft están transformando substancialmente los procesos creativos de la gran mayoría de las profesiones. ¿Por qué el urbanismo permanece ajeno a estas lógicas contemporáneas? (...) Aplicar las lógicas derivadas del beta permanente al urbanismo y a la ciudad supone entender los proyectos urbanos como procesos abiertos, dinámicos y en constante evolución" 68. Estos procesos abiertos se caracterizan por avanzar hacia un objetivo desconocido, en los que se marca el punto de partida y se van formalizando mediante decisiones colectivas producto de los conocimientos técnicos y de la comunidad, de la experiencia profesional y el saber cotidiano de los habitantes; generando de este modo propuestas concretas.

Son caminos nuevos a experimentar, "urbanismo de código abierto" que conjugan las prácticas de la cultura libre y la generación de ciudad, tratados desde hace décadas por autores relevantes como José Fariña o Saskia Sassen. Por parte de las administraciones, esta vía se encuentra aún menos explorada, sin duda su complejidad es mucho mayor, pero los avances en ámbitos a fines como la transparencia o el desarrollo de una gobernanza global, son líneas sutiles de acercamiento que deberán reforzarse para ir superando el denominado "divorcio" entre la sociedad civil y las administraciones.

\footnotetext{
67 Un caso interesante y reciente es el de las DOT del País Vasco, que emplea las nuevas tecnologías en su elaboración y difusión.

68 PAISAJE TRANSVERSAL (2014).
} 


\subsection{Las iniciativas ciudadanas y la administración}

Son muchas las iniciativas ciudadanas que constantemente se crean de modo espontáneo entre vecinos, asociaciones y colectivos diversos... en su mayoría sin ánimo de lucro con la intención de apoyar, defender o impulsar acciones a favor de intereses comunes; en estrecha relación con las nuevas tecnologías como se ha apuntado en el apartado anterior.

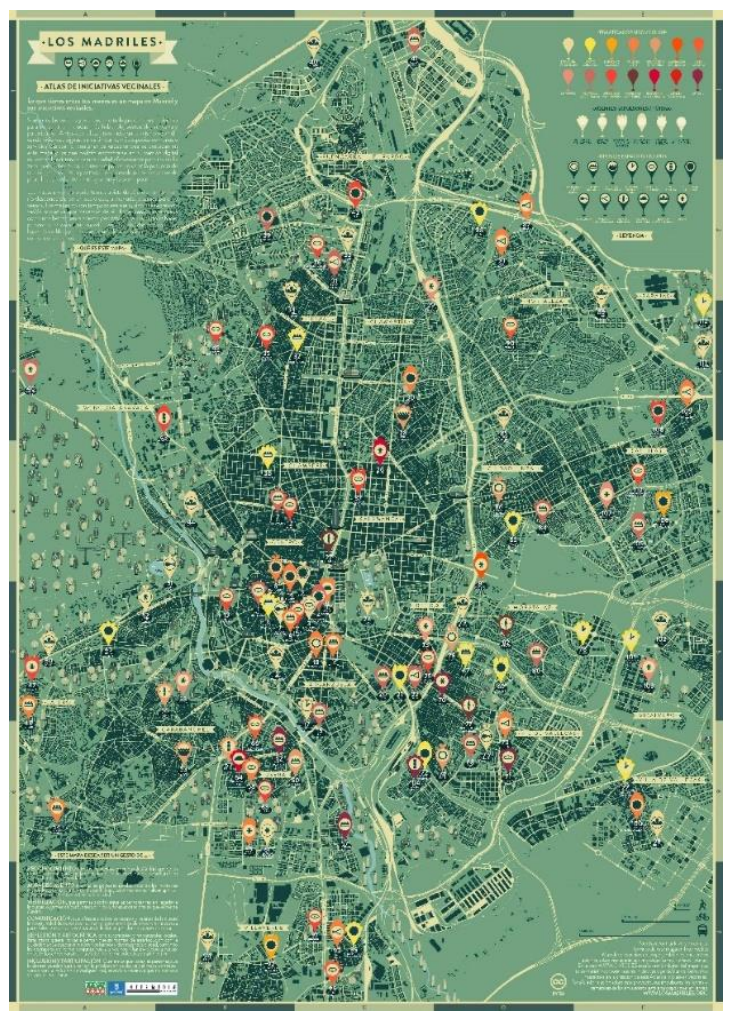

Figura 3. Mapa Los Madriles. (VIC) Vivero de Iniciativas Ciudadanas. 2015. Fuente: http://viveroiniciativasciudadanas.net/

En algunas ciudades estas iniciativas han sido cartografíadas, e incluso se han generado herramientas para la aportación colaborativa de información en cualquier parte del mundo: "Son miles las vecinas y vecinos que trabajan de forma colectiva para construir una ciudad más habitable, sostenible, inclusiva y participativa. Antes que ellos, otros hicieron lo mismo reivindicando viviendas dignas, calles sin barro, más espacios comunes o servicios básicos. El centenar de espacios que se destacan en este mapa... muestran la existencia de una ciudad efervescente pero invisibilizada, pero sobre todo, pretenden poner en valor la potencia de una ciudadanía crítica y activa que ha creado nuevos espacios de posibilidad, mediante la autogestión y la participación" ${ }^{69}$.

\footnotetext{
69 VIVERO DE INICIATIVAS URBANAS VIC (2017). Proyecto Los Madriles. Un mapa de Madrid que destaca más de un centenar de iniciativas vecinales y espacios construidos autónomamente pos la ciudadanía.
} 
Efectivamente se trata de un enorme potencial que constituye el poder creativo y vital de las ciudades. De hecho muchas administraciones locales apoyan y dotan de recursos estas iniciativas. Sin embargo, en la práctica no llegan a producir el impacto y repercusión deseada. Tal vez porque no llegan a involucrar a la suficiente cantidad de ciudadanos, o con la suficiente intensidad o conocimiento o por la dificultad de que se mantengan a lo largo del tiempo, pero lo cierto es que no se puede hablar aún de un cambio a nivel social motivado por estas iniciativas. Si bien son una muestra fehaciente de la diversidad social y de la realidad que opera en nuestras ciudades.

Como se preguntan CAZ, R. del y SARAVIA, M. (2005): "¿No es cierto que ninguna comunidad o ciudad (en opinión de Janice E. Perlman) "puede realizar a la larga su completo potencial sin una vibrante sociedad civil independiente y sin la participación activa de su ciudadanía (dos aspectos complementarios, pero no sinónimos)?".

Es misión de la administración pública actuar buscando el interés general, este objetivo determina las políticas públicas. De hecho es la Administración la que puede mantener determinadas acciones con el objeto de generar verdaderos cambios en la sociedad. Tanto por abarcar todo el territorio como por la intensidad de sus acciones que se manifiestan en el ámbito legislativo y en la dotación de recursos y medios para obtener el resultado perseguido y la orientación al interés general, no económico. Por tanto, se podría considerar que es la administración la responsable de generar el cambio necesario para que la participación entre a formar parte de las vidas de los ciudadanos como refuerzo y confirmación de la democracia colaborativa. Más aún cuando los asuntos les afectan directamente en su calidad de vida. A partir de estas reflexiones se plantean algunas líneas de estudio o acción, que se desarrollan en los capítulos siguientes, para impulsar este urbanismo colaborativo, como alternativa deseable al actual modelo y concepto de participación en esta disciplina.

\section{IMPLANTANDO EL URBANISMO COLABORATIVO}

"No disponemos de instrumentos eficaces para reconstruir la complejidad de la vida cotidiana, ese sustrato fundamental, de economías diversas y fuente de innovaciones que vive de proximidad (no de movilidad) sobre lo que se apoya todo lo demás, incluida la Gran Economía" 70

Suele ocurrir en cuestiones relacionadas con las políticas públicas, la gestión o la planificación, que se plantean los objetivos y los beneficios en caso de cumplir estos, pero rara vez se definen soluciones prácticas, acciones concretas y modelos que puedan ser replicables o al menos que puedan servir de referencia para otros casos.

${ }^{70} \mathrm{ROCH}, \mathrm{F} .(2016)$. 
Ya sabemos que cada situación es única, los problemas que surgen en cada ciudad o comunidad, con sus propias circunstancias, administración, tradiciones, cultura... supone que los mecanismos, herramientas y soluciones en cada caso sean también únicas; como apuntaba Healey no hay modelos en la práctica de procesos colaborativos. Sin embargo, hay factores comunes, elementos cuyo efecto ya está contrastado. Y por ello conviene identificar dichos factores básicos para el éxito de los planes y proyectos, y facilitar su conocimiento entre las administraciones y los ciudadanos. De hecho este tipo de benchmarking ${ }^{71}$ tan utilizado en áreas como la evaluación de la calidad de las políticas y programas públicos con contrastadas metodologías de evaluación y análisis ${ }^{72}$, no se suele aplicar en el ámbito del urbanismo.

No obstante diversas administraciones, organismos públicos y organizaciones a nivel internacional, han dedicado recursos y esfuerzos a la recopilación de las mejores prácticas y experiencias en este ámbito, en los que la participación está presente. $Y$ de los que se pueden obtener conclusiones prácticas ${ }^{73}$.

A lo largo de lo expuesto en el presente trabajo, se pueden identificar algunos aspectos clave y comunes a cualquier planteamiento relacionado con la participación que conviene sean tenidos en cuenta a la hora de intentar plantear propuestas útiles para el fomento de la participación. Ya se han comentado, en el capítulo 2.2, cuales son los requisitos previos para involucrar a los ciudadanos en la toma de decisiones, pero ¿qué acciones concretas pueden poner en marcha las administraciones para alcanzar un urbanismo colaborativo que sean asequibles, eficientes y que perduren en el tiempo?

Haciendo un análisis de los requisitos y en relación a lo expuesto en el capítulo anterior: los procesos deben ser transparentes y accesibles; los ciudadanos deben asumir una responsabilidad y desarrollar una cultura participativa; y las administraciones deben contar con un alto nivel de gobernanza y de calidad de democracia participativa.

Pero además las administraciones son las responsables de procurar que se den las condiciones relativas a los procesos y a los ciudadanos. Son las administraciones las que establecerán las normas y regulaciones de los procesos y sistemas para la participación, que en todo caso deberán ser debatidas y consensuadas con los ciudadanos. Y son las administraciones las que deben proporcionar a los ciudadanos la cultura participativa y responsabilizarles en los procesos urbanos.

En lo relativo al urbanismo la fase de información está asumida por la legislación, pero aún de un modo poco propenso a fomentar la participación activa. Por ello lo realmente importante, no es tanto la información en un proceso concreto sino acercar esta disciplina a los ciudadanos, por un lado facilitando el acceso a sus

\footnotetext{
${ }^{71}$ Benchmarking: en las ciencias de administración de empresas se define como un proceso sistemático y continuo para evaluar comparativamente los productos, servicios y procesos de trabajo en organizaciones que evidencien las mejores prácticas sobre el área de interés.

72 Agencia Española de Evaluación (2017).

${ }^{73}$ Premios ONU HABITAT, Ciudades para un Futuro más Sostenible. CF+S. (2017).
} 
contenidos, procesos y documentos, poniendo a disposición de los ciudadanos toda la ayuda necesaria para su correcta y completa compresión. Por otro, para la participación efectiva se propone flexibilizar el plan.

Como se indicaba más arriba, en el marco de este trabajo, no interesan tanto los procesos puntuales -cuyas metodologías y desarrollo están muy estudiados- como las condiciones requeridas para generar la cultura de la participación. Que podríamos relacionar con las hard y las soft infraestructures, las relativas a normas y regulaciones y las que tienen que ver con la organización social, como se trata a continuación.

\subsection{Generación de cultura participativa}

Generar esta cultura es la base para que la colaboración ciudadana como práctica interiorizada por los ciudadanos, pueda ser una realidad. No se trata sólo de una colaboración en un proceso, sino de generar el hábito, la costumbre, una ciudadanía educada en el diálogo, la generación de soluciones de consenso y la asunción de responsabilidades directas en la puesta en marcha de las soluciones y los recursos para la participación. Empezando por el cambio de la propia administración, como cuestionan FERNÁNDEZ, M. y GIFREU, J. (2016): "Estas preguntas razonables están presentes a lo largo del texto pero podemos apuntar aquí algunas de ellas: (...) la capacidad real de las instituciones para transformar sus procedimientos, su cultura y sus principios de funcionamiento para entender y acompasar las transformaciones socioculturales que están detrás de estas prácticas" (en relación al uso temporal de espacios vacíos en la ciudad).

Empezando por la administración, convendría superar -en cuanto a ir más alláel estricto cumplimiento de la legislación vigente; y plantear medios de información y acercamiento del urbanismo a los ciudadanos. Como ya se recogía en el Libro Blanco de la Sostenibilidad en el Urbanismo ${ }^{74}$ es la creación de los llamados Observatorios Territoriales: "su misión no debería ser sólo de seguimiento sino también educativa, de forma que fueran los organismos encargados de explicar a los ciudadanos el plan, su evolución y las consecuencias de tomar determinadas decisiones".

La legislación de la administración local prevé la creación de los denominados Consejos Sectoriales, precisamente para canalizar la participación de los ciudadanos y de sus asociaciones en los asuntos municipales; sin embargo su capacidad de actuación se limita a las funciones de informe y, en su caso, propuesta en relación con las iniciativas municipales relativas al sector de actividad ${ }^{75}$. Aunque se tiene en cuenta la participación, no prevé que los Consejos generen un sistema de información suficiente ni fomenten un cambio cultural.

\footnotetext{
74 FARIÑA, J. Y NAREDO. JM. (2010).

75 Real Decreto 2568/1986, de 28 de noviembre, por el que se aprueba el Reglamento de Organización, Funcionamiento y Régimen Jurídico de las Entidades Locales.
} 


\subsubsection{Oficina del Plan: Observatorios Territoriales}

La propuesta recogida en el Libro Blanco, de la que se hace eco este trabajo, va mucho más allá, podría aplicarse a cualquier ámbito de la actividad municipal, si bien la ciudad en sí misma, constituye el factor más importante en la vida de los ciudadanos. Por lo que la creación de un instrumento como el observatorio territorial engloba una gran cantidad de los servicios municipales $y$, en definitiva, de la vida de la ciudad. Las funciones primordiales de estos Observatorios serían:

- Seguir en tiempo real la evolución del plan general y planes de desarrollo ${ }^{76}$.

- Monitorizar lo que ocurre en la ciudad, manteniendo el diagnóstico actualizado.

- Toma de decisiones o bien propuestas concretas de intervención en el planeamiento, ejecución y uso mediante el urbanismo colaborativo o bien a la vista de los datos de la evolución de las determinaciones de los planes y proyectos urbanísticos.

- Introducción de formas de participación social que incorpore a políticos, técnicos y sociedad en general. Sistemas de participación continua y organización de jornadas específicas.

- Impulso del comité territorial de urbanismo.

- Catalizador de iniciativas urbanas.

- Empleo de las nuevas tecnologías para la información y generación de conocimiento, en la participación urbanística y el desarrollo de procesos abiertos.

- Actividad didáctica en la difusión del planeamiento y los estudios y análisis realizados en su aplicación, su evolución y actualización.

- Información disponible y atención personal.

- Redacción de los planes y propuestas.

- Evaluación continua mediante indicadores de impacto de las medidas de la planificación urbanística.

- Evaluación de la participación: cualitativa y cuantitativa.

\subsubsection{Servicio de información y formación}

El trámite de la información pública previsto en la legislación sectorial no tiene vocación de introducir a la población en las cuestiones urbanas, de planeamiento, gestión y ejecución, sino de atender al derecho a la información de los interesados

\footnotetext{
76 Ley 19/2013, de transparencia acceso a la información pública y buen gobierno, artículo 6 Información instituciones, organizativa y de planificación.
} 
en los procedimientos administrativos 77 como garantía para la defensa de los derechos que puedan resultar afectados; ha sido reforzado por la Ley 19/2013, de 9 de diciembre, de Transparencia, acceso a la información pública y buen gobierno, que introduce la creación de Unidades especializadas de Información en el funcionamiento de las administraciones públicas. Apoyado en estos avances legislativos, el Observatorio, asume la función de cubrir el derecho a la información según los principios técnicos:

- Accesibilidad: documentación estructurada y con recursos para facilitar su identificación y búsqueda.

- Interoperabilidad.

- Posibilidad de reutilización.

Y según los objetivos de educación en la participación:

- Impulso de la información activa.

- Claridad en los conceptos y contenidos.

- Disponibilidad de medios técnicos y personales para formación

- Mantenimiento a largo plazo.

Buscando analogías, en otros ámbitos de la actividad pública hay experiencias que se pueden asimilar a este concepto como ocurre con la incorporación del concepto de Salud Pública -que se ha ido introduciendo en la vida diaria y creando esta cultura en relación a la vida saludable- como el Centro de Salud, el Observatorio, como un Centro de Ciudad, ejercería estas funciones de fomento, educación, seguimiento, evaluación basado en la participación, apoyado en las nuevas tecnologías y con espíritu experimentador.

\subsubsection{Accesibilidad y facilidad para la participación directa y espontánea}

La propuesta del Observatorio implica un cambio en la actitud de la administración pública en los asuntos de interés para los ciudadanos, en un campo tan "delicado" como es el urbanismo. "En cambio, también dentro de la Administración, toma fuerza una nueva actitud que seguramente convive mejor con la complejidad, y a veces con la incerteza, de ser el principal pero no el único agente responsable de lo público. En este caso, la administración da un pequeño paso atrás y se concentra en sus labores de facilitación, regulación y defensa del interés público, dejando espacio para experiencias de colaboración y corresponsabilización sobre el espacio público" 78. Para ello, es obligado que en la administración nos movamos dentro de una seguridad jurídica que permita afrontar nuevos retos con garantías de legalidad. El programa Pla BUITS, por ejemplo, defiende el cumplimiento del marco legal mientras que diversos artículos jurídicos denuncian su falta de adecuación a lo

\footnotetext{
77 Artículo 53 "Derechos del interesado en el procedimiento administrativo", Ley 39/2015, de 1 de octubre, del Procedimiento Administrativo Común de las Administraciones Públicas. En cumplimiento del artículo 103 de la Constitución Española

78 TORRAS, L. (2016).
} 
legalmente establecido. Evidentemente, para que desde la administración se pongan en marcha acciones de apertura y flexibilidad, el marco jurídico debería estar claramente definido.

Como se ha visto, en relación a las posibles funciones atribuidas al Observatorio Territorial, tendrían un encaje legal que facilitaría su consolidación como un servicio público, con las peculiaridades mencionadas.

La actividad de este Centro contendría tanto las iniciativas de la administración como las iniciativas ciudadanas y de grupos o asociaciones. Se plantea como un centro social cuyo eje de giro es la ciudad y la intervención en ésta para mejorar la vida de las personas, que implica la redacción y tramitación de planes e instrumentos técnicos o administrativos para la ejecución real de las propuestas consensuadas.

Precisamente la clave de éxito de esta propuesta está en la accesibilidad al lugar, por supuesto desde el empleo de las TICs y sistemas más abiertos, pero fundamentalmente desde el concepto tradicional, físico y sensorial, de crear centros abiertos y próximos (como el comercio básico o el "bar de la equina") que se integre en la vida cotidiana de los vecinos. Algo similar a los "Puntos de información Turística" que se han instalado por la ciudad de Madrid ${ }^{79}$, los "Puntos de Información Urbanística" podrían incorporar algunas de estas características:

- Situados en lugares representativos (desde el punto de vista de la vida urbana).

- Atractivos y fácil acceso.

- Con servicios sobre urbanismo y vida de barrio.

- Servicios complementarios: realización de trámites, buzones de sugerencias y quejas, WIFI, conexión a red, ...

Podríamos pensar que en la administración local esto ya se da: es fácil acceder a las dependencias municipales, concertar cita con los técnicos, solicitar información... sin embargo sigue habiendo barreras, el recorrido para acceder a las oficinas administrativas sigue siendo complejo y la disponibilidad relativa. En estos casos el "interesado" debe estarlo mucho para afrontar el reto de la información. De este modo se fomentaría una administración de "Puertas Abiertas", que vaya al ciudadano, que le busque y le cuente sus planes, que escuche los otros y mediante el conocimiento, el diálogo y el consenso cree mejores ciudades y mejores ciudadanos.

\subsubsection{Centros en Red}

Es innegable que la implicación de todos los actores en las cuestiones relacionadas con la ciudad y el territorio, deben activarse desde la administración local, al ser la más cercana y accesible para el ciudadano. Sin embargo, la planificación territorial debe superar las barreras municipales e integrarse en una estrategia de desarrollo

${ }^{79}$ Ayuntamiento de Madrid (2017). 
comarcal coherente y duradera ${ }^{80}$. De hecho el territorio no conoce de límites administrativos y políticos, sino que se caracteriza precisamente por la variedad y riqueza de su contenido: condiciones ambientales, de paisaje, hidrológicas, de flora, fauna, sociales, culturales... que provoca multitud de delimitaciones según el tema de estudio.

Las directrices europeas resaltan la importancia de las políticas territoriales de ámbito comarcal, regional, o incluso a nivel internacional. En España, comunidades como el País Vasco ${ }^{81}$ o Asturias cuentan con legislación específica o referencias a los planes territoriales de Navarra, que refuerzan la importancia de superar el ámbito municipal, sin embargo, en todo caso la iniciativa es autonómica, no se reconoce la potestad del planeamiento a otras administraciones o instituciones locales intermedias, como son las diputaciones o mancomunidades, por lo que su viabilidad es relativa.

En otros países, como en Francia, una de las mayores transformaciones del modelo de planificación territorial, ha sido la definición de la comarca como unidad geográfica, cultural y socialmente cohesionada, como unidad de referencia para la planificación y las políticas urbanas. "La experiencia francesa demuestra la importancia de evolucionar desde las dinámicas de competencia entre municipios hacia procesos de cooperación que favorezcan la construcción de territorios medioambientalmente más equilibrados, socialmente más solidarios $y$ económicamente más fuertes" ${ }^{82}$.

Estos Observatorios, como herramienta fundamental para la participación en el urbanismo y las políticas urbanas, no pueden funcionar de modo aislado y centralizado al contrario, adquieren su sentido como nodos de una red interconectada que se extiende en el territorio, según sus características tendrá diversas escalas. Propiciando la colaboración entre centros, la coordinación territorial y la coherencia de las políticas, los planes y las acciones que se tomen en cada ámbito local.

De hecho en el Libro Blanco de la Sostenibilidad en el Planeamiento Urbanístico Español, se plantean los "Observatorios territoriales", indicando que "deberían gozar de una cierta autonomía y que en muchos casos incluirían en su ámbito de actuación varios municipios" al considerar el territorio en su conjunto a nivel de mancomunidad, isla, comarca...

Por otro lado, como se ha indicado al inicio de este apartado, es preciso que los asuntos relativos a los instrumentos de ordenación del territorio y urbanísticos, estén centralizados de modo que para los vecinos y usuarios sea sencillo acceder a la información, hacer consultas o el seguimiento de los instrumentos, así como

\footnotetext{
80 COMISIÓN EUROPEA (1990), esta iniciativa ya se planteaba por la UE en relación al urbanismo y las políticas europeas, la conveniencia de crear redes y tender puentes para el intercambio de información y conocimiento. Se hace referencia en el apartado 4.2.

${ }^{81}$ Ley 4/1990 de 31 de mayo, de Ordenación del Territorio del País Vasco

82 FERNÁNDEZ, B. (2013).
} 
participar cuando se abran procesos y colaborar como práctica abierta y corriente en los temas de ordenación y urbanismo.

Esta Red tiene, además, un sentido de conexión sectorial orientado a la mejora de la propia actividad, al trasvase de conocimiento y a la colaboración entre Centros. La creación de redes de ciudades se lleva promoviendo desde hace décadas, con todo tipo de motivos: Red Española de Ciudades por el Clima, Red de Ciudades Saludables, Red de Ciudades Inteligentes, por la accesibilidad, creativas... se trata de crear sinergias, relaciones fructíferas para todos los componentes de la red, complementándose y enriqueciéndose mutuamente.

La creación de redes territoriales y sectoriales permitiría mantener un flujo de información constante, de buenas prácticas, experiencias, conocimientos... que podrían influir a nivel supramunicipal en aspectos legislativos, normativos, de coherencia global.

Este beneficio para las administraciones también se vería reflejado en la población, pues igualmente dichos centros trabajando en red permitirían la interconexión de asociaciones, vecinos, personas a nivel individual, agrupaciones de todo tipo, a nivel territorial más amplio, generando nuevos ámbitos de relación, conocimiento y actividad.

\subsection{Flexibilidad normativa a nivel local y territorial.}

Como hemos visto, la participación ciudadana no está incorporada a la legislación actual que se limita a la información pública y el periodo de alegaciones, como parte del procedimiento de tramitación del planeamiento y proyectos de ejecución de éste. Sin más vinculación a cómo esta debería influir en el trazado del modelo territorial ni, yendo más allá, cómo los ciudadanos pueden continuar participando en los procesos de ejecución y mejora de la ciudad y el territorio.

Lejos de fomentar la participación y el conocimiento general, el urbanismo se ha ido convirtiendo en una práctica de gran complejidad jurídica y técnica, poco comprensible, poco accesible y poco transparente. Muy al contrario de lo que postulaba JACOBS, J. (1961) "Los procesos que tienen lugar en las ciudades no son en modo alguno arcanos, comprensibles sólo para los expertos. Casi todo el mundo puede comprenderlos. Muchos ciudadanos corrientes ya los entienden perfectamente; lo que ocurre es que no han puesto nombres a estos procesos o bien no han reparado en que comprendidos sus mecanismos de causa y efecto, si queremos, podemos dirigirlos".

En relación a este tema distinguiremos entre el contenido del planeamiento y los procedimientos y sistemas de actuación de la administración para facilitar la participación, la corresponsabilidad y colaboración en aquellos asuntos que pueden ser factibles y que la sociedad demanda. Es necesario identificar los problemas más determinantes y comunes en la práctica urbanística para analizarlos y buscar soluciones que puedan facilitar la participación en el urbanismo. 
En FARIÑA, J. y NAREDO. JM. (2010) se reflexiona sobre este asunto enumerando los siguientes obstáculos:

1. El Plan determina el derecho de propiedad del suelo por lo que se convierte en un instrumento para distribuir el valor monetario del suelo.

2. El Plan General es un instrumento sumamente pesado.

3. Se basa en un sistema complejo, con un tratamiento monolítico.

4. La información que contiene es poco comprensible.

5. En muchas ocasiones no se parte de datos reales, o bien ya son obsoletos en el momento de aprobar y aplicar el plan.

6. El sistema de revisión es rígido y se dilata en el tiempo.

7. En muchas ocasiones las modificaciones cambian de forma determinante la imagen global del plan.

8. La planificación territorial no está vinculada al planeamiento urbano.

9. El ámbito administrativo del plan no se corresponde con la realidad territorial, natural o socio-económica.

10. No hay un seguimiento del plan ni conocimiento real de cómo se desarrolla.

"Esta situación, tanto en la planificación territorial como en el planeamiento urbanístico, es muy negativa para la ordenación racional de nuestros territorios, porque existe una falta de visión global y una escasa implicación de la ciudadanía en procesos que se les escapan, dando lugar a la atención del corto, frente al largo plazo".

En España, el Plan General define objetivos a largo plazo como el modelo urbano y territorial y determinaciones de aplicación inmediata, como las ordenanzas y normas zonales, con rango normativo. Debido al arduo proceso de elaboración y la variedad y complejidad del contenido, y dados los tiempos de redacción, tramitación y de vigencia del plan, y la afección al régimen de propiedad derivado de la clasificación del suelo, el Plan General de Ordenación Urbana tiene enormes consecuencias entre los ciudadanos y propietarios, y por tanto una gran repercusión política. De hecho, las revisiones del plan, no es tarea que los gobiernos municipales aborden habitualmente, otra cosa son las modificaciones puntuales, que terminan siendo más o menos sustanciales. Es por ello que éstos se siguen aplicando 30 años después de iniciar su redacción, con el consiguiente desfase entre la realidad y sus determinaciones. Esto genera situaciones de frustración e incomprensión, un clima de falta de confianza en las administraciones y el alejamiento de los ciudadanos.

\subsubsection{El derecho de propiedad y el planeamiento}

En el sistema urbanístico español esta vinculación puede ser uno de los problemas más importantes del momento actual, y uno de los mayores inconvenientes para conseguir un planeamiento más flexible que permita adaptaciones sencillas a las 
situaciones reales, respondiendo con agilidad a las necesidades de la población y constituyendo un elemento de impulso y fomento de la calidad de vida, la actividad social y económica, y herramienta para la innovación y la mejora de nuestros territorios y ciudades; como concluye FERNÁNDEZ, C. (2011): "En el caso del sistema urbanístico español, (...) el factor más influyente que condiciona la participación "real" entendido como el ejercicio del "derecho a la ciudad" se encuentra en cómo se configuran los pesos de los agentes que intervienen en lo urbano".

Desde la legislación estatal reciente, Real Decreto Legislativo 7/2015, de 30 de octubre, por el que se aprueba el Texto Refundido de la Ley de Suelo y Rehabilitación Urbana y el Real Decreto 1492/2011, de 24 de octubre, por el que se aprueba el Reglamento de valoraciones del Suelo-como ya se hiciera en la Ley 8/1990 y el posterior Texto Refundido de la Ley del Suelo de 1992- se trata de desvincular el valor del suelo de su clasificación en el plan general, "el Reglamento desarrolla el texto refundido de la Ley de Suelo en lo relativo a "la valoración inmobiliaria", con la intención de dar respuesta al deseo expresado por el legislador estatal, de mejorar el funcionamiento del mercado del suelo, para hacerlo más transparente y eficiente, combatiendo además, en la medida de lo posible, las eventuales prácticas especulativas en la utilización del mismo, que en ocasiones, afectaban directamente a la fijación de valores a efectos expropiatorios."

En el mencionado Libro Blanco, los autores proponen algunas alternativas contrastadas en otros países europeos como el reconocimiento de una "edificabilidad mínima" o el retorno de las plusvalías a la comunidad, "en cualquier caso parece que resulta imprescindible abordar este problema si se quiere conseguir un urbanismo más sostenible y más justo, que desactive la voracidad urbanizadora y recalificadora de los suelos con el fin de obtener plusvalías y reducir las posibilidades de incidir en prácticas corruptas." Tal vez la opción de recuperar las plusvalías sea la más acertada, si bien para ello las administraciones deberían ejercer la potestad de ejecución del planeamiento, y ofrecer los suelos urbanizados a la actividad privada cuyos precios finalistas serían mucho más asequibles, al haber eliminado la especulación del suelo y el incremento de los gastos de ejecución. Como recogía la Ley de 12 de mayo de 1956 sobre Régimen del Suelo y Ordenación Urbana en su preámbulo "Si ideal en la empresa urbanística pudiera ser que todo el suelo necesario para la expansión de las poblaciones fuera de propiedad pública, mediante justa adquisición, para ofrecerle, una vez urbanizado, a quienes desearen edificar, la solución, sin embargo, no es viable en España. Requeriría fondos extraordinariamente cuantiosos, que no pueden ser desviados de otros objetivos nacionales, y causaría graves quebrantos a la propiedad y a la iniciativa privadas."

El problema planteado de los fondos precisos para su ejecución, en realidad, es una situación puntual de partida, pues en las actuaciones urbanas el suelo financia la ejecución de la transformación. El asunto estaría en saber ponderar la oferta y la demanda. En esta situación, si fuera la administración quien llevara a cabo la transformación del suelo, sería mucho más viable acercarse a posiciones más flexibles, adaptando el desarrollo a las verdaderas carencias de la población, y por 
tanto la participación tendría mucho más sentido, los ciudadanos se sentirían escuchados y protagonistas de la evolución de la ciudad, y ésta respondería a sus necesidades y expectativas, tendría un efecto en la implicación y motivación de los vecinos para continuar colaborando creándose en torno al urbanismo un círculo virtuoso tal y como debería ser.

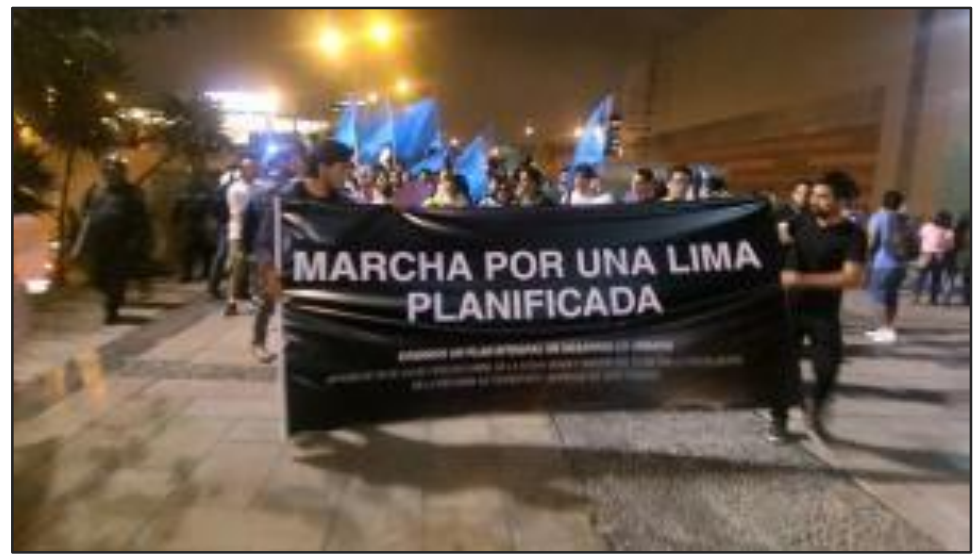

Figura 4. Marcha "por una Lima Planificada" promovida por la Unión de Estudiantes de Arquitectura. 8/05/2015.

Fuente: https://www.forosperu.net/temas/estudiantes-de-arquitectura-marchan-contra-el-by-pass-28-de-julio.738515/pagina-4

\subsubsection{Planeamiento flexible}

Independientemente de los efectos jurídicos, conviene diferenciar entre el largo y el corto plazo, en los objetivos y las determinaciones que componen el plan. En relación a los sistemas referidos, la planificación a largo plazo establecería las líneas estratégicas, el modelo de ciudad, los objetivos de desarrollo y sus principios (de sostenibilidad, cohesión, calidad de vida, protección cultural, paisajística...) estos objetivos tienen repercusión para toda la comunidad y el territorio, y son susceptibles de mayor participación y aportaciones por parte de los ciudadanos.

Y por otro lado, se establecerían los criterios de desarrollo y objetivos a corto plazo, algunos de carácter más técnico, pero otros más vinculados con el día a día de vecinos y usuarios. Estas normas estarían sometidas a adaptaciones según los momentos y circunstancias, sin caer en la arbitrariedad, en función del mejor cumplimiento de los fines a largo plazo, y en todo caso sometidas a la participación ciudadana. Las normas para la revisión de cada bloque de determinaciones deberán ser distintas, pero imbricadas en procesos transparentes, abiertos y accesibles por toda la ciudadanía.

En este sentido resulta revelador el trabajo de Beatriz Fernández Águeda ${ }^{83}$, en las propuestas de adaptación de las políticas urbanas al modelo francés, del que se pueden destacar las siguientes líneas fundamentales para una planificación más flexible "La mayor innovación del modelo francés es (...) la integración del factor temporal en la planificación y la evolución desde un proceso lineal (en el que la pequeña escala y el corto plazo quedaban supeditados a la gran escala y al largo

${ }^{83}$ FERNÁNDEZ, B. (2013). 
plazo) a procesos dinámicos", que se resumen en las siguientes líneas de adaptación:

- Recuperar una cultura urbanística para hacer frente a los nuevos retos del territorio, la sociedad y la economía; que parta de los elementos locales diferenciales.

- Establecer un modelo territorial a nivel nacional que ponga en valor el potencial y la diversidad de nuestras regiones, dada la distribución competencial administrativa, este modelo tendría que estar basado en aspectos medioambientales y/o económicos.

- Planificación integrada, apartada de las estrategias sectoriales, con posibilidad de entrecruzar políticas urbanas, económicas y sociales con la planificación espacial y los programas sectoriales de transporte y vivienda. Inscrito en el proyecto de desarrollo del territorio y la preservación de medio ambiente y sistemas productivos locales.

- Incorporar la comarca ${ }^{84}$ como unidad geográfica, cultural y socialmente cohesionada, como medida para la planificación y las políticas urbanas. Es una referencia escalar más cercana al ciudadano y permite incorporar formas de gobernanza orientadas a la solidaridad y cohesión territorial. Permitiría evolucionar desde dinámicas de competencia entre municipios a relaciones de cooperación ${ }^{85}$. Como sistema voluntario, para la construcción colectiva de un modelo integrado de territorio, fomentado por incentivos fiscales.

- Dos etapas en el planeamiento territorial y municipal: Fase Estratégica: definición del modelo integrado de desarrollo territorial: municipal y comarcal. Tiene un carácter integrador y basa en un proceso colectivo ${ }^{86}$. Fase Técnica: desarrollo de los documentos técnicos necesarios para materializar el proyecto. Esto daría prioridad al modelo territorial y desplazar la parte normativa a la fase técnica, no se trata de "desregular" sino de evolucionar a modos de planificación más flexible. Sería conveniente una renovación de los documentos de planeamiento.

- Esta estructura implica la necesidad de crear un cuerpo técnico de seguimiento del proyecto que garantice la progresiva puesta en marcha y las posibilidades de evolución del proyecto incorporando modificaciones a lo largo del tiempo.

\footnotetext{
${ }^{84}$ En España existen referencias a otras escalas del territorio distintas de las administrativas en diversas leyes autonómicas como la Comunidad Autónoma de Aragón en relación a la comarca, en el País vasco, Navarra o Asturias han avanzado en la planificación territorial incorporando planes territoriales parciales, o especiales.

85 FERNÁNDEZ, B. (2013). "El ejemplo francés revela que la existencia de un proyecto común de futuro constituye un impulso a la acción, que permite reforzar los vínculos de cooperación y, al mismo tiempo, construir territorios atractivos a escala global."

86 Project d'Aménagement el Dévoloppement Durable. "A través del nuevo modelo, las decisiones sobre la propiedad individual quedan definitivamente supeditadas a la construcción de un modelo integrado de territorio y permite alejar las decisiones políticas de las consideradas puramente técnicas."
} 
- Incorporar el diagnóstico como una etapa esencial de la planificación, orientado a la comprensión de los problemas, identificación y movilización de capacidades. Como se ha indicado, la construcción del diagnóstico permite la construcción de una identidad común y un compromiso de todos los agentes con el proyecto de futuro de su comarca.

- El modelo debe estar basado en el consenso de todos los actores, movilización de recursos desde la fase de toma de decisiones; permitiendo crear una cultura común para el desarrollo de los valores de cada comarca, como impacto social de la fase de diagnóstico.

"La experiencia francesa revela la importancia de no plantear modelos cerrados sino, por el contrario, adecuarlos a las condiciones específicas de cada territorio y permitir que evolucionen en el tiempo."

La actual situación de crisis y el agotamiento de modelos anteriores, el nuevo modelo de desarrollo urbano que establece la legislación vigente, la vitalidad de nuestra sociedad y la imperiosa necesidad de proteger nuestros valores naturales y medioambientales, son motivos suficientes para acometer los cambios precisos a nivel legislativo que permitan evolucionar hacia una planificación más coherente con la realidad social, económica y territorial. En el que la participación se integre como una parte imprescindible de todo el proceso, en el que las aportaciones de los ciudadanos y grupos tengan cabida, con metodologías de consenso y colaboración, que produzcan verdadero impacto en la creación de redes, co-responsabilización, creación de sentimiento de pertenencia que, trasladado a la ciudad y al territorio, mejoren la cohesión social, económica, la calidad de vida.

En palabras de José María Ezquiaga sobre la función del planeamiento "El plan urbanístico ha muerto si lo entendemos como un instrumento solamente jurídico, como un instrumento o norma vacía y fría, pero en cambio tiene un largo recorrido y una vida bien necesaria si lo concebimos como expresión de ese compromiso, de ese pacto que es necesario entre la propia ciudadanía y las administraciones desde esa perspectiva de un desarrollo distinto, de un desarrollo sostenible" ${ }^{87}$.

\subsection{Empleo de las nuevas tecnologías}

Relacionar la tecnología y la ciudad nos lleva a pensar en las "Smart Cities" o "Ciudad Inteligente, referido a un tipo de desarrollo urbano basado en la sostenibilidad que es capaz de responder adecuadamente a las necesidades básicas de instituciones, empresas, y de los propios habitantes, tanto en el plano económico, como en los aspecto operativos, sociales y ambientales. Se basan en el uso intenso de las Tecnologías de la Información y Comunicación (TIC) en prestación de servicios públicos de alta calidad y calidez, seguridad, productividad, competitividad, innovación, emprendimiento, participación, formación y capacitación. (...) en una gobernanza participativa" ${ }^{88}$.

\footnotetext{
${ }^{87}$ EZQUIAGA, J.M. (2015)

${ }^{88}$ Definición obtenida de Wikipedia: https://es.wikipedia.org/wiki/Ciudad inteligente\#cite ref-7 (26/04/2017).
} 
A estas alturas, 15 años después de empezar a utilizar este término con altas expectativas en los resultados en el "funcionamiento" de la ciudad, podemos sacar conclusiones como comenta Manu Fernández "podemos atrevernos a pensar que las cosas no están yendo tan rápido como se han planteado a veces y existe frustración por la falta de resultados prácticos, coherentes y significativos. Las razones de esta situación apuntan claramente a problemas de fondo y de definición" ${ }^{89}$.

En lo relativo al uso de la tecnología aplicada a la ciudad, habría que distinguir entre los aspectos de gestión de la ciudad que pueden ayudar a un mejor funcionamiento y los que verdaderamente aportan valor, como apunta José Fariña: "La tecnología puede ayudar pero el foco no hay que ponerlo ahí. La dificultad está en dotarnos de instrumentos de organización verdaderamente participativos que permitan que una sociedad con una cultura específica, anclada en un territorio, con relaciones no depredatorias sobre el mismo, se aglutine en torno a valores con los que la mayor parte esté de acuerdo".

En relación con los temas tratados en este trabajo, el uso de las nuevas tecnologías tiene especial relevancia en las actividades de información y participación, como se ha expuesto en el capítulo anterior. Desde el punto de vista de la información, la aplicación de las nuevas tecnologías en la gestión de la ciudad puede incrementar la eficiencia y proporcionar información de forma bidireccional. En un primer nivel de información podemos situar los sistemas de gestión de los servicios públicos, ya bastante asumidos por las administraciones, que no solo permiten un uso más eficiente de los recursos, sino que además proporcionan información relativa al funcionamiento de los servicios, al gasto y consumo, y las condiciones de éstos: calendario, horarios, incidencias habituales, ... todo ello genera una enorme cantidad de datos en relación al funcionamiento básico de las ciudades.

El asunto del tratamiento de esta información comprende dos aspectos fundamentales, por un lado la accesibilidad de los datos, por otro la selección de los mismos. La Ley 19/2013, establece que debe ser publicada la información relativa a los actos de gestión administrativas con repercusión económica, que deberá ser publicada en las correspondientes sedes electrónicas o páginas web, de manera clara, estructurada y entendible para los interesados, y preferiblemente en formatos reutilizables; las administraciones establecerán los mecanismos adecuados para facilitar la accesibilidad, la interoperabilidad, la calidad y la reutilización de la información publicada, su identificación y localización.

Qué información debe ser suministrada, queda a criterio de cada administración. Más allá de la gestión de los servicios públicos, la información urbanística que se genera en la ciudad debe ser facilitada por las administraciones para el conocimiento general, el seguimiento por parte de la población y la dación de cuentas. Además, como ya se ha comentado es la base para una participación efectiva y una colaboración real.

${ }^{89}$ FERNÁNDEZ, M (2017). 
En otro sentido, son los ciudadanos los que proporcionan información a la administración: sobre uso de los servicios, el estado de los bienes públicos o su opinión sobre la gestión; por lo que es razonable que los datos obtenidos vuelvan a las manos que los han generado (con las salvedades y cautelas legalmente establecidas), Bernardo Gutiérrez destacó en el hangout entre \#SmartciticensCC y \#CiudadesEmocionales "Ciudadanos que transforman sus teléfonos móviles en sensores para medir la contaminación de la urbe y compartir esos datos, por ejemplo. O la elaboración de un mapa digital de calles tranquilas para circular en bicicleta por Madrid" 90.

En unos casos la tecnología es una herramienta para la obtención/emisión de información básica y el procesado de datos. Otro aspecto más relevante es el empleo de ésta como instrumento de relación, de comunicación, colaboración, participación. Usos fundamentales, aunque no exclusivos, para la generación de la cultura participativa y colaboradora entorno a la ciudad, la vida urbana y el territorio que la acoge ${ }^{91}$. Como se ha analizado en el apartado 7.3 en relación a las nuevas tecnologías desde el punto de vista social y urbano, manteniendo el foco en la participación, constituyen el motor de cambio para la generación de procesos abiertos y alcanzar soluciones conjuntas a problemas comunes.

\subsubsection{Medios de comunicación, páginas Web, redes sociales}

El uso de la tecnología en sus diferentes facetas en la administración es a día de hoy un imperativo legal 92 independientemente del nivel tecnológico de la propia administración y los usuarios. En todo caso es una tendencia que no hará más que aumentar, todos, administraciones, empresas, sociedad en general debemos asumir. Sin olvidar que es un instrumento, que suma como medio de información y comunicación, no sustituye a los tradicionales tan necesarios en muchos casos: atención personalizada, resolución de dudas, obtención de información concreta... y abre otras puertas a nuevas formas de relación y producción.

Más allá de las determinaciones legales, que principalmente regulan las relaciones entre "interesados" y administraciones públicas, los responsables políticos han encontrado en las nuevas tecnologías medios de comunicación ágil y directa con los usuarios y población en general, como es el caso de las páginas web y las redes sociales. Además de las herramientas habituales y disponibles gratuitamente, encontramos aplicaciones específicas y hechas a medida en cada caso; se utilizan para la información pasiva, que realmente no facilita el acceso a la información a los interesados, ni fomenta la creación de una cultura participativa ni colaborativa. Se convierten en una ventana de la administración con posibilidades de interacción muy limitadas.

Desde el punto de vista de las atribuciones de los Observatorios, en el ámbito de la información al ciudadano y el uso de la tecnología, habría que distinguir entre los

\footnotetext{
90 PAISAJE TRANSVERSAL (2013)

91 PAISAJE TRANSVERSAL (2016)

92 Ley 39/2015, de 1 de octubre, del Procedimiento Administrativo Común de las Administraciones Públicas.
} 
medios propuestos por la administración y los medios propuestos por los ciudadanos, o al menos por los avances tecnológicos que están al alcance de todos (abrir una cuenta en un banco con una foto, pagar recibos con un "click" desde el móvil).

Los medios de la administración, actualmente basados en las páginas web y las redes sociales, como escaparates de la ciudad orientados al desarrollo de un urbanismo colaborativo, podrían evolucionar en dos sentidos:

- Como herramienta para que los ciudadanos obtengan información, superando la situación actual, de modo rápido y fácil: páginas web, portales de transparencia, perfiles de Facebook, twitter, Instagram. Para ello tendría que estar sistematizada y actualizada. Esto requiere tiempo y conocimiento. Se trataría de poner a disposición de los interesados la información existente, que comprendería tanto la documental -aquella que forma parte del expediente administrativo- como la obtenida en los procesos de análisis, seguimiento y evaluación de los planes y proyectos.

Esta información más dinámica debería ser operativa y reutilizable por los interesados, de modo que, al estilo de los geógrafos radicales, la sociedad pueda acceder, conocer y analizar directamente las cuestiones relacionadas con la ciudad y su territorio, en la línea del mencionado "urbanismo de código abierto".

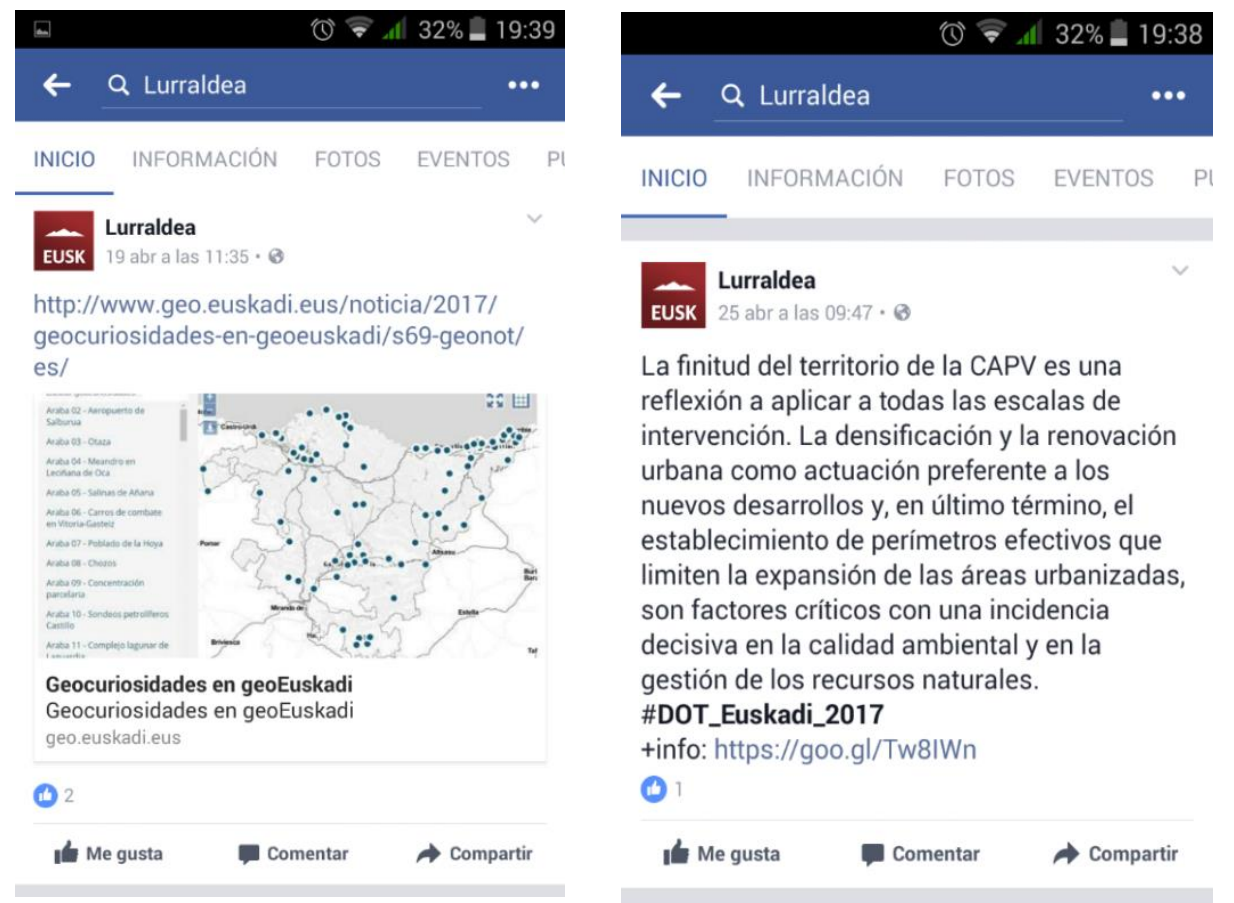

Figura 5. Capturas de pantalla de la página de Facebook de Lurraldea difundiendo información urbanística.

Fuente: https://es-la.facebook.com/lurraldea/ 
A su vez, estos medios permitirían ofrecer información constante, específica y divulgativa de temas relacionados con el urbanismo, de modo que esta materia y las diversas disciplinas que la componen y complementan, sean cada vez más conocidas, con el objetivo de crear una cultura orientada a la información y participación en materia de urbanismo.

- Como herramienta de comunicación, participación y colaboración, pueden ser empleadas como medios de comunicación abierta y continua (en función también de las posibilidades de la administración de mantener dicha comunicación). Superando las comunicaciones habituales mediante correo electrónico o buzones de sugerencias y quejas o incidencias; las webs y las redes sociales permiten establecer comunicación directa bidireccional. En las redes sociales la participación y los comentarios son públicos -conviene que así sea- permitiendo que haya interacción entre todos los interesados. También es cierto que en muchas ocasiones los comentarios e interacciones están motivados por intereses personales o poco relacionados con el asunto en sí. No obstante, un mal uso no implica la falta de interés y utilidad de la herramienta.

\section{PARTICIPACIÓN DIGITAL}

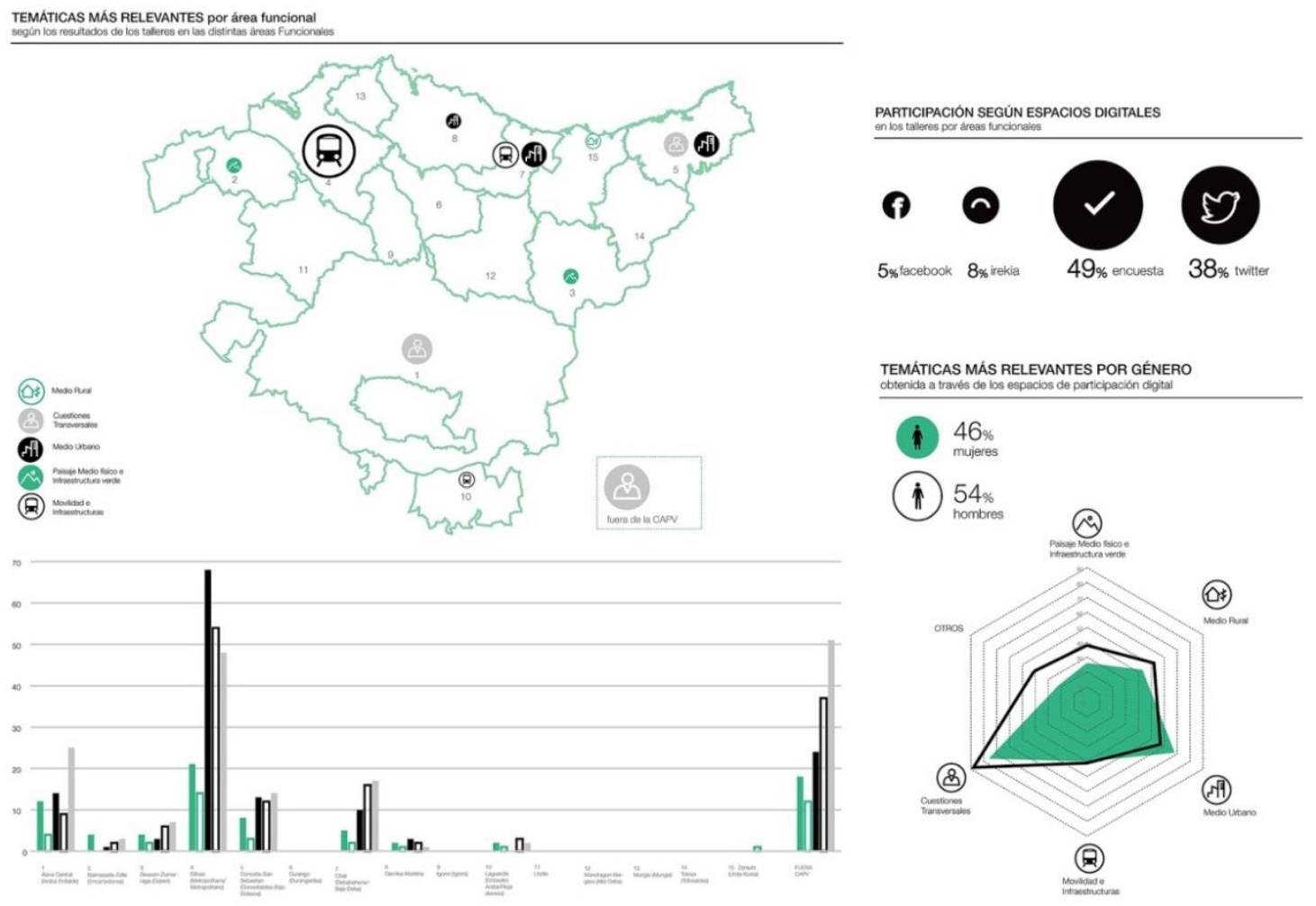

Figura 6. Participación digital en la elaboración de las DOT. Fuente Paisaje Transversal

Como aparece en el gráfico anterior, en el caso de las DOT del País Vasco, el espacio digital más utilizado por los ciudadanos para la participación han sido las 
encuestas, posiblemente por ser accesibles desde cualquier plataforma, y de respuesta sencilla.

Estos espacios digitales tienen una gran versatilidad si la administración tiene capacidad necesaria para aprovechar su potencial:

- Recopilación de propuestas: twitter, web, Facebook,...

- Encuestas y cuestionarios: mediante herramientas de código abierto cuyos resultados se procesan automáticamente, pequeños cuestionarios en la web, recopilación de microacciones en las redes sociales...

- Inscripciones, creación de grupos de trabajo, de colaboración: coordinadas por responsables de participación, con posibilidad de tratamiento de datos e información para la sistematización de propuestas, análisis, evaluación y seguimiento de resultados, mediante documentos compartidos y abiertos.

El uso de las herramientas tecnológicas es útil en todos los procesos y etapas de los desarrollos y transformaciones urbanas, incluidas las fases previas de información y diagnóstico, en las tareas de información, participación y colaboración.

\subsubsection{Medios de formación y colaboración}

Por otro lado está la sociedad, pero ¿dónde está?

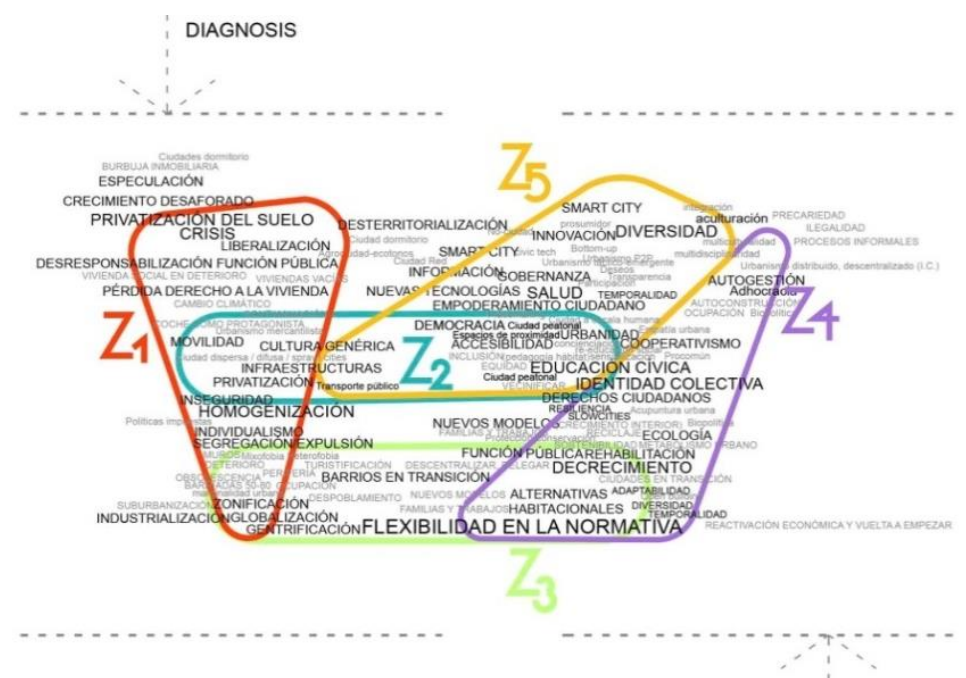

Figura 7. Cuadro de Zonas de nuevas formas de participación.

Fuente: Reyes Gallegos

No es objeto de este trabajo, entrar a desenmarañar la situación actual de colectivos, grupos, nuevas metodologías, nuevos objetivos, formas de colaboración... en lo que podríamos llamar el "urbanismo emergente" por su novedad y por el sentido de abajo-arriba. Esta tarea sobrepasa con mucho el objeto del presente trabajo; como se ha visto, esta actividad y diversidad se debe en gran medida a las nuevas tecnologías y las posibilidades que proporcionan de 
comunicación, colaboración, producción, de compartir y coincidir. Aunque siempre han existido formas de colaboración y de aprovechamiento de las sinergias, como parte del comportamiento y la actividad humana.

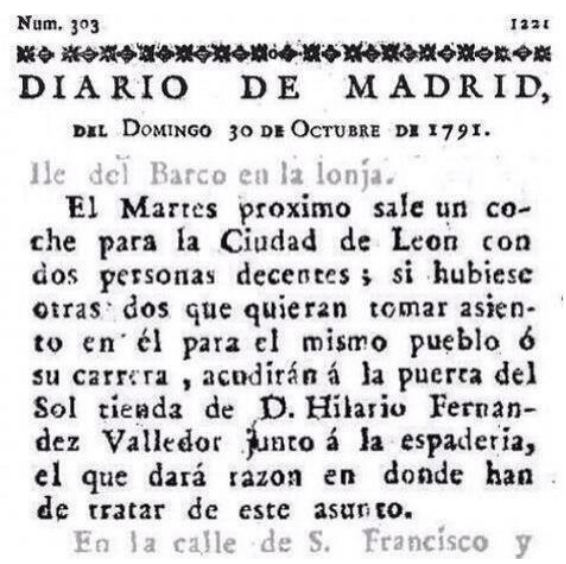

Figura 8. Diario de Madrid 1791. Blablacar del siglo XVIII

Fuente: http://www.ileon.com/actualidad/041578/blablacar-para-leon-en-el-ano-1791

Sí interesa conocer aquí, a nivel básico, el uso diferencial -con respecto a la administración- de las TIC, como aprendizaje para su aplicación en los Observatorios, que podría ser estructurado del siguiente modo:

- Presencia en redes sociales y página web: la base principal de comunicación e información es la web $3.0{ }^{93}$.

- Accesible para recibir y emitir comunicaciones.

- Con posibilidad de crear grupos de trabajo, sectoriales, territoriales, ...que generen sus propios contenidos.

- Notificación de eventos y actividades de interés con contenidos e información completa.

- Información actualizada, sistematizada y completa, sobre los procesos y resultados. Posibilidad de realizar búsquedas y descargar contenidos.

- Disponibilidad de recursos y utilidades para la difusión del conocimiento, la participación y la colaboración.

- Generación de actividades impulsadas por el propio Centro orientadas al urbanismo colaborativo y el conocimiento desde todos los puntos de vista: técnico, jurídico, orientado a la acción, a la participación, de análisis, para el diagnóstico...

\footnotetext{
93 Wikipedia. Web 3.0: "Mientras que la web 2.0 se ha desarrollado con una tecnología que ha posibilitado a un gran número de personas el compartir, la colaboración, la co-creación, la comunicación... la web 3.0 plantea extender esto a más personas, usos y aplicaciones, y dotar de sentido humano y de repercusión para el beneficio social y medioambiental."
} 
- Generación de contenidos, abierto a colaboraciones, sobre la ciudad, el territorio, urbanismo, actividad municipal, actualidad, otros lugares, otros colectivos, mejores prácticas...

Este tipo de webs son más dinámicas y participativas, aunque sujetas a un control y administradores, cuyo funcionamiento podría estar regulado por las ordenanzas de participación y consensuado entre los ciudadanos, principales actores, administración y grupos de interés.

El desarrollo de este tipo de contenidos y páginas, como puerta abierta a los ciudadanos, desde la confianza, el consenso y la colaboración sería un verdadero avance en la administración no sólo para la relación formal sino para la inclusión real de los usuarios, ciudadanos y vecinos en la actividad de la administración, al menos en la municipal como administración más cercana y en aquellos aspectos que afectan directamente a la sociedad. No tiene que ver tanto con el funcionamiento y procedimiento administrativo, sino con los servicios $y$ el papel activo $y$ corresponsable de los ciudadanos.

Esta actividad digital, no sustituye ni la información y documentación en papel editada en todos los formatos disponibles- imprescindible por su disponibilidad y facilidad para la transferencia de información y conocimiento. Tampoco a la relación personal directa, que constituye la esencia de la ciudad; sin la relación personal no se generarían las redes de conocimiento y relación - entre instituciones/personas/grupos- imprescindibles para la creación de una cultura del consenso y la implicación de la sociedad en los asuntos políticos, en sus asuntos.

\section{WEB 3.0 PARA LA PARTICIPACIÓN}

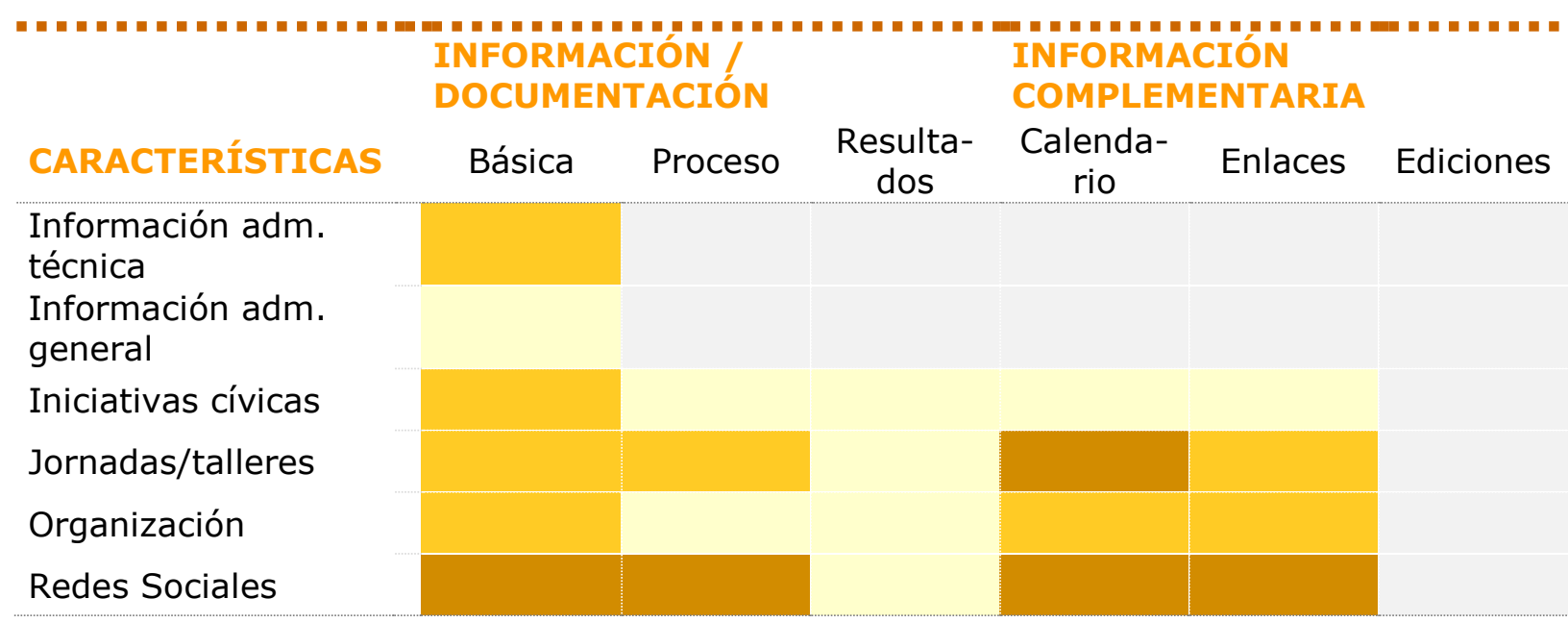

Tabla 17. Matriz: Evaluación de página web. Ciudadanos conectados.

Fuente: Ayuntamiento de Burgos. 


\subsection{Acercando la administración al ciudadano}

No podemos aislar el planeamiento y la actividad urbanística del marco jurídicoadministrativo en el que se desarrolla. Ya se ha indicado la barrera comunicativa que este marco supone en muchos casos, con el efecto directo en la sociedad de alejamiento y la consiguiente falta de confianza, con el resultado conocido de la actual situación. "Por otra parte, y seguramente a consecuencia de lo anterior, no podemos obviar que el divorcio entre instituciones y sociedad civil es cada vez más amplio. Buena muestra de ello es el hecho de que el número de protestas sociales en contra de la degradación del sistema democrático y el estado del bienestar haya crecido exponencialmente en los últimos años" ${ }^{94}$.

Este alejamiento produce un empobrecimiento de la ciudad, un proceso en el que todos pierden tanto las administraciones públicas como los ciudadanos. Todos somos conscientes de esta situación, por eso recientemente se están poniendo en marcha iniciativas vecinales que buscan un espacio de reflexión con políticos y técnicos de la administración. Precisamente la participación de estos técnicos en dichas jornadas es la gran novedad y lo que permite analizar la situación con mayor profundidad para llegar a conclusiones más ajustadas a la realidad administrativa y normativa.

Estas experiencias demuestran de qué modo las relaciones y actitudes están cambiando, tanto por parte de la sociedad que reclama mayor transparencia, participación, ser parte de la gestión y de la vida activa y creativa de la ciudad, sin que eso conlleve sanciones o actuaciones "alegales"; como de la propia administración -al fin y al cabo ciudadanos- que son conscientes del distanciamiento y la falta de coherencia, en ocasiones, de la gestión de lo público en la aplicación de normas que van quedando obsoletas. Se han analizando algunas conclusiones obtenidas de jornadas recientes: "Citykitchen" 95 en Matadero Madrid o "Cómo tramitar un unicornio" 96 en Zaragoza, observando que coinciden en el diagnóstico y puntos para la reflexión y puesta enmarcha de acciones a favor del conocimiento mutuo y del entendimiento. "Actualmente en Madrid se encuentran en ebullición muchas e interesantes iniciativas ciudadanas implicadas en la construcción activa de su entorno, con todas las implicaciones sociales, políticas, culturales y emocionales que ello conlleva. Madrid está efervescente. Es el momento de construir una herramienta que sirva de lugar de encuentro de todas estas situaciones y permita tender los puentes necesarios para construir la metodología que las haga

\footnotetext{
94 PAISAJE TRANSVERSAL (2014)

95 CITYKITCHEN (2014). De la presentación: "Citykitchen quiere generar una nueva forma de construir ciudad, partiendo de la colaboración entre los ciudadanos, las empresas, la administración y los profesionales de los diferentes ámbitos."

96 TRAMITAR UN UNICORNIO (2017). "El investigador cultural Jaron Rowan define como unicornios esas nuevas prácticas, paradigmas, espacios y redes que, en cultura, van más allá de lo probable y lo posible y se mueven en el marco de lo deseable y lo extraordinario. (...) Fórmulas de contratación, regulación del uso del espacio público, mecánicas de gestión de espacios, criterios para la concesión de ayudas y subvenciones...se han convertido en los últimos tiempos en constantes caballos de batalla para los gestores culturales municipales que teniendo que afrontar las nuevas realidades y desafíos de la cultura, se encuentran a menudo bloqueados por la falta de marcos reguladores específicos o (...) que sirva de orientación a la hora de atenderlos".
} 
replicables. Un espacio de intervención directa en la ciudad. Una cocina para la ebullición ciudadana". Dichas conclusiones se pueden resumir en tres aspectos básicos para una administración renovada:

- Necesidad de crear un marco legal urbanístico, de contratación, de gestión y creación, mediante procedimientos simplificados y flexibles.

- Necesidad de una administración más abierta, accesible y transprente, necesidad de un nuevo tipo de técnico/funcionario que sirva de puente entre las diversas realidades que confluyen en el hecho urbano.

- Necesidad de espacios de relación, diálogo, consenso, información, formación... que sirvan tanto para la creación de redes ciudadanas, como el conocimiento mutuo, la información, la cultura participativa y la colaboración.

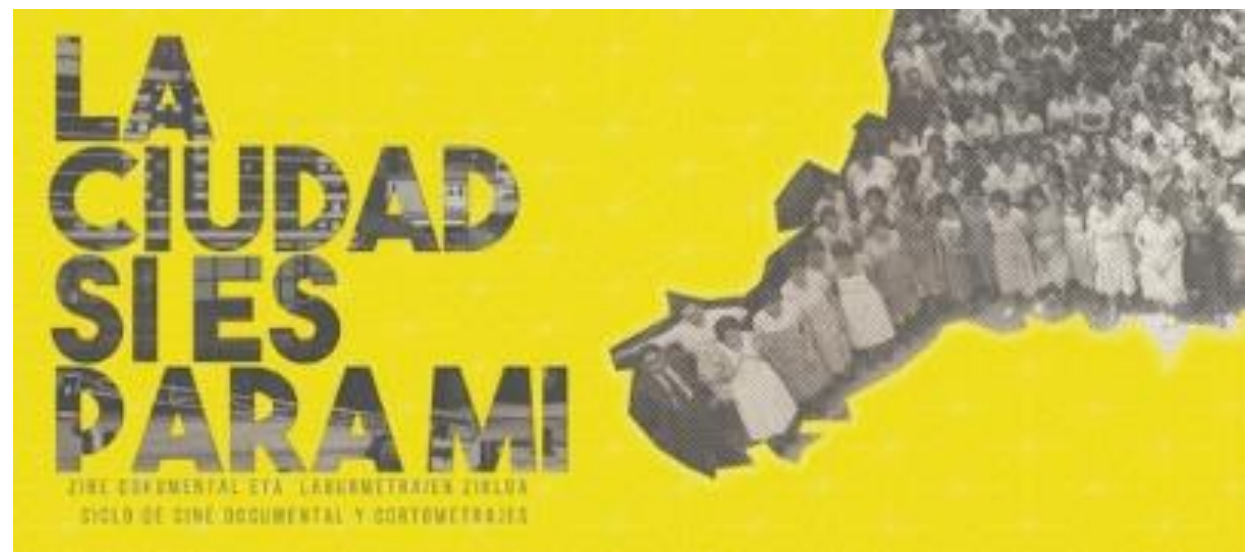

Figura 9. La Ciudad sí es para mí. Abril 2017. Festival de cine urbano en ZAWP. Zorrozaurre Bilbao. Fuente: http://www.zawp.org/

"Sólo una nueva cultura de la planificación urbana y territorial podría reconocer esas realidades fundamentales excluidas, y eso significa volver a empezar desde un proyecto emancipador con una base social amplia y con enfoques integradores: lo contrario del actual divorcio" ${ }^{97}$.

${ }^{97} \mathrm{ROCH}, \mathrm{F} .(2016)$. 


\section{CONCLUSIONES}

"Acaso la mejor definición de la ciudad, en sus aspectos más elevados, consiste en decir que es un lugar destinado a ofrecer las mayores facilidades para la conversación significativa" 98

Las conclusiones de este trabajo desde el punto de vista de la generación de las condiciones para la creación de un urbanismo colaborativo, recorren con más o menos intensidad, la escala completa de la activad pública, desde las condiciones básicas para generar una cultura de la participación ciudadana en los sistemas democráticos basados en los principios de gobernanza europea: de apertura, participación, responsabilidad, eficacia y coherencia ${ }^{99}$; hasta la actividad cívica y su reflejo en el uso de las nuevas tecnologías.

Las conclusiones de ese trabajo se agrupan entorno a dos ámbitos de incidencia en el urbanismo, que son complementarios y necesarios: desde un punto de vista más teórico los medios necesarios para generar una cultura de la participación (que se ha ido desarrollando hasta aquí); y desde un punto de vista más práctico, la propuesta de una herramienta para la evaluación de los procesos de participación, a falta de una calibración verificable, según veremos en el capítulo 10.

Se presentan las líneas de reflexión y actuaciones de mejora, en los ámbitos de la gobernanza, la actividad urbanística, el empleo de la tecnología y la definición de los observatorios. Ideas que se han ido recogiendo a lo largo de este trabajo y que se condensan en las siguientes conclusiones.

El marco normativo define los límites de la participación, por ello en esta investigación han sido revisadas las normas que delimitan este derecho, desde las directrices europeas hasta las ordenanzas municipales, y su contraste con las propuestas sociales más recientes, que ponen de manifiesto la necesidad de dotar de mayor flexibilidad a los planes, su ejecución y la práctica urbanística.

Se hace especial hincapié en la trascendencia de las nuevas tecnologías, su influencia decisiva para la generación de una nueva realidad desde el punto de vista económico, social y urbano. Se han considerado todos los aspectos de aplicación a la ciudad y al urbanismo, desde las Smart Cities, redes sociales y el urbanismo de código abierto. Desde su aportación a la participación y las posibilidades que ofrecen para facilitar los procesos, hasta la generación de procesos abiertos de nuevos modos de información y colaboración que han renovado los campos de la innovación y la creatividad y por tanto el urbanismo.

Se avanza en la definición del observatorio urbano y territorial como elemento básico para recuperar la cultura de la participación y concretamente el Urbanismo Colaborativo, retomando tanto las propuestas del "Libro Blanco del Urbanismo Sostenible", como las que ya enunciaba la "Carta de Atenas" apelando a la "Ciudad

\footnotetext{
98 MUMFORD, L. (1961).

${ }^{99}$ PAREJO, L. (2004).
} 
Participativa", o la Comisión Europea en cuanto a la creación de centros de información y creación de redes entorno al hecho urbano.

Aun teniendo presente la premisa de que no hay modelos para el Urbanismo Colaborativo, este trabajo plantea un sistema de evaluación de estas experiencias. Se trata, de un modelo no calibrado, por tanto de momento hasta que no esté verificado, solo ofrece una idea sobre la pertinencia o no proceso. En la elaboración de este sistema de evaluación se han empleado los parámetros obtenidos en este trabajo como elementos básicos de la participación y la consideración de los impactos deseables para la generación de una cultura colaborativa.

Se aportan a estas conclusiones las matrices que permiten evaluar los casos, y en el apartado 10.2.1 se incluye un resumen de procesos reales a modo de posible método práctico, adaptable y sencillo para el seguimiento y evaluación de procesos puntuales.

Se condensan las líneas de reflexión bajo la mirada de facilitar la colaboración público-privada (en el contexto de creación y mejora de la ciudad y puesta en valor del territorio) la co-responsabilidad entre administración y sociedad. Para que las líneas de reflexión no sólo sean conceptos genéricos o abstractos, se aportan posibles soluciones o vías para aplicar el método científico -de prueba y erroravanzando de lo general a lo particular.

\subsection{En relación a la gobernanza}

Las administraciones públicas tienen pendiente un ejercicio de acercamiento a la sociedad, en función de las actuaciones fundamentales relacionadas en el apartado 7.1, se han estudiado en el apartado 8.4 los aspectos más demandados para un mayor entendimiento, y los retos que habría que procurar afrontar según lo expuesto en el apartado 6.2. Se condensan en las siguientes ideas:

- Normativa más flexible, desarrollada en dos niveles: principios básicos comunes y condiciones específicas adaptables a las circunstancias.

- Procedimientos más claros, sencillos y directos.

- Técnicos y funcionarios en contacto con los vecinos, grupos, asociaciones, agentes...

- Gestión mediante convenios con bases generales comunes y cláusulas específicas.

- Marco de contratación asequible a nuevos agentes, grupos, asociaciones: solvencia técnica, económica, criterios sociales, medioambientales, culturales...

- Posibilidad de "experimentar" en nuevos marcos de relación en la gestión de la ciudad.

- Posibilidad de "experimentar" en nuevos marcos de acción en la ciudad. 


\subsection{Actividad urbanística}

La legislación y la técnica urbanística cada vez más compleja y, por su naturaleza, poco flexible ha sido objeto de revisión en el apartado 3.3 desde el punto de vista de la participación. Se apuntan diversas líneas de actuación para la "Ciudad participativa" recogida en la Carta de Atenas, para acercar la práctica urbanística a la sociedad actual, según el análisis del apartado 8.2:

- Impulso del Planeamiento territorial:

- Crear cultura urbanística.

- Recuperar el protagonismo del planeamiento territorial.

- Utilizar escalas de planeamiento más coherentes con el territorio: comarca, isla, región

- Priorizar aspectos de cohesión social, medioambientales, ecológicos, culturales... acordes con el territorio y la mitigación del cambio climático.

- Reforma estructurante del Plan General:

- Que comprenda dos fases: una estratégica fija y otra funcional flexible.

- Desvincular urbanismo y derecho de la propiedad, propiciando la ejecución por la administración o mediante la actividad privada dirigida por la administración.

- Considerar del Diagnóstico elemento fundamental de la planificación y participación.

- Ampliar las fases del urbanismo: seguimiento y evaluación del desarrollo del plan.

- Incluir la colaboración activa en la normativa urbanística.

- Ejecución del planeamiento/construcción de la ciudad:

- Crear cultura urbanística a nivel de barrio y sectorial.

- Crear cultura participativa.

- Facilitar marcos de desarrollo y creación de redes.

- Responsabilizar a la ciudadanía y grupos.

\subsection{Empleo de las nuevas tecnologías}

Se ha analizado en el apartado 7.3 la importancia del empleo de las nuevas tecnologías en la creación de cultura de participación y como instrumento de comunicación entre administración y ciudadanos, se aportan como ideas para su incorporación al urbanismo colaborativo y de código abierto, lo expuesto en el apartado 8.3:

- Superar el empleo de las nuevas tecnologías orientadas al procedimiento administrativo.

- Ampliar el uso de las nuevas tecnologías en la comunicación con el ciudadano. 
- Web 3.0: abierta a la colaboración y creación de redes, conocimiento y acción.

- Redes sociales como nexo de información y comunicación.

- Medio para el conocimiento que facilite el entendimiento, compartir experiencias, avanzar sobre lo ya hecho.

- Nuevas tecnologías al servicio de los ciudadanos para la mejora de la calidad de vida: smart citizens.

\subsection{Impulso de los Observatorios Territoriales}

Impulso de los "observatorios territoriales": motor, generador y difusor de la cultura urbanística. Sus condiciones y objetivos, estudiados en el apartado 8.1, son:

- Actividad emitida:

- En contacto con el entorno social, educativo, económico, vital de la ciudad.

- Conocimiento de las inquietudes, problemas, expectativas de vecinos y grupos.

- Impulsor de actividades, proyectos y jornadas en relación a la ciudad: colegios, centros sociales, deportivos, asistenciales... Contando con: profesionales, técnicos y expertos.

- Elaboración de censos, mapeos, de la actividad social y ciudadana, mantener su actualización y seguimiento.

- Creación de grupos estables abiertos y regulados: consejo de barrio, comisiones...

- Diagnóstico en tiempo real.

- Redacción de documentos de planeamiento.

- Ejecución del planeamiento.

- Impulsor de usos y desarrollo de actividades en el espacio público, solares, edificios, locales.

- Seguimiento y evaluación: cualitativa y cuantitativa.

- Intercambio de conocimiento y experiencias.

- Feedback a administraciones autonómicas para evaluación de políticas.

- Actividad recibida:

- Atención personal: asesoramiento e información.

- Proporcionar información administrativa clara y comprensible.

- Proporcionar información generada por los ciudadanos.

- Disposición de espacios de relación y de desarrollo de proyectos cívicos.

- Facilitar medios técnicos y recursos para iniciativas ciudadanas de valor social.

- Mantenimiento de redes, comunicación e información. 
- Facilitar el desarrollo de proyectos e iniciativas ciudadanas de interés general.

- Desarrollo de marcos normativos de colaboración y gestión.

- Características:

- Centros de barrio y ciudad, en red.

- Ubicación céntrica, en el espacio público o con acceso directo desde éste.

- Publicidad visible de las actividades.

- Atención presencial: asesoramiento, seguimiento.

- Disponibilidad espacios para iniciativas vecinales.

- Acceso a TICs.

- Servicios complementarios: tramitaciones, solicitudes, informes,...

Estos centros no suponen un cambio sustancial en la práctica urbanística municipal, únicamente implican un cambio en la mirada y la orientación de dicha actividad, en lugar de ser ejercida "hacia dentro", se plantea que sea ejercida "hacia fuera".

\section{EVALUACIÓN Y SEGUIMIENTO}

"Acaso la mejor definición de la ciudad, en sus aspectos más elevados, consiste en decir que es un lugar destinado a ofrecer las mayores facilidades para la conversación significativa" 100

Como se ha indicado en el apartado 7.1 crear una verdadera cultura participativa no depende tanto de actuaciones aisladas, cuya evaluación principalmente sería cuantitativa, como acciones continuadas y prolongadas en el tiempo de las que conviene hacer una valoración cualitativa siguiendo el modelo lógico de las teorías del cambio, recogidas en la Tabla 15.

Con el objeto de condensar las características tanto de la participación como de la información y consulta, expuestas a lo largo de este trabajo, analizadas en los capítulos 2 y 3 y complementado por el marco teórico del capítulo 5, se ha elaborado un sistema de matrices y tablas orientadas a su evaluación y seguimiento. Se presenta como una herramienta sencilla, adaptable y replicable en cada caso, y se propone como modelo para su calibración y validación en la práctica. Su utilidad principal es servir de base:

- Para evaluar las condiciones básicas de una administración u organización en general, en cuanto a las facilidades que ofrece y su orientación hacia la participación, considerando las condiciones básicas de confianza, consenso y colaboración. Mediante el empleo de Matrices: de información, colaboración y participación.

100 MUMFORD, L. (1961). 
- Para realizar el seguimiento y evaluación de los procesos de participación concretos. Mediante el empleo de Tablas de participación.

\subsection{Herramientas para la evaluación}

Se distingue entre información, consulta y participación en función de las características de cada una, tal y como se han descrito en los apartados 2.3 y 2.4 del capítulo 2, y recogidas en las correspondientes tablas. Dichos parámetros se contrastan con los medios, instrumentos y herramientas más habituales según establece la legislación en su caso, en función del análisis normativo del capítulo 3.

Se valora cada una de las acciones más habituales en relación con el cumplimiento de cada uno de los parámetros más favorables para la generación de una cultura colaborativa. Se completa con el análisis de los resultados que se han obtenido.

Estas matrices se orientan a la evaluación interna de las administraciones o a los equipos - públicos o privados- que coordinan estas prácticas. Se pueden emplear tanto en un análisis global sobre los sistemas de información y los procedimientos de consulta en las organizaciones, como en casos puntuales. Otra utilidad fundamental es la de evaluar el progreso de las acciones encaminadas a la mejora de estas actividades. Para ello se deberían establecer los parámetros de análisis previamente a iniciar las acciones previstas e ir haciendo evaluaciones a lo largo de su desarrollo.

\subsubsection{Matriz para la información}

Orientada a la evaluación de los medios de información más habituales, tanto los establecidos por la legislación en los procesos de información pública, como los relacionados con el procedimiento administrativo y la actividad habitual de las administraciones. Las características que debe cumplir dicha información, se relacionan por orden de importancia para el usuario. La clasificación -las tonalidades de color- se establece en cuatro niveles, valorando si cada sistema es más o menos favorable a la participación desde la óptica de las condiciones de confianza, consenso y colaboración. 


\section{INFORMACIÓN PARA LA PARTICIPACIÓN}

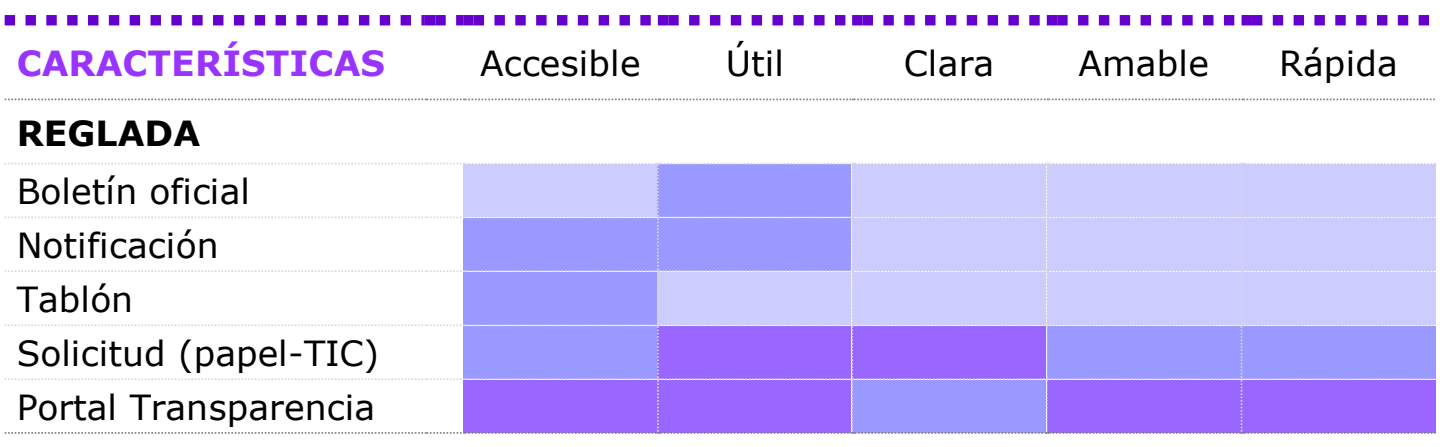

\section{NO REGLADA}

Solicitud papel
Solicitud TIC
Presencial
Institucional
Presencial accesible
Publicidad
Institucional
Página web
Redes sociales

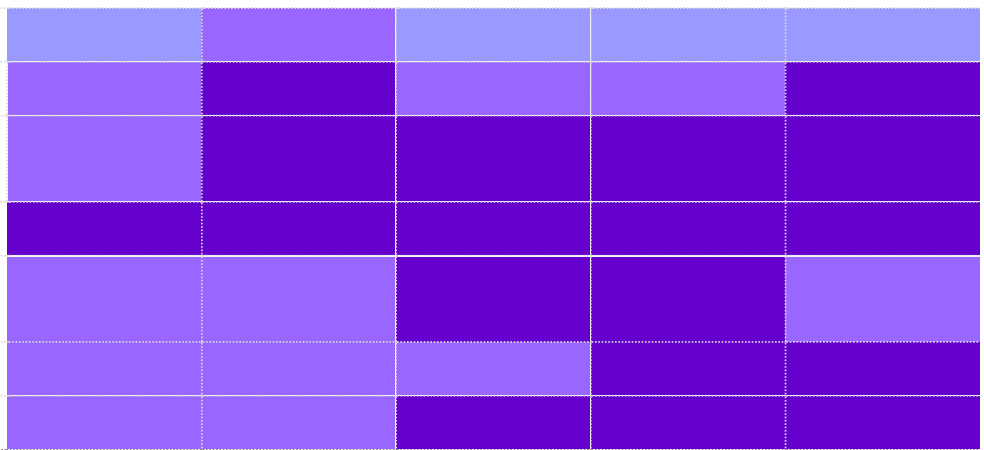

Tabla 18. Matriz de Evaluación de la Información para la participación.

Fuente. Elaboración propia.

En esta evaluación se parte de una situación genérica, se podría concluir que los medios oficiales de información: Boletín Oficial, notificaciones, tablón de anuncios... no facilitan la participación, sin embargo, la atención presencial y el empleo de nuevas tecnologías cumplen mejor las condiciones óptimas para favorecerla.

\subsubsection{Matriz para la consulta}

Siguiendo el mismo proceso que para la información, se evalúan las características de los procesos de consulta en función de los medios e instrumentos que habitualmente se utilizan desde las administraciones bien en cumplimiento de la legislación vigente, bien facilitadas por la administración, como pueden ser las redes sociales.

Aplicando los mismos criterios que en el caso anterior, podemos concluir que el empleo de medios tecnológicos y los presenciales son los que aportan mejores resultados para favorecer la colaboración ciudadana, mientras que los más formales o impersonales, ofrecen menos condiciones para que se produzca el clima de confianza y la colaboración productiva. Posiblemente, como se ha comentado a lo largo de esta investigación, por el empleo de un lenguaje poco comprensible, resulta poco accesible al trato personal y al conocimiento mutuo. 
CONSULTAS PARA LA PARTICIPACIÓN

\begin{tabular}{|c|c|c|c|c|c|c|}
\hline CARACTERÍSTICAS & Accesible & Reducida & $\begin{array}{l}\text { Puntual - } \\
\text { petición }\end{array}$ & $\begin{array}{l}\text { Encuesta } \\
\text { opinión }\end{array}$ & $\begin{array}{l}\text { Plebiscito / } \\
\text { referendum }\end{array}$ & Pública \\
\hline \multicolumn{7}{|l|}{ MEDIOS } \\
\hline \multicolumn{7}{|l|}{ Quejas y sugerencias } \\
\hline \multicolumn{7}{|l|}{ Oficina información } \\
\hline \multicolumn{7}{|l|}{$\begin{array}{l}\text { Comisiones } \\
\text { consultivas }\end{array}$} \\
\hline \multicolumn{7}{|l|}{$\begin{array}{l}\text { Comisiones } \\
\text { Parlamentarias }\end{array}$} \\
\hline $\begin{array}{l}\text { Instituciones de } \\
\text { vigilancia }\end{array}$ & & & & & & \\
\hline
\end{tabular}

\section{INSTRUMENTOS}

Solicitud papel

Solicitud TIC

Presencial

Página web

Redes sociales

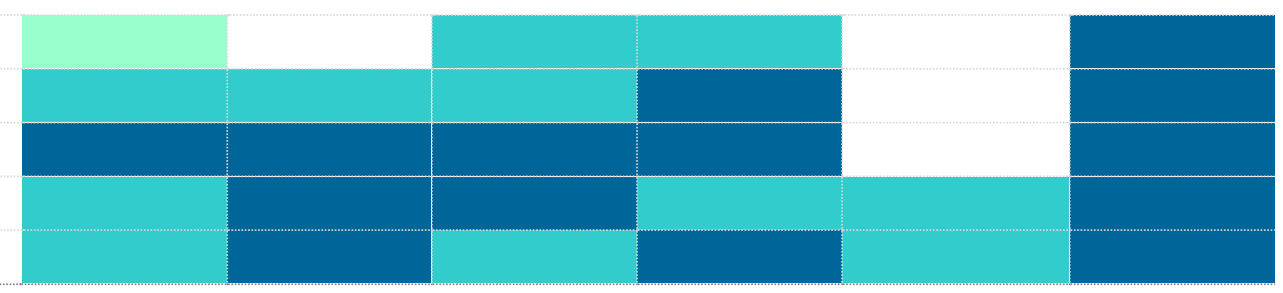

Tabla 19. Matriz de Evaluación de la Consulta.

Fuente. Elaboración propia.

\subsubsection{Matriz para la participación ciudadana}

Se analizan las estructuras participativas y las herramientas más habituales, desde la perspectiva de las posibilidades de influir en un cambio social a raíz de la implantación de la participación como herramienta básica de la actividad públicoprivada. Para ello, se ha empleado el esquema del modelo lógico de evaluación del cambio de las políticas públicas, analizado en el apartado 7.1 avanzando desde la implicación personal y el análisis del corto plazo hasta el impacto social a largo plazo.

En cuanto a los parámetros que definen cada uno de los estadios del modelo, se han empleado los beneficios de planificación colaborativa descritos por P. Healey que se resumen y clasifican en la Tabla 16 . Esta matriz permite poder analizar todos los datos de un proceso en un solo cuadro, facilitando la visión de conjunto, el análisis global y pormenorizado, así como establecer posibles interrelaciones entre parámetros que de otro modo pasarían desapercibidas.

La evaluación se ha realizado como en las matrices anteriores, considerando una administración tipo, cuantificando cada uno de los parámetros como más o menos propicio para procurar las condiciones óptimas de participación.

De los resultados obtenidos se podría deducir que en relación a las estructuras, se considera que para la producción de un verdadero impacto, las organizaciones formales (consejo de barrio, comité de participación) son más favorables que otras 
prácticas más informales o individuales que tienen mejores condiciones para las actuaciones a corto plazo si bien no generan el cambio cultural que se persigue.

En cuanto a las herramientas, y en la línea de lo aquí expuesto, las oficinas permanentes como elemento base y la organización de jornadas puntuales, apoyadas en el empleo de las TICs, son las herramientas más efectivas para conseguir un urbanismo colaborativo a largo plazo y manteniendo el nivel de actividad vivo y activo, tanto desde las administraciones como fomentando la acción cívica, siempre dentro del marco normativo establecido. 


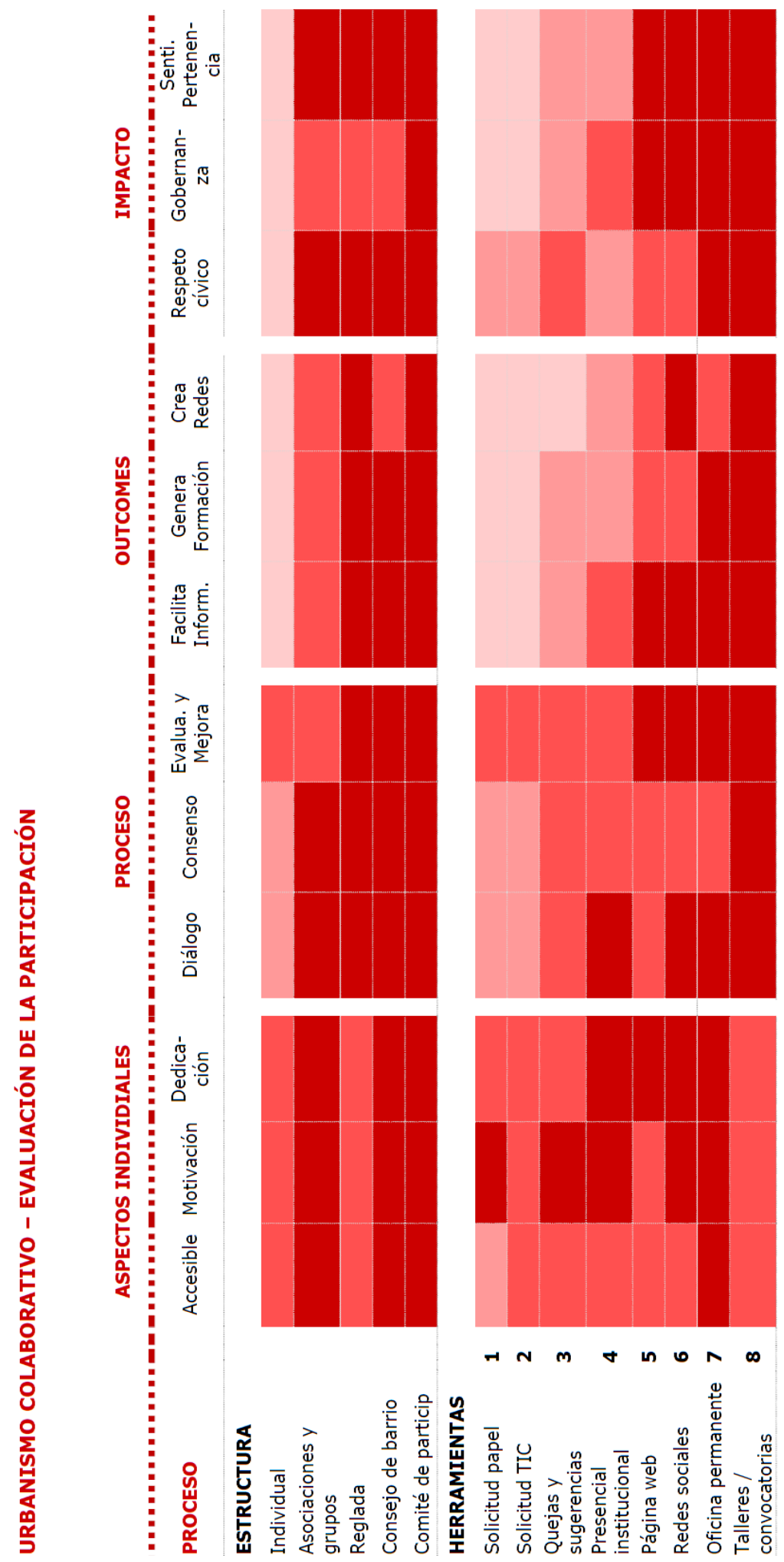

Tabla 20. Matriz de Evaluación de la Participación.

Fuente. Elaboración propia. 


\subsection{Herramienta para el seguimiento de la participación}

Los procesos participativos se analizan habitualmente desde un punto de vista cuantitativo o según aspectos orientados. Por falta de continuidad en el tiempo, 0 de posibilidades de realizar un seguimiento futuro, estos datos rara vez están disponibles, se trata de un análisis puntual cuya mayor utilidad es mejorar el siguiente proceso.

Se propone el empleo de la siguiente tabla elaborada desde los planteamientos del presente trabajo, para la evaluación de procesos y grado de madurez democrática. Se recogen las condiciones de análisis en función de las características genéricas del proceso, considerando su contexto inicial, el desarrollo y las acciones posteriores. Con todo ello se puede evaluar si se ha generado un impacto y si éste se mantiene en el tiempo, como resultado del establecimiento de una verdadera cultura de la colaboración.

Si consideramos la siguiente escala de valoración, en la que se bonifica la mejor práctica con una puntuación de valor 5 como incremento de calidad, podremos dar clasificación mesurable a las distintas experiencias analizadas. La valoración total oscila entre los 20 y los 100 puntos.

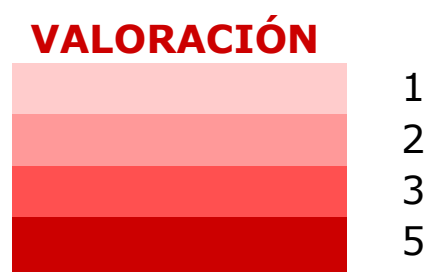

Tabla 21. Valoración de los parámetros de participación.

Fuente. Elaboración propia.

Aunque con esta herramienta se pretende una evaluación cualitativa, otorgar valores numéricos facilita la clasificación del caso, si bien éste es sólo un valor. Para comprender su significado real es necesario analizar la información que ofrece la tabla de cada uno de los parámetros que definen los procesos y los resultados del mismo. Con ello se podrá avanzar, en la mejora de los procesos, en la comprensión de los mismos, tomar medidas para su reajuste y adaptación a las circunstancias cambiantes, obtener una visión global de su desarrollo en el tiempo y comparar con otros casos.

\subsubsection{Una aplicación práctica}

Se comparan cinco casos de participación urbana y su evolución, teniendo en cuenta que:

- Se parte de la información disponible por lo que el análisis de los procesos mejor documentados será más acertado.

- El análisis de cada caso profundiza en unos aspectos y no tanto en otros de los que se evalúan, que influye en su apreciación para la valoración. 
- En los cuadros elaborados en este trabajo se han considerado los parámetros fundamentales de los procesos colaborativos, en función del estudio realizado en la presente investigación. Se podrán adaptar en cada caso para el análisis pretendido.

- La escala de valoración utilizada, en función de si el parámetro analizado está más o menos conseguido -que se representa con intensidad de color- tiene un considerable sesgo de subjetividad; sin embargo, el resumen comparativo parece suficientemente fiable considerando las diferencias relativas entre casos y la evolución de cada uno de ellos.

Aparecen como procesos más "fuertes" aquellos que se han mantenido en el tiempo, aunque puedan fluctuar en cuanto a intensidad, originados por irrupción, en los que las administraciones han desarrollado una actitud colaborativa, generando una verdadera cultura de la participación llegando a la co-gestión de los espacios públicos, reforzando tanto el sentimiento de pertenencia como el desarrollo de las capacidades de diálogo, consenso y colaboración entre los vecinos y grupos ciudadanos. 
EVALUACIÓN DE PROCESOS DE PARTICIPACIÓN

PROCESO

NOMBRE DEL PROCESO

\begin{tabular}{|c|c|c|c|}
\hline ANÁLISIS & Fase I & Fase II & Fase III \\
\hline \multicolumn{4}{|l|}{ GENERICO } \\
\hline Iniciativa & - & - & - \\
\hline Integral/sectorial & - & - & - \\
\hline Información & $1-5$ & & \\
\hline \multicolumn{4}{|l|}{ Abierto/Inclusivo } \\
\hline \multicolumn{4}{|l|}{ Empleo de TIC's } \\
\hline \multicolumn{4}{|l|}{ DESARROLLO } \\
\hline Transparencia & $1-5$ & & \\
\hline \multicolumn{4}{|l|}{ Asesoramiento técnico } \\
\hline \multicolumn{4}{|l|}{ Consenso } \\
\hline Interés ciudadano & & & \\
\hline
\end{tabular}

Ejecución de objetivos

$1-5$

Asesoramiento/mediadores

Periodicidad

Evaluación/Mejora

\section{RESULTADOS}

PREVIO

Experiencia/cultura

participativa

Normas reguladoras

Sentimiento de pertenencia

OUTCOMES

Facilita información

Genera formación

Crea redes

IMPACTOS

Respeto cívico

Estructura

Continuidad

VALORACIÓN

20-100

20-100

20-100

Tabla 22. Evaluación y seguimiento de procesos de participación.

Fuente. Elaboración propia. 

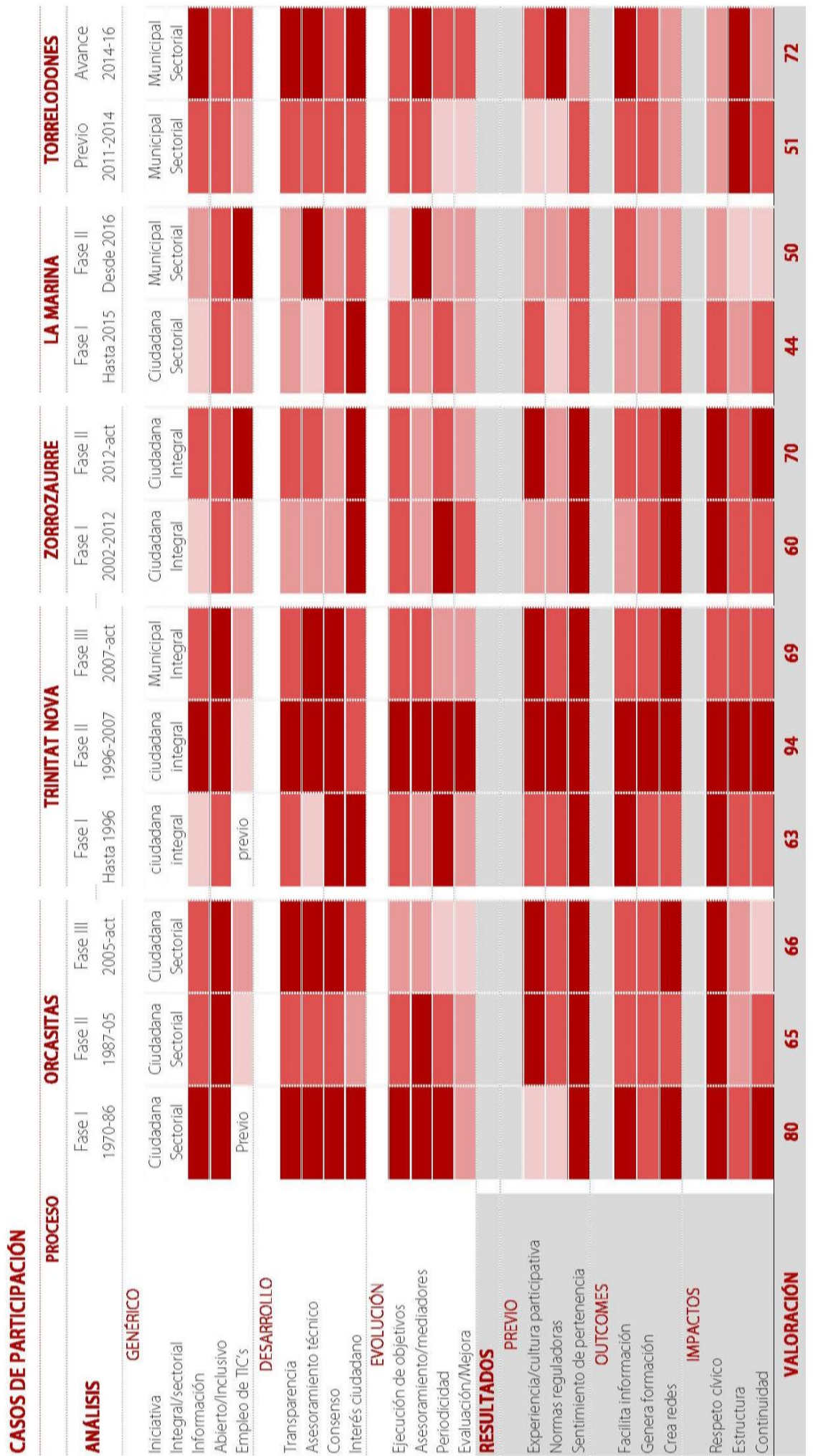

Tabla 23. Resumen ponderado de los casos de estudio.

Fuente. Elaboración propia. 


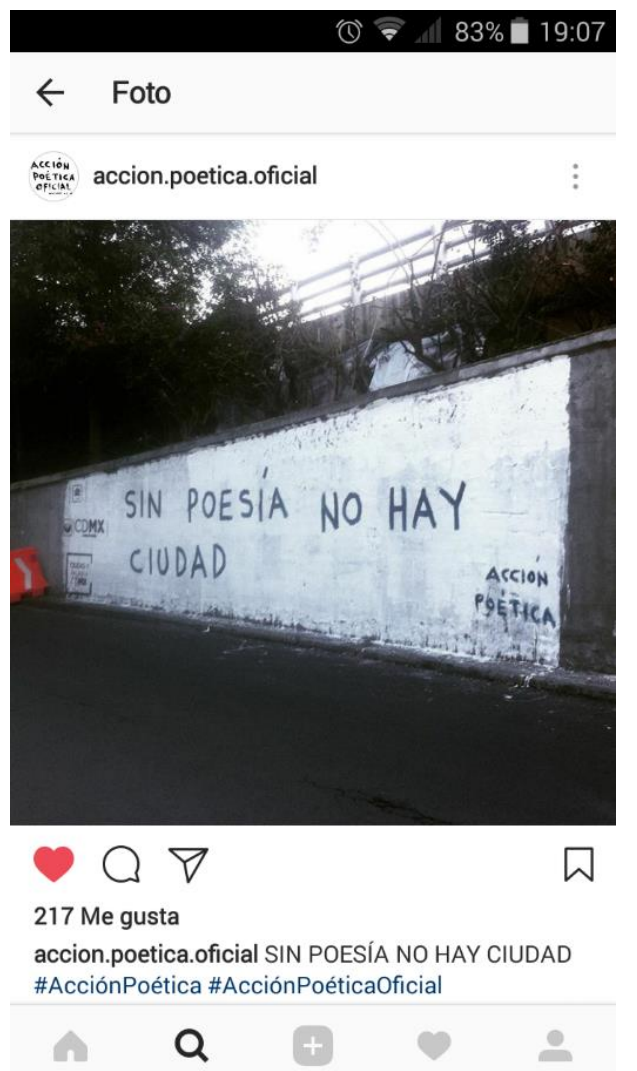

Figura 10. Acción poética Méjico. Sin poesía no hay ciudad.

Fuente: Instagram (@accion.poetica.oficial).

"Los lugares habitados, con una historia, una evolución (hacia la degradación, hacia el éxito o anclados en el tiempo) no se pueden tratar igual que si no existiera nada. Porque existe. Y esta existencia marca una identidad, algo intangible que se ha ido acumulando con los años y que, aunque se modifique debido a las necesidades de las generaciones que se suceden, mantiene su ser.

Porque una ciudad, un barrio, no se deberían entender en ningún caso como un proyecto personal, sino más bien como una construcción colectiva". 


\section{BIBLIOGRAFÍA}

ALEXANDER, Ch. (1975). Urbanismo y participación: el caso de la Universidad de Oregón. (Edición en castellano de 1976). Barcelona: Gustavo Gili (Título original: The Oregon experiment).

ALGUACIL, J. (2000). Ciudad, ciudadanía y Democracia urbana. Documentación Social, N0119.

ARSTEIN, S.R. (1969). A ladder of Citizen Participation. En Journal of American Institute of Planners, volumen 35 (4), pp. 216-224.

BHAGAT, A. and MOGEL, L. (2009). An Atlas of radical Cartography. Los Angeles: Journal of Aesthetics and Protest Press.

CAZ, R. del y SARAVIA, M. (2005). ¿Participar o ser participado? 200 preguntas sobre participación en el urbanismo. En Participación ciudadana para el urbanismo del siglo XXI. Valencia: ICARO, CTAV.

CHAMORRO, J.M. (2016) Planeamiento Urbanístico y transparencia. En El Derecho.com. 06/05/2016.

CHINCHILLA, J.A. (2017). Las consultas a la ciudadanía como instrumento de legitimación social de concretas ordenaciones urbanísticas. En Revista de Derecho urbanístico y Medio ambiente. Año no 51, no 311. Ejemplar dedicado a: Especial 50 aniversario). Pp. 57-78.

COMISIÓN EUROPEA (1990). Libro verde sobre el medio ambiente urbano. Comunicación de la Comisión al Consejo y al Parlamento, COM (90). Publicaciones de la Comunidad Europea.

CONSEJO DE EUROPA (2009). Código de Buenas Prácticas para la Participación Ciudadana en el proceso de toma de decisiones. En Conferencia de OING. Estrasburgo: Consejo de Europa 1-19.

CONSEJO EUROPEO DE URBANISTAS. (2003). Nueva Carta de Atenas 2003. La Visión de las ciudades en el siglo XXI del Consejo Europeo de Urbanistas. Parte B.

DAVIDOFF, P. (1965). Advocacy and pluralism in Planning. En Journal of the American Institute of Planning no 31, pp. 331-338.

ECTP-CEU. (2015). La Carta Europea de la Democracia Participativa en procesos urbanísticos. Dublín.

FARIÑA, J. y NAREDO, JM (Dir) (2010). Libro Blanco de la Sostenibilidad en el Planeamiento Urbanístico Español. Madrid: Ministerio de Vivienda. 
FERNÁNDEZ, B. (2013). Políticas urbanas innovadoras, gobernanza y planificación flexible. Análisis de la evolución en Francia y propuestas de adaptación al contexto español. En Estudios de Progreso nº 72. Fundación Alternativas.

FERNÁNDEZ, C. (2011). Democracia y participación: El Plan General de Madrid de 1985 en Cuadernos de Investigación urbanística no 79. Madrid: Instituto Juan de Herrera.

FERNÁNDEZ, M. y GIFREU, J. (2016). El Uso temporal de los vacíos urbanos. Serie Urbanismo y Vivienda Diputación de Barcelona: Colección Estudios.

FERNÁNDEZ, M (2017). La desilusión de las Smart Cities (parte I). En Papers 57.

FORESTER, J. (1989). Planning in the face of power. Los Angeles: University of California Press.

FORESTER, J. (2000). The Deliberative Practitioner: Encouraging participatory planning processes. Cambridge (Mass.) y Londres: The MIT Press.

FRIEDMANN, J. (2001). Planificación en el Ámbito público. Madrid: Ministerio de las Administraciones Públicas. (ed. Original, Princeton 1987. Planning in the public Domain: from knowledge to action).

GALLEGOS, R. (2017). Tesis doctoral en elaboración.

GARCÍA-BELLIDO, J. (1978). Participación popular y lucha de clases en el planeamiento urbanístico. Esbozos para un debate, CAU: construcción, arquitectura, urbanismo, No 51.

GARCÍA-BELLIDO, J. (2004). Por una liberalización del paradigma urbanístico español. En Ciudad y Territorio Estudios Territoriales, 36 (140). Pp: 289-298. Madrid.

GREGORIO, S. de (2012). Políticas Urbanas de la Unión Europea desde la perspectiva de la planificación colaborativa. Las iniciativas Comunitarias URBAN y URBAN II en España. Madrid: Universidad Politécnica de Madrid.

HEALEY, P. (2006-1997). Collaborative Planning: Shaping Places in fragmented Societies. Londres: Macmillan (ed. Origin, Londres 1997).

IGLESIAS, F. (dir.) (2007). Urbanismo y Democracia. Alternativas para evitar la corrupción, Madrid: Fundación Alternativas.

INNES, J. (1995). Planning theory's emerging paradigm: Communicative action and interactive practice. En Journal of Planning Education and Research, Volumen 14 (3), pp. 128-135. 
INNES, J. Y BOOHER, D. (2000). Public Participation in Planning: New Strategies for the 21st Century. Berkeley: Institute of Urban and Regional Development, University of California.

JACOBS, J. (1961) Muerte y Vida de las grandes ciudades. Madrid: Capitán Swing. $3^{a}$ edición 2013.

LEFEBVRE, H. (1968). El derecho a la ciudad. (Edición en castellano de 1969). Barcelona: Ediciones 62. (Título original: Le droit à la ville).

MENÉNDEZ, Á., GIFREU I FONT, J. BASSOLS, M. (2016). El derecho de la ciudad y el territorio. Madrid: Instituto Nacional de Administración Pública.

MENÉNDEZ, Á. (2008). El fomento de las buenas prácticas administrativas en la nueva Ley del Suelo y otras normas estatales recientes. En Anuario de la Facultad de Derecho de la Universidad Autónoma de Madrid, no 12. (Ejemplar dedicado a Urbanismo y Corrupción/coord. Por Ángel Menéndez Rexach) pp. 135-168

MIKOLEIT, A. y PÚRCKHAUER, M. (2011). Urban Code. Cambridge: The MIT Press.

MOORE, M. (1998). Gestión estratégica y creación de valor en el sector público. Barcelona: Paidós.

MUMFORD, L. (1961). La ciudad en la historia. Buenos aires: Ediciones infinito.

MUÑOZ, D. (2011). La influencia de la flexibilidad de las previsiones del planeamiento sobre las contribuciones del privado en el urbanismo de Inglaterra, España y los Países Bajos.

OCDE (2006). Participación Ciudadana. Manual de la OCDE sobre la información, consulta y participación en la elaboración de políticas públicas.

ONU-HABITAT III. (2016). Conferencia de las Naciones Unidas sobre la Vivienda y el Desarrollo Urbano Sostenible (Habitat III). Declaración de Quito sobre ciudades sostenibles para todos. Nueva Agenda urbana.

ORDUÑA, Ma A. (2016). Barrios y Sostenibilidad. La aplicación de criterios sociales, medioambientales $y$ económicos en el diseño $y$ evaluación de procesos de regeneración urbana sostenible en ciudades europeas. Tesis Doctoral. Dirigida por: Dra. Ma del Rosario del Caz Enjuto. Valladolid: Universidad de Valladolid.

PAISAJE TRANSVERSAL (2014). La nueva praxis urbana ante el cambio de época. En Papers 57 Discursos emergentes para un nuevo urbanismo. Barcelona: Centro de Estudios Regionales y Metropolitanos.

PAREJO, L. (2016). Urbanismo temporal, derecho a la ciudad y marco estatal de las políticas urbanas. En El Uso temporal de los vacíos urbanos. Manuel Fernández y 
Judith Gifreu. Serie Urbanismo y Vivienda. Diputación de Barcelona: Colección Estudios.

PAREJO, L. (2004). Los principios de la "Gobernanza Europea. Revista de la Unión Europea n6. $1^{\circ}$ semestre 2004.

SASSEN, S. (1991). The Global City: New York, London, Tokyo. Princeton University Press. Segunda edición revisada (2001)

SUBIRATS, J. (2001). Nuevos mecanismos participativos y democracia: promesas y amenazas. En Ciudadanos y decisiones públicas, J. Font (ed.) Barcelona: Ariel. P3342

SUBIRATS, J. (2015). Innovación social y políticas urbanas en España. Experiencias significativas en las grandes ciudades. Barcelona: Icaria.

TORRAS, L. (2016). El espacio del técnico municipal: el Pla BUITS como síntoma. En El Uso temporal de los vacíos urbanos. Manuel Fernández y Judith Gifreu. Serie Urbanismo y Vivienda. Diputación de Barcelona: Colección Estudios. Texto basado en las reflexiones del curso "La utilització temporal dels buits urbans". Recogidas en el artículo "El Pla BUITS en Barcelona: algunos aprendizajes" incluido en la publicación Subirats, Joan; García-Bernardos, Ángela (coords) Innovación social y políticas urbanas en España. Experiencias significativas en las grandes ciudades. Barcelona: Icaria 2015.

VERDAGUER, C. (2003). Por un urbanismo de los ciudadanos. En Ecología y Ciudad. Raíces de nuestros males y modos de tratarlos. Madrid: Fundación de Investigaciones Marxistas. Ediciones de Intervención Cultural. El Viejo Topo.

VILLORIA, M. (2007). Las nuevas medidas al servicio de la transparencia, la participación y el control en el gobierno local en la Ley de Suelo. En Ciudad y Territorio Estudios Territoriales, XXIX (152-153). Pp. 493-513. Madrid.

\section{Páginas WEB}

AGENCIA ESPAÑOLA DE EVALUACIÓN. (2017). Consultado: 4/04/2017. http://www.aeval.es/es/index.html

ARQUITECTURAS COLECTIVAS (2017). Consultado: 18/04/2017. https://arquitecturascolectivas.net/ayuda

AYUNTAMIENTO DE MADRID (2017). Consultado: 4/05/2017. http://www.esmadrid.com/centros-de-informacion-turistica/

CITYKITCHEN (2014). Consultado: 20/11/2016. http://citykitchen.es 
CIUDADANOS CONECTADOS. (2017). Consultado: 9/05/2017. Consultada: 20/05/2017. http://www.ciudadanosconectados.com/

CIUDADES PARA UN FUTURO MÁS SOSTENIBLE CF+S (2017). http://habitat.aq.upm.es/

COMISIÓN EUROPEA (2016). En https://ec.europa.eu/futurium/en/content/whaturban-agenda. Consultado: 25/02/2017.

ECTP-CEU. (2017). Consultado: 13/02/2017. http://www.ectpceu.eu/index.php/en/

EXPANSIÓN (2016). Consultado: 1/04/2017. http://www.expansion.com/agencia/europa_press/2016/12/30/20161230104735.ht $\mathrm{ml}$.

EZQUIAGA, J.M. (2015) Conferencia en el Colegio Oficial de Arquitectos de Madrid con motivo de la presentación del programa TRANSFORMING Madrid: http://www.coam.org/es/canal-coam/videos/transformingmadrid-transformacionesespaciales-y-sociales-madrid

FARIÑA, J. (2012). William Bunge en Fitzgerald. en El Blog de José Fariña. Consultada el 26/03/2017. En https://elblogdefarina.blogspot.com.es/2012/06/william-bunge-en-fitzgerald.html

FARIÑA, J. (2013). El Urbanismo en la UE: no sabe, no contesta en El Blog de José Fariña. Consultada el $13 / 02 / 2017$

en https://elblogdefarina.blogspot.com.es/search?q=europea

LENGUAJE ADMINISTRATIVO (2017). Consultado: 23/03/2017. http://lenguajeadministrativo.com/

MINISTERIO DE FOMENTO (2017): Consultada: 25/02/2017 https://www.fomento.gob.es/MFOM/LANG_CASTELLANO/_ESPECIALES/SIU/OTROS _PROYECTOS/AGENDA/CARTA_LEIPZIG/

PAISAJE TRANSVERSAL (2013). Las emociones inician los procesos de creación colectiva. Consultado: 12/05/2017. http://www. paisajetransversal.org/2013/12/lasemociones-inician-los-procesos-de.html

PAISAJE TRANSVERSAL (2016) Smartciticens VLC. Ciudadanía y Empoderamiento. Consultado:

12/05/2017. http://www.paisajetransversal.org/search/label/\%23SmartcitizensCC

PLA BUITS. (2017) Consulado: 14/05/2017. http://ajuntament.barcelona.cat/ecologiaurbana/es/que-hacemos-y-porque/ciudadverde-y-biodiversidad/pla-buits 
PNUD. (2013). Programa de las Naciones Unidas para el Desarrollo. Consultado: $15 / 03 / 2017$. http://www.undp.org/content/undp/es/home/ourperspective/ourperspectivearticles/ 2013/03/19/sustainable-development-goals-and-the-post-2015-agenda-why-doesparticipation-matter-.html.

ROCH, F. (2016). Entrevista de José Fariña a Fernando Roch publicada en "El blog de José Fariña" https://elblogdefarina.blogspot.com.es/2016/06/entrevistafernando-roch.html

TRAMITAR UN UNICORNIO (2017). Consultado: 6/05/2017. http://tramitarunicornio.com/presentacion/

URBACT III. (2014). Comisión Europea. Consultada: 26/02/2017. http://ec.europa.eu/regional_policy/es/atlas/programmes/20142020/italy/2014tc16rfir003.

VITORIA-GASTEIZ (2017). Consultado: 8/05/2017. http://www.vitoriagasteiz.org/we001/was/we001Action.do?idioma $=$ es\&aplicacion $=$ wb021\&tabla $=$ conte nido\&uid=65c21a87_117e9336274__ffe4

VIVERO DE INICIATIVAS URBANAS (2017). Iniciativas. Consultada: 5/03/2017. http://www.viveroiniciativasciudadanas.net/civics/iniciativas/ 
LOS CUADERNOS DE INVESTIGACIÓN URBANÍSTICA El departamento de Urbanística y Ordenación del Territorio de la Escuela Técnica Superior de Arquitectura de Madrid, lleva publicando desde el año 1993 la revista Cuadernos Investigación Urbanística, (Ci(ur)), para dar a conocer trabajos de investigación realizados en el área del Urbanismo, la Ordenación Territorial, el Medio Ambiente, la Planificación Sostenible y el Paisaje. Su objetivo es la difusión de estos trabajos. La lengua preferente utilizada es el español, aunque se admiten artículos en inglés, francés, italiano y portugués.

La publicación presenta un carácter monográfico. Se trata de amplios informes de la investigación realizada que ocupan la totalidad de cada número sobre todo a aquellos investigadores que se inician, y que permite tener accesibles los aspectos más relevantes de los trabajo y conocer con bastante precisión el proceso de elaboración de los mismos. Los artículos constituyen amplios informes de una investigación realizada que tiene como objeto preferente las tesis doctorales leídas relacionadas con las temáticas del Urbanismo, la Ordenación Territorial, el Medio Ambiente, la Planificación Sostenible y el Paisaje en las condiciones que se detallan en el apartado "Publicar un trabajo".

La realización material de los Cuadernos de Investigación Urbanística está a cargo del Departamento de Urbanística y Ordenación del Territorio de la Escuela Técnica Superior de Arquitectura de Madrid. El respeto de la propiedad intelectual está garantizado, ya que el registro es siempre en su totalidad propiedad del autor $y$, en todo caso, con autorización de la entidad pública o privada que ha subvencionado la investigación. Está permitida su reproducción parcial en las condiciones establecidas por la legislación sobre propiedad intelectual citando autor, previa petición de permiso al mismo, y procedencia.

Con objeto de verificar la calidad de los trabajos publicados los originales serán sometidos a un proceso de revisión por pares de expertos pertenecientes al Comité Científico de la Red de Cuadernos de Investigación Urbanística ( $\mathrm{RCi}(\mathrm{ur})$ ). Cualquier universidad que lo solicite y sea admitida por el Departamento de Urbanística y Ordenación del Territorio de la Universidad Politécnica de Madrid (DUYOT) puede pertenecer a esta red. Su único compromiso es el nombramiento, como mínimo, de un miembro de esa universidad experto en el área de conocimiento del Urbanismo, la Ordenación Territorial, el Medio Ambiente, la Planificación Sostenible y el Paisaje para que forme parte del Comité Científico de la revista y cuya obligación es evaluar los trabajos que se le remitan para verificar su calidad.

A juicio del Consejo de Redacción los resúmenes de tesis o partes de tesis doctorales leídas ante el tribunal correspondiente podrán ser exceptuados de esta revisión por pares. Sin embargo dicho Consejo tendrá que manifestarse sobre si el resumen o parte de tesis doctoral responde efectivamente a la aportación científica de la misma.

\section{NORMAS DE PUBLICACIÓN}

Las condiciones para el envío de originales se pueden consultar en la página web: http://www2.aq.upm.es/Departamentos/Urbanismo/publicaciones/ciurpublicar.html

\section{FORMATO DE LAS REFERENCIAS}

Monografías: APELLIDOS (S), Nombre (Año de edición). Título del libro (No de edición). Ciudad de edición: Editorial (Traducción castellano, (Año de edición), Título de la traducción, No de la edición. Ciudad de edición: editorial).

Partes de monografías: APELLIDOS (S), Nombre (Año de edición). "Título de capítulo". En: Responsabilidad de la obra completa, Título de la obra (No de edición). Ciudad de edición: Editorial. Artículos de publicaciones en serie: APELLIDOS (S), Nombre (Año de publicación). "Título del artículo", Título de la publicación, Localización en el documento fuente: volumen, número, páginas. Se deberá indicar el DOI de todas las publicaciones consultadas que dispongan del mismo. Así como el número ORCID del autor.

Asimismo, se recuerda que el autor tendrá derecho a dos ejemplares gratuitos. 
CONSULTA DE NÚMEROS ANTERIORES/ACCESS TO PREVIOUS WORKS

La colección completa se puede consultar en color y en formato pdf en siguiente página web:

The entire publication is available in pdf format and full colour in the following web page:

http://www2.aq.upm.es/Departamentos/Urbanismo/institucional/publicaciones/ciur/numeros-

publicados/

\section{ÚLTIMOS NÚMEROS PUBLICADOS:}

114 Carlos Alberto Tello Campos: "Segregación espacial por renta. Concepto, medida y evaluación de 11 ciudades españolas", 101 páginas, octubre 2017.

113 Carlos Alberto Tello Campos: "Revitalización urbana y calidad de vida en el sector central de las ciudades de Montreal y México", 69 páginas, agosto 2017.

112 Andrea González: "Valores compositivos fundamentales del jardín privado chino o la mirada urbana sobre el paisaje a lo largo de su historia hasta la Revolución de 1949", 74 páginas, junio 2017.

111 Pedro Górgolas Martín: "Burbujas inmobiliarias y planeamiento urbano en España: Una amistad peligrosa", 71 páginas, abril 2017.

110 Lourdes Jiménez: "Dinámicas de ocupación urbana del anillo verde metropolitano de Madrid", 80 páginas, febrero 2017.

109 Manuel Fernández González: "La Smart-city como imaginario socio-tecnológico", 72 páginas, noviembre 2016.

108 Narges Bazarjani: "Espacio público: conflicto y poder en la ciudad de Teherán", 70 páginas, septiembre 2016.

107 Ricardo Alvira Baeza: "Proyecto Haz(Otea)", 84 páginas, julio 2016.

106 Gloria Gómez Muñoz: "Intervención en el alojamiento con criterios ecológicos", 90 páginas, mayo 2016.

105 Irene Zúñiga Sagredo: "La forma del límite en las ciudades medias españolas", 66 páginas, marzo 2016. 
PROGRAMA OFICIAL DE POSGRADO EN ARQUITECTURA

MASTER PLANEAMIENTO URBANO Y TERRITORIAL

URB

Escuela Técnica Superior de Arquitectura de Madrid (UPM)

\author{
COORDINADORA DEL MÁSTER: Ester Higueras García \\ PERIODO DE DOCENCIA: Septiembre - Julio \\ MODALIDAD: Presencial y tiempo completo \\ NUMERO DE PLAZAS: 40 plazas \\ CREDITOS: 60 ECTS
}

El Máster se centra en la comprensión, análisis, diagnóstico y solución de los problemas y la identificación de las dinámicas urbanas y territoriales en curso, atendiendo a las dos dimensiones fundamentales del fenómeno urbano actual: por un lado, el proceso de globalización y, por otro lado, las exigencias que impone la sostenibilidad territorial, económica y social. Estos objetivos obligan a insistir en aspectos relacionados con las nuevas actividades económicas, el medio físico y natural, el compromiso con la producción de un espacio social caracterizado por la vida cívica y la relación entre ecología y ciudad, sin olvidar los problemas recurrentes del suelo, la vivienda, el transporte y la calidad de vida. Estos fines se resumen en la construcción de un espacio social y económico eficiente, equilibrado y sostenible. En ese sentido la viabilidad económica de los grandes despliegues urbanos y su metabolismo se confrontan con modelos más maduros, de forma que al estudio de las técnicas habituales de planificación y gestión se añaden otras nuevas orientaciones que tratan de responder a las demandas de complejidad y sostenibilidad en el ámbito urbano.

El programa propuesto consta de un Máster con dos especialidades:

- Especialidad de Planeamiento Urbanístico (Profesional)

- Especialidad de Estudios Urbanos (Investigación Académica)

Se trata de 31 asignaturas agrupadas en tres módulos:

MÓDULO A. Formación en Urbanismo.

MÓDULO B. Formación en Estudios Urbanos e Investigación.

MÓDULO C. Formación en Planeamiento.

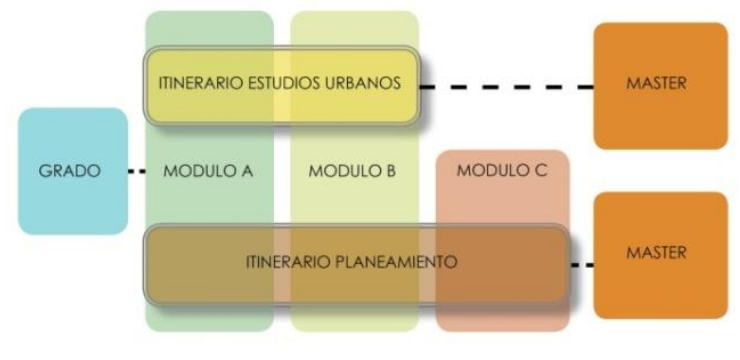

PROFESORADO:

Eva Álvarez de Andrés Carmen Andrés Mateo

Sonia de Gregorio Hurtado José María Ezquiaga Domínguez

José Fariña Tojo

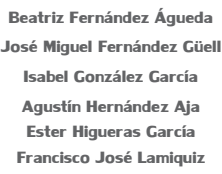

Beatriz Fernández Águeda

José Miguel Fernández Güel

Isabel González García

Agustín Hernández Aja

Ester Higueras García

Francisco José Lamiquiz

Emilia Románn López Inés Sánchez de Madariaga Llanos Masiá González Javier Ruiz Sánchez Álvaro Sevilla Buitrago

ENTIDADES COLABORADORAS:

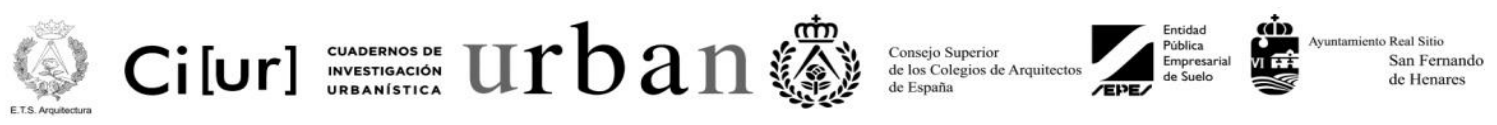

CONTACTO: masterplaneamiento.arquitectura@upm.es www.aq.upm.es/Departamentos/Urbanismo/masters/index.html

Otros medios divulgativos del Departamento de Urbanística y Ordenación del Territorio: 


\section{urbain}

\section{ReVISTA del DEPARTAMENTO de URBANÍSTICA y ORDENACIÓN del TERRITORIO ESCUELA TÉCNICA SUPERIOR DE ARQUITECTURA}

\section{PRESENTACión SEgUNDA ÉPOCA}

DESDE el año 1997, URBAN ha sido vehículo de expresión de la reflexión urbanística más innovadora en España y lugar de encuentro entre profesionales y académicos de todo el mundo. Durante su primera época la revista ha combinado el interés por los resultados de la investigación con la atención a la práctica profesional, especialmente en el ámbito español y la región madrileña. Sin abandonar dicha vocación de saber aplicado y localizado, la segunda época se centra en el progreso de las políticas urbanas y territoriales y la investigación científica a nivel internacional.

\section{CONVOCATORIA PARA LA RECEPCIÓN DE ARTÍCULOS:}

Urban mantiene abierta una convocatoria permanente para la remisión de artículos de temática relacionada con los objetivos de la revista: Para más información:

http://www2.aq.upm.es/Departamentos/Urbanismo/institucional/publicaciones/urban/ns/instrucciones-para-autores/

Por último, se recuerda que, aunque La revista URBAN organiza sus números de manera monográfica mediante convocatorias temáticas, simultáneamente, mantiene siempre abierta de forma contínua una convocatoria para artículos de temática libre.

\section{DATOS DE CONTACTO}

Envío de manuscritos y originales a la atención de Javier Ruiz Sánchez: urban.arquitectura@upm.es

Página

web:

http://www2.aq.upm.es/Departamentos/Urbanismo/institucional/publicaciones/urban/ns/presentacion/

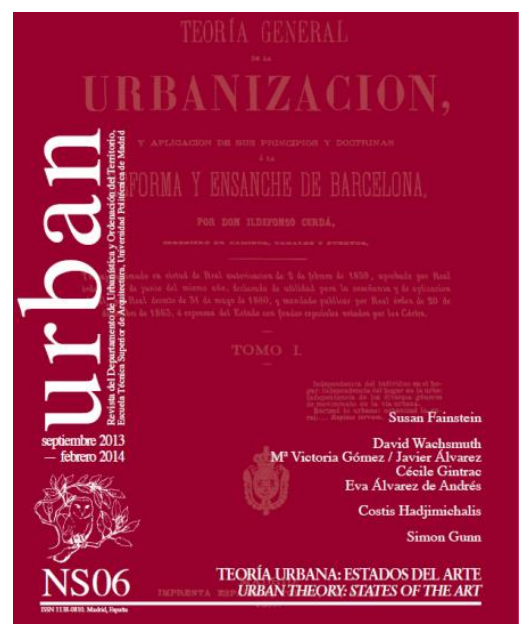

Consulta y pedido de ejemplares: ciur.urbanismo.arquitectura@upm.es

Web del Departamento de Urbanística y Ordenación del Territorio:

http://www.aq.upm.es/Departamentos/Urbanismo

Donde figuran todas las actividades docentes, divulgativas y de investigación que se realizan en el Departamento con una actualización permanente de sus contenidos. 


\section{territorios en formación \\ NE RE AS \\ NET RESEARCH ASSOCIATION ETSAM UPM}

ESCUELA TÉCNICA SUPERIOR DE ARQUITECTURA

Territorios en formación constituye una plataforma de divulgación de la producción académica relacionada con los programas de postgrado del Departamento de Urbanística y Ordenación del Territorio de la ETSAM-UPM proporcionando una vía para la publicación de los artículos científicos y los trabajos de investigación del alumnado y garantizando su excelencia gracias a la constatación de que los mismos han tenido que superar un tribunal fin de máster o de los programas de doctorado del DUyOT.

Así, la publicación persigue dos objetivos: por un lado, pretende abordar la investigación dentro del ámbito de conocimiento de la Urbanística y la Ordenación del Territorio, así como la producción técnica de los programas profesionales relacionados con ellas; por otro, promueve la difusión de investigaciones o ejercicios técnicos que hayan sido planteados desde el ámbito de la formación de postgrado. En este caso es, principalmente, el Departamento de Urbanística y Ordenación del Territorio el que genera esta producción, gracias a la colaboración con la asociación Ne.Re.As. (Net Research Association / Asociación Red Investiga, asociación de investigadores de urbanismo y del territorio de la UPM), que, por acuerdo del Consejo de Departamento del DUyOT, es la encargada de la edición de la revista electrónica.

\section{DATOS DE CONTACTO}

Antonio J. Antequera Delgado y Alejandro Rodríguez Sebastián (Editores): territorios.arquitectura@upm.es Página web: http://www2.aq.upm.es/Departamentos/Urbanismo/institucional/publicaciones/territorios-enformacion/

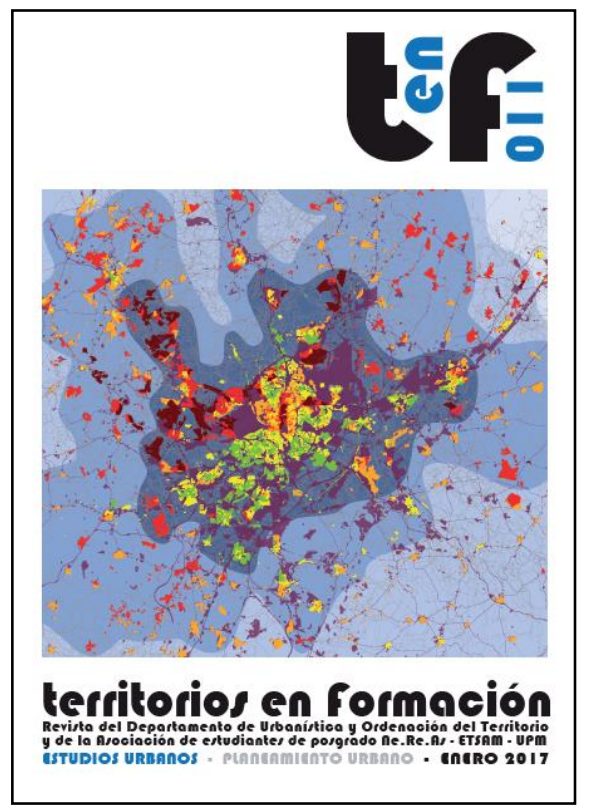

